University of Louisville

ThinkIR: The University of Louisville's Institutional Repository

Electronic Theses and Dissertations

$12-2020$

\title{
Assaults on law enforcement officers: a spatial and theoretical analysis through social disorganization.
}

Brian Keith Simpkins

University of Louisville

Follow this and additional works at: https://ir.library.louisville.edu/etd

Part of the Criminology Commons

\section{Recommended Citation}

Simpkins, Brian Keith, "Assaults on law enforcement officers: a spatial and theoretical analysis through social disorganization." (2020). Electronic Theses and Dissertations. Paper 3546.

https://doi.org/10.18297/etd/3546

This Doctoral Dissertation is brought to you for free and open access by ThinkIR: The University of Louisville's Institutional Repository. It has been accepted for inclusion in Electronic Theses and Dissertations by an authorized administrator of ThinkIR: The University of Louisville's Institutional Repository. This title appears here courtesy of the author, who has retained all other copyrights. For more information, please contact thinkir@louisville.edu. 


\title{
ASSAULTS ON LAW ENFORCEMENT OFFICERS: \\ A SPATIAL AND THEORETICAL ANALYSIS \\ THROUGH SOCIAL DISORGANIZATION
}

\author{
By \\ Brian Keith Simpkins \\ B.A., Marshall University, 2002 \\ M.S., Eastern Kentucky University, 2004 \\ Ed.D., Eastern Kentucky University, 2015
}

\begin{abstract}
A Dissertation
Submitted to the Faulty of the

College of Arts and Sciences of the University of Louisville in Partial Fulfillment of the Requirements

for the Degree of
\end{abstract}

Doctor of Philosophy

in Criminal Justice

Department of Criminal Justice

University of Louisville

Louisville, Kentucky

December 2020 
Copyright 2020 by Brian Keith Simpkins

All right reserved 



\title{
ASSAULTS ON LAW ENFORCEMENT OFFICERS: \\ A SPATIAL AND THEORETICAL ANALYSIS \\ THROUGH SOCIAL DISORGANIZATION
}

\author{
By \\ Brian Keith Simpkins \\ B.A., Marshall University, 2002 \\ M.S., Eastern Kentucky University, 2004 \\ Ed.D., Eastern Kentucky University, 2015 \\ A Dissertation Approved on
}

November 17, 2020

by the following Dissertation Committee

Dissertation Director

Dr. Kristin Swartz

Dr. Bradley Campbell

Dr. Deborah Keeling

Dr. Derek Paulsen 


\section{DEDICATION}

This dissertation is dedicated to my children

Gavin, Gabrielle, and Graham

my parents

Wesley and Rhonda Simpkins

and my sister and brother

Becky Simpkins and Sean Simpkins

who have always supported me no matter what. 


\section{ACKNOWLEDGEMENTS}

I would like to thank my dissertation chair, Dr. Kristin Swartz, for her guidance and patience throughout my dissertation process. I would also like to thank the other University of Louisville committee members, Dr. Deborah Keeling and Dr. Bradley Campbell, for their time and commitment to my dissertation. I would also like to express my thanks to Dr. Derek Paulsen for his willingness to serve for the second time on a committee related to my graduate studies. I would also like to say thanks to fellow faculty members with the Eastern Kentucky University Homeland Security Program (Dr. Ryan Baggett, Dr. Michael Collier, Dr. Chad Foster, Dr. Joanne McGlown, Dr. Tom Schneid, and Dr. Bill Sullivan) for their professional support during my studies at the University of Louisville. 


\section{ABSTRACT \\ ASSAULTS ON LAW ENFORCEMENT OFFICERS: \\ A SPATIAL AND THEORETICAL ANALYSIS \\ THROUGH SOCIAL DISORGANIZATION \\ Brian Keith Simpkins}

November 17, 2020

The purpose of the present study was to gain a better understanding of assaults on law enforcement officers to identify correlations and spatial concentrations related to theoretical constructs of social disorganization. The present study was based on official assault on law enforcement officer data from a major metropolitan area within a southeastern state for the years 2010-2019. In addition to bivariate and multivariate statistical testing (e.g., Pearson correlation coefficient and multiple linear regression), multiple spatial analyses were utilized to understand the statistical significance, visualize results, and compare to previous theoretical explanations of crime concentration. The findings revealed that assaults on law enforcement officers are spatially concentrated in census tracts in the downtown urban core that exhibit indicators of social disorganization. More specifically, assaults on law enforcement officers are spatially concentrated within downtown urban core areas with high levels of the following characteristics of social disorganization: Supplemental Nutrition Assistance Program (SNAP) benefit receivership, vacant housing units, and disrupted families. 


\section{TABLE OF CONTENTS}

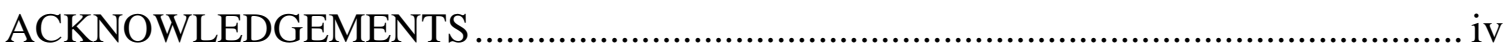

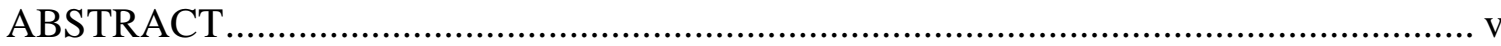

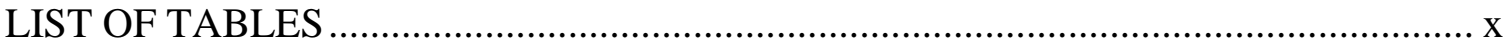

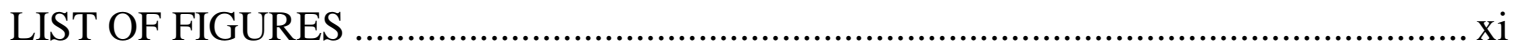

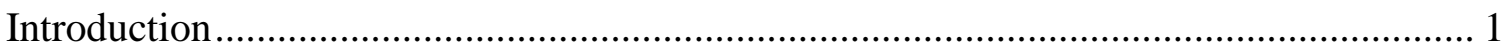

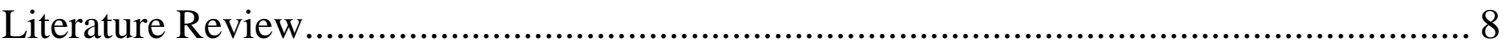

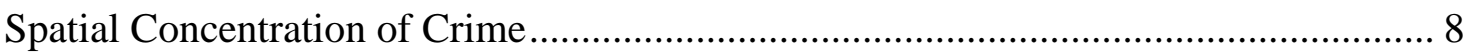

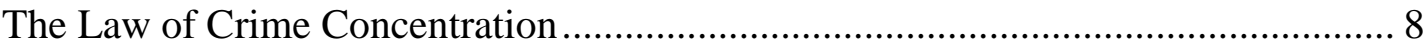

Assaults on Law Enforcement Officers ........................................................... 10

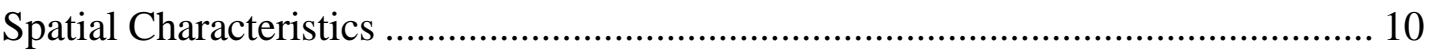

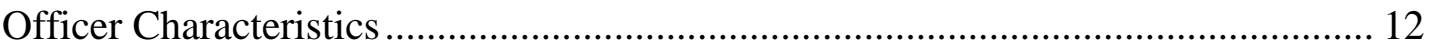

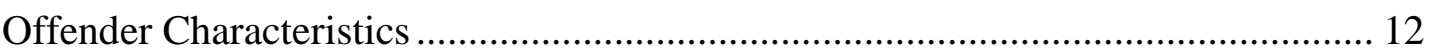

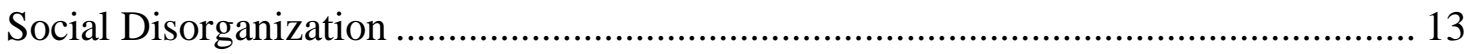

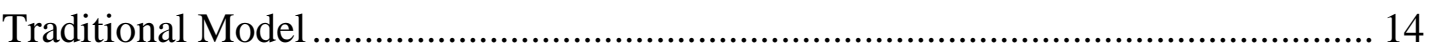

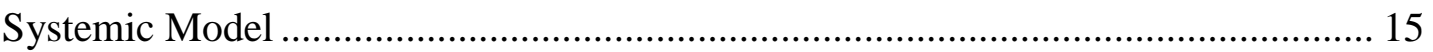

Social Ties and Crime

Concentrated Disadvantage …………….......................................................... 24

Social Disorganization and Assaults on Law Enforcement Officers ............................ 26

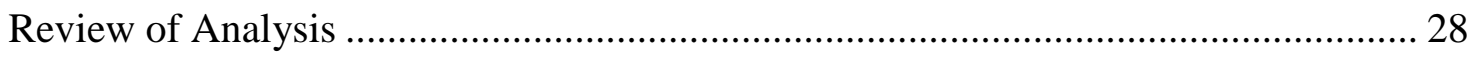

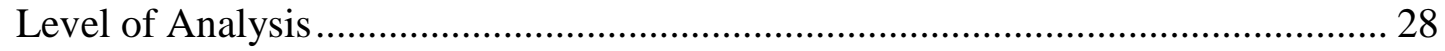

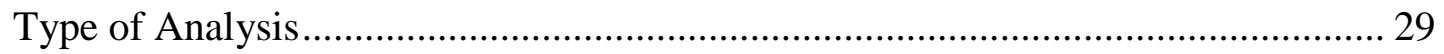


Summary

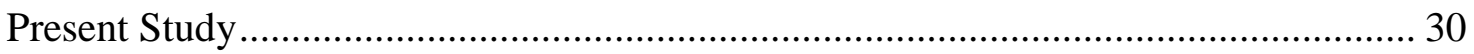

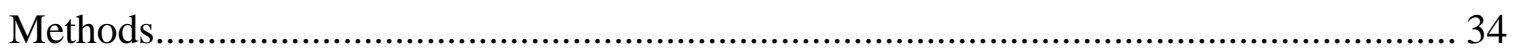

Study Location Contextual Background .................................................................. 34

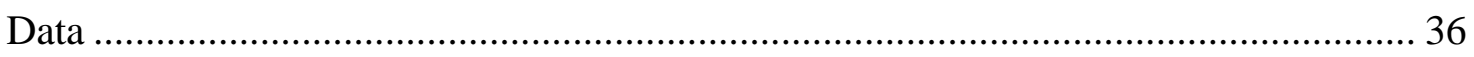

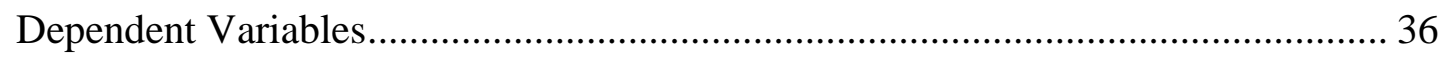

Independent and Predictor Variables..................................................................... 37

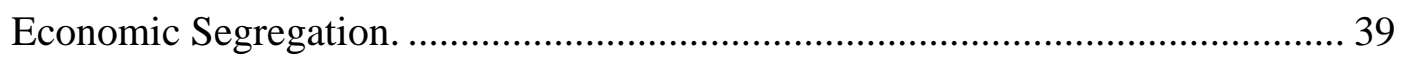

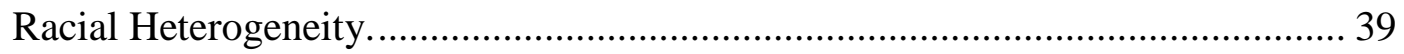

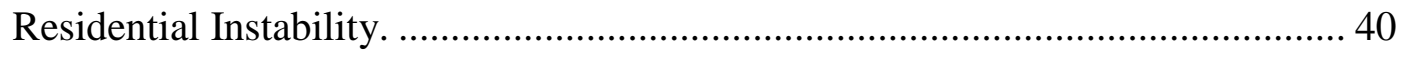

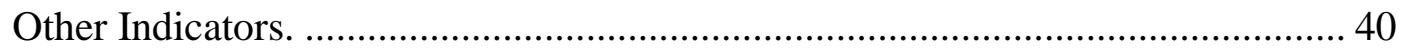

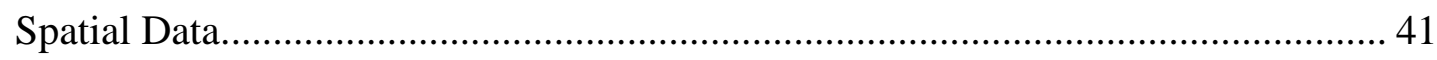

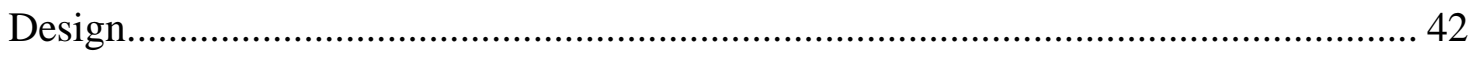

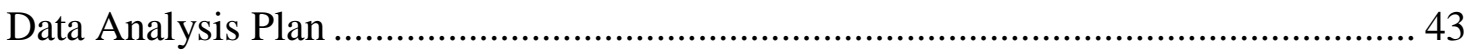

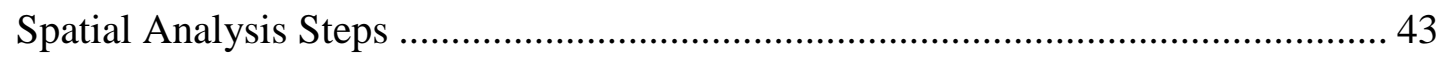

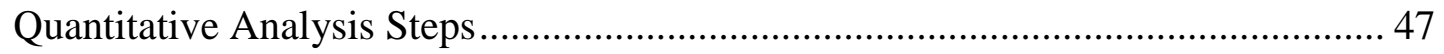

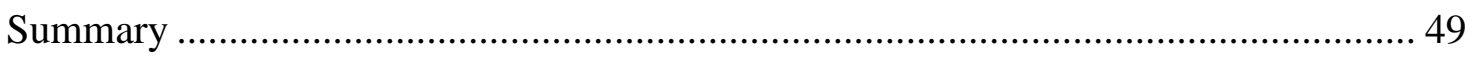

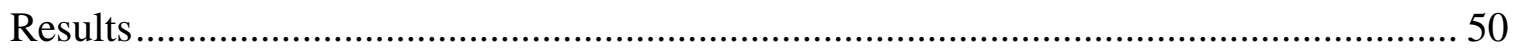

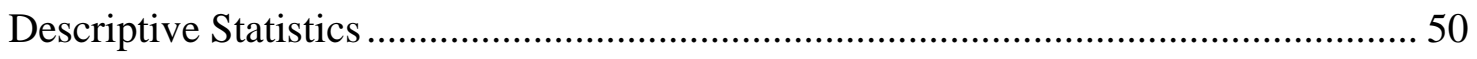

Assaults on Law Enforcement Officers (Dependent Variable) ……........................... 50

Removal of Outlier Census Tract for Statistical Analyses. ................................... 51

Social Disorganization Statistics (Independent Variables) ………………............... 53

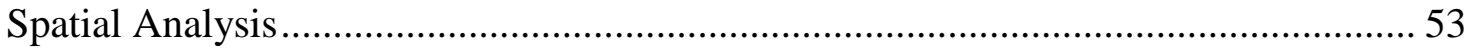




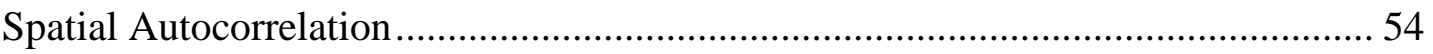

Street Segment Spatial Concentration .................................................................... 55

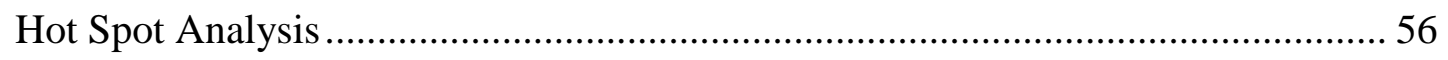

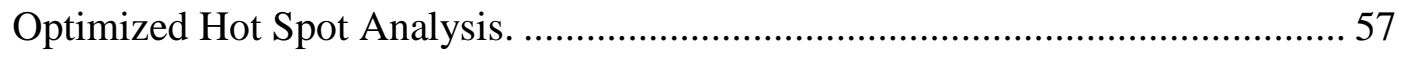

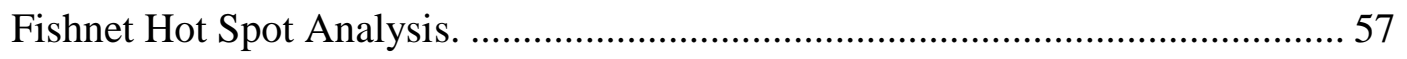

Kernel Density Hot Spot Analysis...................................................................... 58

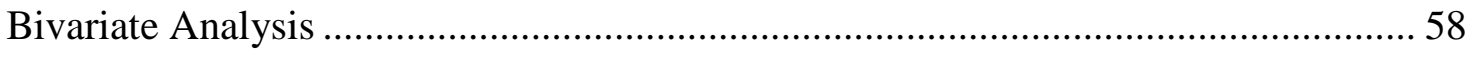

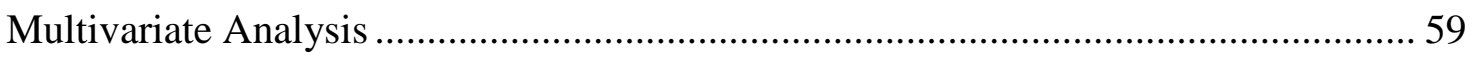

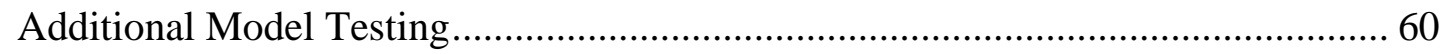

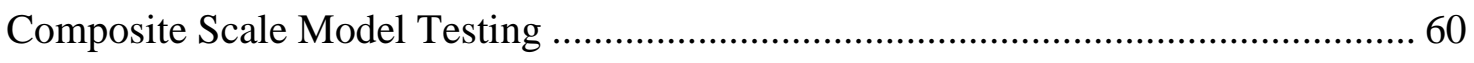

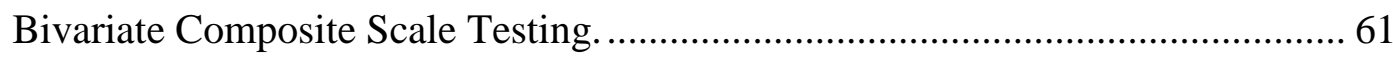

Multivariate Composite Scale Testing................................................................. 61

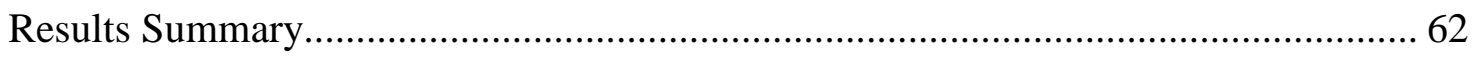

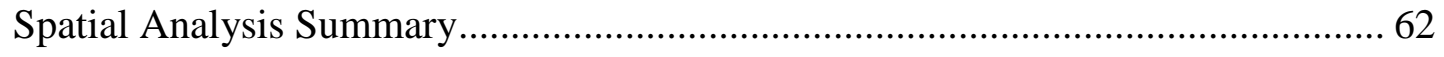

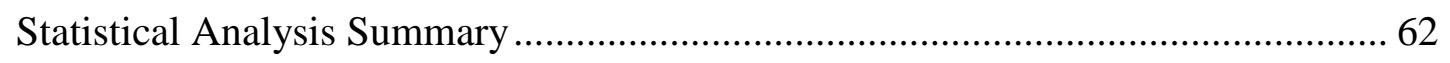

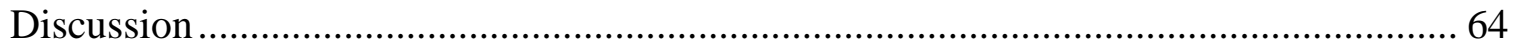

Number of Assaults on Law Enforcement Officers Per Year....................................... 65

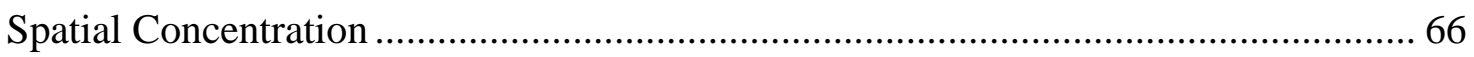

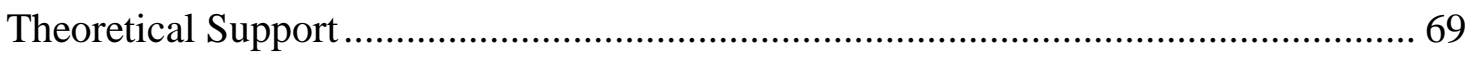

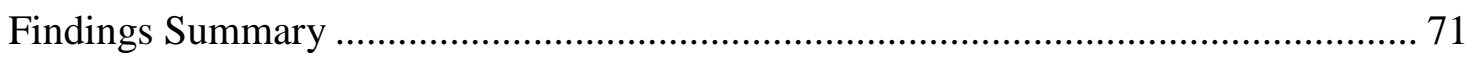

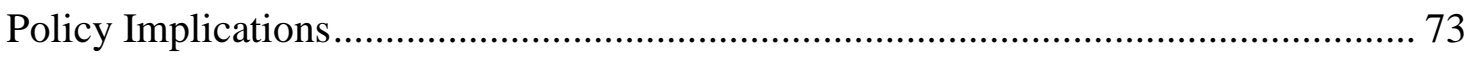

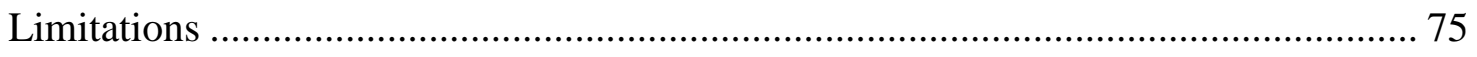

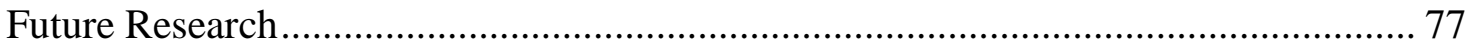




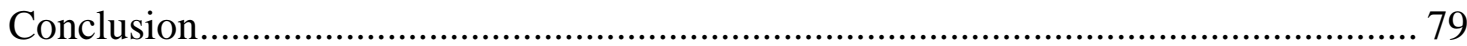

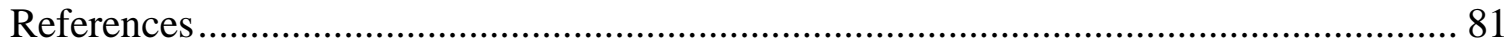

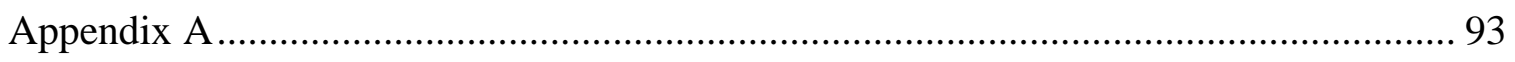

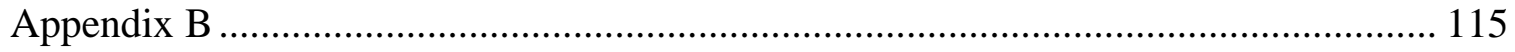

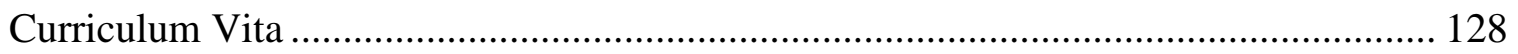




\section{LIST OF TABLES}

TABLE $\quad$ PAGE

1. Selected Metropolitan Area Contextual Information............................................... 116

2. Descriptive Statistics for All Variables (Census Tract Unit of Analysis) ................ 117

3. Outlier Census Tract Contextual Information....................................................... 118

4. Correlation Coefficients for Assaults on Law Enforcement Officers and Community

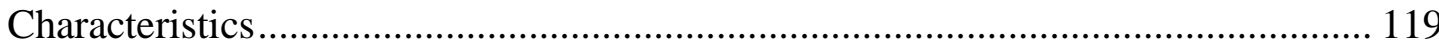

5. Regression of Assaults on Law Enforcement Officers and Community Characteristics (Full Theoretical Model) f................................................................................. 120

6. Regression of Assaults on Law Enforcement Officers and Community Characteristics

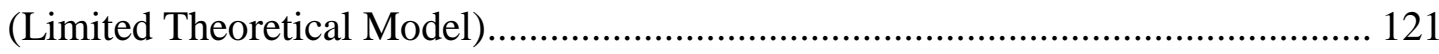

7. Principal Component Analysis for Economic Segregation and Residential Instability

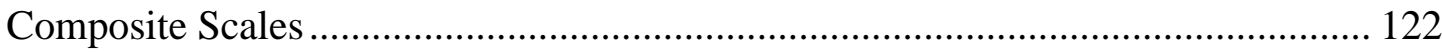

8. Correlation Coefficients for Assaults on Law Enforcement Officers and Composite Scales 123

9. Regression of Assaults on Law Enforcement Officers and Composite Scales......... 124

10. Main Hypotheses Analytical Support Summary ...................................................... 125

11. Sub-Hypotheses Analytical Support Summary ………………............................ 126 


\section{LIST OF FIGURES}

FIGURE

PAGE

1. Graphical Representation of Systemic Model of Social Disorganization .................. 94

2. Census Tracts of Selected Metropolitan Area .................................................... 95

3. Downtown Urban Core of Selected Metropolitan Area ........................................ 96

4. Total Assaults on Law Enforcement Officers per Year......................................... 97

5. Assault Rate per 1,000 Residents per Census Tract ........................................ 98

6. Total Assaults on Law Enforcement Officers per Census Tract (2010-2019)........... 99

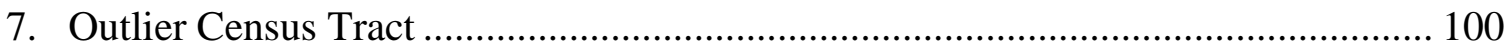

8. Total Assaults on Law Enforcement Officers Point Data (2010-2019).................. 101

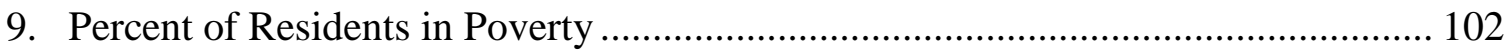

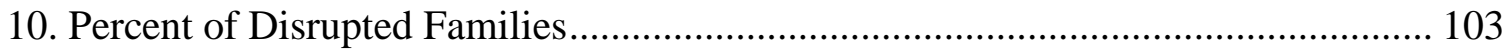

11. Percent of Families Receiving SNAP Benefits................................................... 104

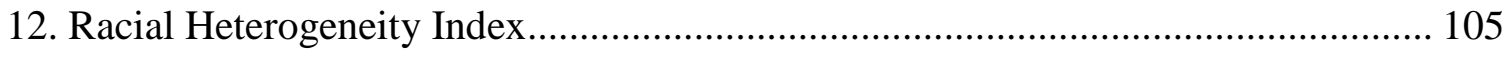

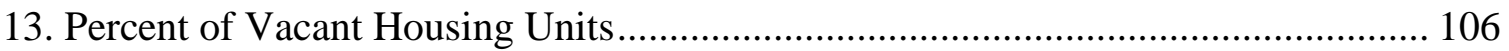

14. Percent of Renter-Occupied Housing Units................................................... 107

15. Percent of Residents Moved in Since 2015 ..................................................... 108

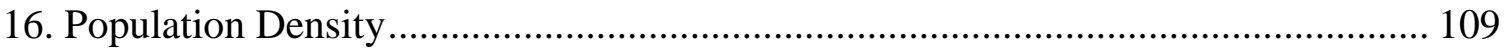

17. Percent of Residents 25+ without a Bachelor's Degree....................................... 110 
18. Percentage of Assaults on Law Enforcement Officers per Percentage of Street Segments

19. Optimized Hot Spot Analysis per Census Tract ............................................... 112

20. Fishnet Grid Hot Spot Analysis (2,500-Foot Grids) ......................................... 113

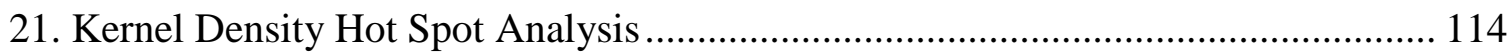




\section{CHAPTER I}

\section{INTRODUCTION}

Law enforcement is considered one of the most dangerous occupations in the United States. In fact, law enforcement officers have the eighteenth highest U.S. occupational fatality rate (Tiesman et al., 2018). Although line of duty deaths have significantly decreased since the 1970s (approximately 70 percent decrease), on average one law enforcement officer is felonious killed each week in the United States (Richardson et al., 2019). When compared to the extensive research on line of duty deaths, assault of law enforcement officers is considered an understudied topic despite the level of occurrence (Bierie, 2017). This is concerning due to the fact that assaults on law enforcement officers have remained consistent since the 1990s despite long-term reductions in violent crime in the United States (Bierie, 2017; Schouten \& Brennan, 2016).

Therefore, one problem associated with assaults on officers is actually achieving a greater understanding of the problem. This greater understanding is warranted to enable command staff to not only distribute resources efficiently, but also to develop policies, procedures, training programs, etc. to help address and mitigate future incidents and to increase officer on-scene safety (Gibbs et al., 2018). Increasing on-scene safety is paramount and is supported by the fact that 10 percent of law enforcement officers are assaulted each year of which 25 percent are injured and a small percentage are killed 
(Bierie, 2017). Although 10 percent may seem as a small number, the total amount of state, county, and municipal law enforcement agencies across the United States illustrates the overall impact. Specifically, there are over 16,000 law enforcement agencies in the United States with approximately 90 percent (or 14,500 ) serving populations under 25,000 (National Institute of Justice [NIJ], 2004). Further, over half of all law enforcement agencies employ 10 or fewer officers (NIJ, 2004). Therefore, an assault on an officer in a small law enforcement agency would have immediate and possibly longterm impacts if that officer cannot return to duty after an assault.

When examining assaults on law enforcement officers from a national perspective, some trends are evident. Specifically, neighborhoods within urban areas with high levels of crime, population densities, poverty, unemployment, drug use, and other social ills typically have higher rates of assaults on law enforcement officers (Alpert \& Dunham, 1992; Barrick et al., 2014; Bayley \& Garofalo, 1989; Garner \& Maxwell, 2001; Gibbs et al., 2018). This trend is the opposite in more affluent communities that lack social ills and in which both crime and assaults on law enforcement officers occur less frequently (Kaminski et al., 2003; Willits, 2014). Individuals who engage in assaultive acts against law enforcement officer are commonly young (aged 15-29), male, ethnic minority individuals who also have high rates of unemployment, poverty, drug or alcohol use, and prior criminal activity (Barrick et al., 2014; Johnson, 2011; Kaminski et al., 2003; Meyer et al., 1979; Wilson \& Zhao, 2008). As for location, areas near foreclosures, gang territory, and illegal drug markets are common breading grounds for assaults on law enforcement officers (Caplan et al., 2014). It is not surprising that most assaults on law enforcement officers occur at night (Rabe- 
Hemp \& Schuck, 2007). Lastly, one interesting trend of assaults on law enforcement officers is the absence of officer characteristics that are clearly correlated with assaultive events (Caplan, et al., 2014; Rabe-Hemp \& Schuck, 2007; Tiesman et al., 2018; TuckerGail et al., 2010).

When examining the aforementioned trends from a criminological perspective, the association of assaults on law enforcement officers with areas characterized by social disorganization is apparent. Just as social disorganization provides explanations for crime concentrations in specific communities, this theoretical perspective can also provide better understanding of spatial concentrations of assaults on law enforcement officers. This is important because the social disorganization tradition is arguably the most important community-level theory of crime. The main impetus of the social disorganization tradition is that human behavior (including criminal behavior) is influenced by the social and physical environment (Lilly et al., 2015). Early efforts and developments in the social disorganization tradition focused on three specific community characteristics: poverty, racial heterogeneity, and residential mobility (Sampson \& Groves, 1989; Shaw and McKay, 1942). Therefore, the original social disorganization tradition posits these community characteristics lead to higher levels of crime through two interviewing variables: social disorganization (weak informal social control) and weak socialization (transmission of criminal values). This results in crime being spatially concentrated in specific locations, which account for a significant percentage of all crime across an entire geographical area (such as a city).

Contemporary developments in social disorganization theory, however, have focused less on the cultural deviance (transmission of criminal values) and more on 
informal social control due to conflicting theoretical premises of the original social disorganization tradition. This examination resulted in the development of a systemic model of social disorganization, which firmly contests weakened informal social control within a community is the intervening variable between ecological conditions (i.e., low socioeconomic status, residential instability, and racial heterogeneity) and higher rates of criminal activity (Cullen \& Wilcox, 2015; Kornhauser, 2015a; Sampson \& Groves, 1989). Overall, the systemic model of social disorganization posits that a socially disorganized community no longer projects any form of social control, whether it is informal, internal, external, direct, and/or indirect (Kornhauser, 2015a). Therefore, socially disorganized communities are crime-permitting communities (based on weakened informal social control) rather than crime-generating through cultural deviance (Cullen \& Wilcox, 2015). Overall, the systemic model posits that community characteristics can lead to weak informal social control through a lack of shared norms, weak social ties (local network structures), and cultural attenuation (Bellair \& Browning, 2010; Kornhauser, 2015a). This revisioning of social disorganization via the systemic model resulted in research focusing on informal social control and community level crime (Bellair, 1997; Bellair \& Browning, 2010; Bursik, 1988; Carr, 2003; Kasarda \& Janowitz, 1974; Kornhauser, 2015a; Lowenkamp et al., 2003; Pattillo, 1998; Sampson \& Groves, 1989; Warner \& Roundtree, 1997; Warner \& Rountree, 1999; Warner et al., 2015), most of which revealed empirical support for the systemic model.

Overall, the developments in the social disorganization tradition can help to promote greater understanding of assaults on law enforcement officers. To accomplish this and to help fill the current informational gap, the present study examined assaults of 
law enforcement officers from both spatial and theoretical perspectives. First, the examination of the spatial distribution of assaults on law enforcement officers helped to identify the circumstances in which law enforcement officers have a higher risk of assault. Further, the application of theoretical concepts from the law of crime concentration and the social disorganization tradition enabled the identification of structural characteristics that help to explain spatial concentrations of assaults on law enforcement officers. Together, an analysis completed through these multiple perspectives provided a greater understanding of assaults of law enforcement officers. Specifically, the present study attempted to determine whether assaults on law enforcement officers are concentrated within certain areas and whether constructs of social disorganization can explain the spatial concentrations. To accomplish the present study, assault on law enforcement officer data from a major metropolitan area within a southeastern state were utilized along with U.S. Census Bureau data for census tracts within the metropolitan area. From the data, specific theoretical constructs of social disorganization were employed in an attempt to explain higher instances of assaults on law enforcement officers in specific census tracts.

To properly outline the present study, the following chapters follow a specific roadmap. To begin, a comprehensive literature review of assaults on law enforcement officers, crime concentration, and social disorganization is provided. Both a full review and understanding of foundational elements and related concepts are required before developing appropriate research methods to test theoretical premises. Next, the methods section overviews the specific procedures were utilized to test aspects of crime concentration and social disorganization. In addition to spatial mapping, multivariate 
statistical testing was used to determine whether ecological measures of social disorganization are associated with assaults on law enforcement officers.

The specific data used in the present study was assault on law enforcement officer data from a major metropolitan area within a southeastern state, which was examined and compared at the census tract level. This enabled the present study to address noted gaps in the literature. For example, reviews of the current literature of assaults on law enforcement officers revealed that the research is primarily descriptive, offender-focused, completed at the macro-/city-level (or above), is devoid of spatial mapping analyses, and lacks significant focus on full criminological theories (Bierie, 2017; Gibbs et al., 2018; Johnson, 2011; Kaminski et al., 2003). The focus of previous studies has not been fullscale theory testing, but rather a limited focus on certain independent/explanatory variables that fit into one of three general categories: environmental (e.g., poverty rate, population density, racial composition), situational (e.g., inside versus outside, witnesses), and personal (e.g., demographics, presence of alcohol and/or illicit drugs) (Bierie eta al., 2013; Bierie, 2017; Gibbs et al., 2018; Kaminski \& Sorensen, 1995). Therefore, the current literature is rife with studies that seem to pick and choose certain elements from various criminological theories — most notably and commonly social disorganization and routine activities - to examine assaults on law enforcement officers rather than conducting a comprehensive analysis of all relevant factors.

In addition to the variety of independent/predictor variables used, another inconsistency in the current literature is unit or area of analysis. Although cities can be utilized as a suitable unit of analysis, variation within a city may be missed depending on any present segregations in the built environment (Kaminski et al., 2003). Therefore, 
researchers have suggested that a unit of analysis below the city, such as census tract or block group level, can provide a fuller understanding of assaults on law enforcement officers (Bierie eta al., 2013; Bierie, 2017; Gibbs et al., 2018; Kaminski et al., 2003). As such, the present study aimed to contribute to the literature by spatially and theoretically examining variations in assaults on law enforcement officers at the census tract level with a focus on structural characteristics associated with social disorganization. The method to complete this examination is provided in a subsequent section followed by a discussion of the results. 


\section{CHAPTER II}

\section{LITERATURE REVIEW}

Due to the multiple perspectives utilized in the present study, the literature review is classified into four sections. First, relevant research that generally discusses the spatial concentration of crime is overviewed. Second, research on assaults on law enforcement officers is reviewed, which includes examination of spatial aspects and characteristics related to offender, officer, and situational elements. This overview provides a fuller understanding of assaults on law enforcement officers. Third, the social disorganization theoretical perspective is discussed, which examines social factors that impact the prevalence of crime within communities and neighborhoods. Last, the level and type of analysis of previous research is reviewed to identify analysis gaps or other noted issues.

\section{Spatial Concentration of Crime}

\section{The Law of Crime Concentration}

The spatial concentration of crime has been extensively covered in the current research literature. In fact, the consistent research findings have resulted in an empirical establishment of the law of crime concentration. This law posits that a significant amount of crime within a city is located in a narrow bandwidth of a city's geography (Carter et al., 2018; Weisburd, 2015). One of the first studies to underpin this law was completed in 1989 in Minneapolis. The researchers found that only 3.3 percent of street segments accounted for 50 percent of all calls for service (Anselin et al., 2000; Sherman 
et al., 1989). The research further indicated that all assault crime came from only seven percent of street segments, which shows that specific crimes also have spatial concentration (Sherman et al., 1989; Weisburd, 2015). These results were repeated in other studies using geographically dispersed cities as indicated below.

- Boston (MA): 3.6 percent of street addresses produced 50 percent of calls for service (Pierce et al., 1988); 2.0 percent of street segments produced 50 percent of all robberies (Braga \& Fields, 2014); and 5.0 percent of street segments produced 74.0 percent of all shootings (Braga \& Fields, 2014).

- New York (NY) and Baltimore (MD): Most active 10 percent of criminal areas produced 32 percent of robberies, assaults, burglaries, grand larcenies, and auto thefts (Eck et al., 2000).

- Seattle (WA): 4.5 percent of street segments produced 50 percent of crime incidents (Weisburd et al., 2004).

- Vancouver (Canada): 7.8 percent of street segments produced 60 percent of crime incidents (Curman et al., 2015).

- Jersey City (NJ): 4.4 percent of street segments (or 56 drug hot spots) produced 20 percent of disorder crimes and 14 percent of personal crimes (Weisburd \& Mazerolle, 2000).

One of the most important empirical studies of spatial crime analysis was research completed by Weisburd (2015) across multiple cities of varying sizes. Based on the results, a majority of crime is generated by small, concentrated pockets of city geography (Carter et al., 2018). Therefore, Weisburd (2015) stated "that there is a tight bandwidth of crime concentration at places suggesting a law of crime concentration across cities" ( $p$. 
143). This law of crime concentration posits that 50 percent of crime is concentrated within 4 percent of a city and 25 percent of crime is concentrated in less than 1.5 percent of a city (Weisburd, 2015). This this context, 50 percent of crime can be defined as 50 percent of occurrences of a specific crime or crime overall, 50 percent of call for service, or similar statistic. Further, 4 percent of a city can be defined as 4 percent of all street segments within a city or other geographical reference point. Overall, the literature on crime concentration is consistent and supports the notion that most crime is spatially concentrated in specific areas.

\section{Assaults on Law Enforcement Officers}

\section{Spatial Characteristics}

The current literature is plentiful with research that examines police use of force and line of duty deaths, however, much less research is available on assaults of law enforcement officers. The research that does exist illustrates spatial clusters of general violence against law enforcement officers (Gibbs et al., 2018; Johnson, 2011). A consistent finding within the research is areas characterized by social disorganization and high rates of calls for service are significantly related to higher rates of assaults on law enforcement officers (Barrick et al., 2014; Gibbs et al., 2018; Wilson \& Meyer, 1990). Therefore, research shows law enforcement officers serving in communities characterized by social disorganization are subjected to higher assault rates compared to those law enforcement officers serving more socially organized and affluent communities (Kaminski et al., 2003; Willits, 2014). Due to the prevailing characteristics of socially disorganized communities, the common characteristics of those who assault law enforcement offers tend to be young (aged 15-29), male, ethnic minority, unemployed, 
low socioeconomic status, unmarried, under the influence of drugs or alcohol, and have prior criminal offenses (Brandl, 2001; Barrick et al., 2014; Creamer \& Robin, 1968; Johnson, 2011; Kaminski et al., 2003; Wilson \& Zhao, 2008).

The current research illustrates strong correlates between assaults on law enforcement officers and communities characterized by high arrestee density, criminogenic conditions, and propensity for violence (Barrick et al., 2014; Caplan et al., 2014; Ellis et al., 1993; Kaminski et al., 2003; Wilson \& Zhao, 2008). However, resource deprivation and concentrated disadvantage are commonly the strongest correlates and predictors of assaults on law enforcement officers, which includes prolonged economic distress (high unemployment and poverty rates), family disruption (high divorce and single parent household rates), and a higher percentage of ethnic minority residents (Barrick et al., 2014; Caplan et al., 2014; Ellis et al., 1993; Gibbs et al., 2018; Kaminski et al., 2003; Meyer et al., 1986; Wilson \& Zhao, 2008).

Other environmental factors appear to also influence assaults on law enforcement officers. For example, population density plays a role in which a higher officer-to-citizen ratio is related to higher rates of assaults on law enforcement officers (Wilson \& Zhao, 2008). Conversely, calls for service to areas with large numbers of foreclosed homes, areas with high violent crime rates, gang territory, and illegal drug markets significantly increase the occurrence of assaults on law enforcement officers (Caplan et al., 2014). This is in addition to temporal distribution of assaults on law enforcement officers. On average, approximately two-thirds of assaults on law enforcement officers occur at night (between 6:00 PM and 6:00 AM) with the majority occurring between 10:00 PM and 2:00 AM (Rabe-Hemp \& Schuck, 2007). 


\section{Officer Characteristics}

One important element of assault on law enforcement officers is officer characteristics, which can help to identify possible risk factors. Prior research has revealed that the most typical officer characteristics, such as age, race, gender, and physical size, are not significantly associated with assaultive events (Caplan, et al., 2014; Rabe-Hemp \& Schuck, 2007; Tiesman et al., 2018; Tucker-Gail et al., 2010; Wilson et al., 1990). However, officers who have experienced a previous assaultive event tend to have higher risk for future assaults (Tucker-Gail et al., 2010). Of course, this result may be partly due to not only behavioral characteristics of the officer, but also the officer's type of assignment that provides more opportunities for possible assault (e.g., patrol, special operations/response team, investigations, administrative, etc.) (Rabe-Hemp \& Schuck, 2007). Additional research has indicated that single-officer patrols, highway/roadway incidents, and the act of making an arrest are highly correlated with assaults on law enforcement officers (Barrick et al., 2018). One missing element within the research is officer characteristics related to service, such as years of service, rank, job assignment (e.g., patrol, detective), patrol assignment (single versus two-person patrol), etc. Although the present study does not examine these elements, it does illustrate a significant area for future research.

\section{Offender Characteristics}

Unlike officers, the characteristics of offenders who assault law enforcement officers have been fully identified. A consistent finding within the current literature is the typical assailants are young (between ages 18 and 25), male, from a racial minority group, and unemployed (Bierie, 2017; Bierie et al., 2013; Craun et al., 2013; Hosrtman, 
1973; Johnson, 2011; Margarita, 1980; Rabe-Hemp \& Schuck, 2007; Stobart, 1972). In addition to the previously noted general characteristics, other characteristics including citizens with less than a high school education, a criminal record, from broken families, and low socioeconomic status have all been found to correlate with a higher likelihood of assaults against officers (Johnson, 2011; Meyer et al., 1979). Further, some research has indicated that individuals under the influence of alcohol are three time more likely to assault a law enforcement officer (Bierie, 2017; Bierie et al., 2013; Covington et al., 2014; Craun et al., 2013; Engel, 2003; Johnson, 1999; Kavanaugh, 1997; McClusky et al., 1999; Rabe-Hemp \& Schuck, 2007). Additionally, law enforcement officers are most likely to be assaulted when engaging with multiple individuals (Covington et al., 2014), where multi-gender groups represent the most assaultive threat to law enforcement officers followed by all-male groups and all-female groups, respectively (Bierie, 2017). Lastly, the research results associated with the offender characteristics noted above (e.g., demographics, personal history, etc.) within the United States are consistent with results from research performed in other Western nations such as the United Kingdom (Brown, 1994; Johnson, 2011; Moxey \& McKenzie, 1993; Noaks \& Christopher, 1990), Australia (Johnson, 2011; Mayhew, 2001), and Iceland (Bragason, 2007; Johnson, 2011).

\section{Social Disorganization}

The social disorganization tradition is one of the most important community-level theories of crime. The social disorganization tradition is a major component of the Chicago School theories, which perceived that human behavior (including criminal behavior) is influenced by the social and physical environment (Lilly et al., 2015). This ecological view of crime, however, was only the birth of social disorganization. 
Subsequent years resulted in the development of the systemic model focusing on informal social control as well as other perspectives that focus on concentrated disadvantage among other concepts. Not only did these reformulations redefine social disorganization, but also created new measurements to better understanding community aspects that impact crime.

\section{Traditional Model}

Although Robert Park and Ernest Burgess laid the ecological foundation of social disorganization, research by Shaw and McKay (1942) provided the most enduring and influential statement of the social disorganization tradition and are credited with creating social disorganization as it is generally known today (Wilcox et al., 2018). Using decades of records, Shaw and McKay (1942) tested earlier ecological theories and empirically determined that crime was indeed concentrated in the so-called zone of transition (closer to the central business district) with decreasing rates in the outer zones. Further, individual criminal activity also reduced when an individual moved from the zone of transition to outer zones (Shaw and McKay, 1942). This supported the view of Chicago School scholars that "the nature of the neighborhood-not that nature of the individuals within the neighborhood" explains criminal behavior (Lilly et al., 2015, p. 40). According to Shaw and McKay (1942), community structural characteristics of poverty, racial heterogeneity, and residential mobility lead to higher delinquency rates through two intervening variables: social disorganization (weak informal social control) and weak socialization (transmission of criminal values). Further, it does not matter who the individuals are within the community. This is because crime follows a spatial distribution in which certain communities account for a high percentage of all crime due 
to the community characteristics (poverty, racial heterogeneity, and residential mobility), regardless of who are the residents. These findings helped start the main move away from the Lombrosian view of crime to the sociological view of crime thereby focusing on the environment rather than the individual. Following Shaw and McKay (1942), social disorganization became a primary explanation for crime, which posited that (a) crime is spatially patterned, (b) the place/location mattered and not the person, and (c) there are specific community characteristics that result in high crime areas.

\section{Systemic Model}

Following publication and acceptance of Shaw and McKay's (1942) research and findings, tests of the traditional model of social disorganization theory focused on the community characteristics (e.g., poverty, racial heterogeneity, and residential mobility) to explain variations in crime across a city (Bursik, 1988; Kasarda \& Janowitz, 1974). Other researchers, however, began to address theoretical issues with the traditional model of social disorganization. Particularly, Kornhauser (2015a) perceived issues with the incompatibility of some of the theoretical perspectives, most notably cultural deviance, strain, and control. Further, there was also a missing link in the crime causal chain between the community characteristics and crime. As such, researchers began to identify the missing link, or the so-called black box (Lowenkamp et al., 2003; Sampson \& Groves, 1989).

Ultimately, a reformulated and systemic social disorganization model was developed that "removed elements of strain and cultural deviance and clearly defined 'weakened informal social control' as the key theoretical construct intervening between ecological conditions (i.e., low socioeconomic status, residential instability, and racial 
heterogeneity) and rates of crime" (Cullen \& Wilcox, 2015, p. 13). Therefore, the systemic model utilized elements from Shaw and McKay (1942) and fused them with control theory to develop a macro/community-level control theory of community crime that disregarded criminal culture transmission (Cullen \& Wilcox, 2015; Kornhauser, 2015b). The development of the systemic model of social disorganization is credited to Ruth Rosner Kornhauser. From her perspective, Kornhauser viewed the attenuation of culture, and not criminal culture transmission, as a main source of delinquency (Dooley, 2015). Therefore, Kornhauser defined a systematic theoretical framework of social disorganization that removed the strain theory and social learning/cultural transmission components due to their incompatibility with control theory (Dooley, 2015).

Kornhauser helped to revive the social disorganization tradition which at the time was perceived as a theory that simply focused on the poor (Cullen \& Wilcox, 2015). Kornhauser also identified primary causes of disorganization, which was important as it helped the social disorganization tradition shed the historical circular reasoning connotation (Hirschi, 2015). Kornahuser ultimately created the systematic social disorganization model that also lead to the development of new macro-level and systematic research and new theories based around concepts and causal mechanisms supported by Kornhauser such as social networks, systemic control, collective efficacy, and environmental theory (Cullen \& Wilcox, 2015).

Within the systemic model framework, a socially disorganized community is viewed as a place where "a state of community anomie exists" in which the community no longer projects informal social control (internal, external, direct, indirect) (Kornhauser, 2015a, p. 77). This anomic community state also allows non-normative 
means to flourish (Hirschi, 2015). Therefore, this causes crime-permitting cultures in socially disorganized areas, which was counter to the crime-generating perspective based on cultural deviance (Cullen \& Wilcox, 2015). Overall, the systemic model posits that community characteristics can lead to weak informal social control through a lack of shared norms, weak social ties (local network structures), and cultural attenuation (Bellair \& Browning, 2010; Kornhauser, 2015a). Specifically, social disorganization is the inability of a community to share norms and values to control crime thereby resulting in weak informal social control. Therefore, the systemic model provides a full causal model of crime that posits weak informal social control caused by economic segregation and certain community characteristics - low socioeconomic status, residential instability, and racial heterogeneity — that lead to more crime (see Figure 1 for a graphical representation). Most importantly, the systemic model clarified social disorganization as weak informal social control within communities that are comprised of complex social networks. In fact, weak informal social control is the actual social disorganization, and not the community characteristics of the traditional model (Kasarda \& Janowitz, 1974; Sampson \& Groves, 1989).

Due to the development of the systemic model, subsequent research began to measure social disorganization in new ways. Tests of the traditional model of social disorganization theory focused on characteristics of communities (e.g., poverty, racial/ethnic heterogeneity, and residential mobility) to explain variations in crime across a city, and were largely based on the findings from Shaw and McKay's research (Sampson \& Groves, 1989). Subsequent development and tests of the systemic model of social disorganization theory identified what is in the so-called black box, or the 
intervening variables that come after structural characteristics in the causal chain (Lowenkamo et al., 2003; Sampson \& Groves, 1989). Specifically, the systemic model posits that community characteristics can lead to weak informal social control through a lack of shared norms and cultural attenuation (Bellair \& Browning, 2010; Kornhauser, 2015). Ultimately, the black box of the systemic model was tested to determine what weakened informal social control and the ability of a community or neighborhood to provide self-regulation (Bursik, 1988).

A direct or full test of the systemic model of social disorganization was not completed until 1989. Since this time, testing of informal social control has focused on networks, both informal (family, friendship, and neighbors) and formal (community organizational participation), to uncover what affects overall community informal social control (Bellair \& Browning, 2010; Kasarda \& Janowitz, 1974; Sampson \& Groves, 1989). This complex network of social ties forms the basis of social organization/disorganization and subsequent higher/lower levels of community crime (Kasarda \& Janowitz, 1974). Beginning with the foundational study of Sampson and Groves (1989), the following constructs were used to measure the level of community social organization: local friendship networks, control of street-corner teenage peer groups, and prevalence of organizational participation. These measures were further replicated in research by Lowenkamo et al. (2003). Despite the research performed by Sampson and Groves (1989) being considered the most influential test of the systemic model, other systemic crime research has also examined social networks and informal control aspects within communities. Bellair and Browning (2010) provide a summarization of this research, which reveals a wide variety of measures to include: 
- Knowing neighbors by name and frequent interaction (e.g., dinner, sharing tools);

- Willingness to intervene;

- Similar personal interests and perceived consensus throughout neighborhood;

- Friends within neighborhood; and

- Perceived cohesion and trust among neighborhood residents or collective efficacy (e.g., watching each other's property). (p. 500)

Within the systemic model, a community would have strong social organization and subsequent social control if the networks indicated above were fully developed and strong. Or, as Bellair and Browning (2010) explain, "when networks are strong, the capacity of local residents to engage in informal control for the mutual benefit of neighbors, such as intervention to prevent a crime or conscientious surveillance of space, is strengthened" (p. 499).

Over the years, social disorganization research has revealed support for the systemic model the importance of informal social control (Bellair \& Browning, 2010). In essence, informal social control and strong social networks tend to reduce the instances of crime and victimization (Bellair \& Browning, 2010). One of the most compelling supportive arguments for the systemic model is the research performed by Sampson and Groves (1989). Within the research, Sampson and Groves (1989) determined that the characteristics of a weak social structure (or weak informal social control) lead to a higher prevalence of crime and delinquency. Further, Sampson and Groves (1989) found that the effects of the traditional community characteristics were largely mediated by the social structure characteristics. More importantly, Lowenkamo et al. (2003) performed a replication study of the Sampson and Groves (1989) research. Using data from the 1994 
British Crime Survey (Sampson and Groves [1989] used a 1982 dataset), Lowenkamo et al. (2003) found consistent results with Sampson and Groves (1989) research. Therefore, the systemic model received empirical support illustrating the results were consistent over time (Lowenkamo et al., 2003).

Despite findings by Sampson and Groves (1989) and Lowenkamp et al. (2003), other research has shown inconsistent results of the social network aspect due to prevalence of crime within communities with a strong social cohesion (Bellair \& Browning, 2010). This illustrates that strong social networks are sometimes unable to mediate some structural characteristics such as deeply entrenched poverty (Bellair \& Browning, 2010). However, research examining the informal social control aspect of the systemic model consistently reveals an association with lower levels of crime and victimization (Bellair \& Browning, 2010). Overall, these results illustrate the complexity of social structures and their impact on crime. This complexity has resulted in an abundance of research focusing on informal social control and social ties (Bellair, 1997; Carr, 2003; Kornhauser, 2015; Warner \& Roundtree, 1997; Warner \& Rountree, 1999; Warner et al., 2015).

Social Ties and Crime. Prior research determined that aspects such as familiarity among residents, neighboring among residents, organizational participation, and informal surveillance among other factors were all parts of strong social organization and subsequent social control (Bellair \& Browning, 2010; Bursik, 1988; Kasarda \& Janowitz, 1974; Lowenkamp et al., 2003; Pattillo, 1998; Sampson \& Groves, 1989). In the contemporary social disorganization tradition, the concept of informal social control is viewed as a critical element within the theoretical framework and helps to explain the 
variation in crime rates across communities (Warner et al., 2015). One important construct of informal social control is social ties. Social disorganization theory posits that strong social ties (or local network structures) should lead to lower rates of crime as social interaction leads to increased informal control and the ability of a community to self-regulate behavior (Bellair, 1997; Carr, 2003; Warner \& Rountree, 1999; Warner et al., 2015). Within the systemic model of social disorganization, social ties become more important due to the interwoven networks of social and community life that effect informal social control (Bellair, 1997).

Despite the importance of social ties as explained by the systemic model of social disorganization, research has resulted in mixed or conditional conclusions on the effect of social ties on crime levels (Rountree \& Warner, 1999; Warner \& Rountree, 1997). In fact, the macro-theory component of social disorganization has trouble explaining differing effects of social ties on crime across differing communities when examining elements related to the community characteristics (Rountree \& Warner, 1999; Warner et al., 2015). The currently body of literature on social ties has revealed the relationship between social ties and social control (and resulting crime levels) is conditional (Rountree \& Warner, 1999). Further, this conditional relationship is affected by various demographic and contextual factors to include, but not limited to, the frequency of interactions (Bellair, 1997), racial and gender makeup of a community (Rountree \& Warner, 1999; Warner \& Rountree, 1997; Warner et al., 2015), residential stability (Pattillo, 1998), prevalence of interracial social networks (Warner et al., 2015), and the existence of new parochialism (Carr, 2003). Each of these conditions are explained in the following paragraphs. 
Beginning with the frequency of interactions, research indicates more frequent social tie interactions do not necessarily relate to lower crime rates. In fact, research reveals residents interacting just once a year or more seemed to have a stronger deterrent effect on both personal (e.g., robbery) and property (e.g., motor vehicle theft and burglary) crimes in comparison to those who interact on a daily basis (Bellair, 1997). Although this result may go against common sense that more frequent interaction would lead to less crime, the results illustrate the importance of weak ties as a strong deterrent effect on crime (Bellair, 1997). This is because weak social ties "stitch neighborhoods together" or provide important linkages across networks and affect informal social control (Bellair, 1997, p. 699).

Other research suggests dense social networks developed through residential stability facilitate informal social control even when a criminal element is present in one of the interlocked networks (Pattillo, 1998). However, this finding is not conclusive as other research illustrates informal social control can be effective when community individuals and organizations link with outside public agencies to facilitate control actions (Carr, 2003). This points to the concept of new parochialism in which community residents participate in public agency facilitated actions that enables residents to affect informal social control (and intervene in community matters) as part of the group rather than an individual (Carr, 2003).

As for demographics, research findings illustrate social ties are associated with lower levels of crime in predominately white communities, but not in predominantly mixed or minority communities (Warner \& Roundtree, 1997). This suggests that community heterogeneity may result in not only fewer number of social ties, but also 
social ties that are insular (or lack breadth) and ineffective in relation to informal social control when they do form (Warner \& Roundtree, 1997). This research finding proposes that social ties "have little mediating effects between community structure and crime rates" (Warner \& Roundtree, 1997, p. 520). Further, poverty rates affect the ability of social ties to influence crime rates. Specifically, the effect of social ties is more consistent in average poverty communities as compared to poorer communities, which can be the result of limited external institutional ties and oppositional cultures in communities with higher poverty and heterogeneity levels (Rountree \& Warner, 1999). Simply stated, although social ties exist, aspects of the community result in social ties being ineffective in controlling crime (Rountree \& Warner, 1999). Additional demographic research further reveals that although heterogeneity increases the amount of interracial social ties, this increase actually decreases informal social control (Warner et al., 2015). Last, research findings suggest female social ties have a stronger impact on informal social control as women tend to have more internal community ties than men (Rountree \& Warner, 1999). This is due to males predominately making social ties external to the community via employment (Rountree \& Warner, 1999).

The results of the research discussed above have significant implications for social disorganization research related to the systemic model. Most notably, the results call into question the generalization of the systemic model with its emphasis on informal social control (Warner \& Roundtree, 1997). This is due to inconsistent results related to structural characteristics when examining different types of communities. Some view this as the need to add other variables to the theoretical framework to better understand or explain the differences (Warner \& Roundtree, 1997). This can include a further 
examination of weak ties instead of a singular focus on the number and size of social ties (Bellair, 1997). The inconsistent results require more testing of the systemic model to enhance the understanding of what influences social ties and how social ties affect crime. Overall, the research does not outright refute the importance of social ties within informal social control, but identifies instances not consistent with previous assumptions. This means the implication that "all social ties are effective in controlling crime must be carefully examined” (Rountree \& Warner, 1999, p, 805). The inconsistent results, however, should encourage current and future researchers to examine issues related to social ties to produce a fuller understanding of systemic model of social disorganization.

\section{Concentrated Disadvantage}

One contemporary social dimension of the social disorganization tradition is concentrated disadvantage, which is a new category of entrenched poverty that is generational, perpetuating, and cumulative (Krivo \& Peterson, 2000; Wilson, 2012). Specifically, concentrated disadvantage generally refers to those communities with high levels of certain attributes (poverty, female-headed families, male joblessness, welfare dependency, out-of-wedlock births, and teenage pregnancy) that put residents at a disadvantage, which are predominately found in the inner cities with significant minority populations (Krivo \& Peterson, 2000; Wilson, 2012). These attributes have also been termed social dislocations and continue to pose policy challenges to decision makers (Wilson, 2012). The challenge to decision-makers is these attributes can lead to a "selfperpetuating pathology" because residents adapt and create norms associated with concentrated disadvantage (Wilson, 2012, p. 4). Therefore, residents become assimilated into a culture of poverty and welfare within the inner city and raise children who 
succumb to the culture (general lack of ambition, work ethic, and self-reliance) (Wilson, 2012). This results in communities with concentrated disadvantage having the typical lower-class symptoms of "low aspirations, poor education, family instability, illegitimacy, unemployment, crime, drug addiction, and alcoholism, frequent illness, and early death" (Wilson, 2012, p. 4).

In addition to the attributes above, concentrated disadvantage focuses on poverty that has come about because of social forces and movements (Krivo \& Peterson, 2000; Wilson, 2012). These forces include deindustrialization (manufacturing to service industries), white- and middle-class flight (thereby leaving behind the disadvantaged segment of the population), contemporary discrimination within the criminal justice system, etc., which have resulted in individuals living in social isolation and how they all contribute to the creation of social isolation within inner cities (Krivo \& Peterson, 2000; Wilson, 2012). This social isolation results in a lack of conventional social buffers (or informal social control) such as role models and working- and middle-class families that counter the influence of the attributes previously listed (Krivo \& Peterson, 1996). The social forces discussed above have resulted in pervasive social isolation, which is the "lack of contact or of sustained interaction with individuals and institutions that represent mainstream society" (Wilson, 2012, p. 60). Therefore, it is no surprise that communities characterized by concentrated disadvantage have high rates of crime (Krivo \& Peterson, 1996). This is caused by a lack of financial resources, social networks (equaling less informal social control), and community-based crime initiatives to prevent and fight crime (Krivo \& Peterson, 1996). This has resulted in researchers now having to examine the contemporary social forces in addition to the traditional structural characteristics that 
have changed (from heterogeneity to homogeneity, from mobility to a lack of mobility)

with the exception of poverty. Therefore, the continued evolution of social

disorganization through the systemic model and concentrated disadvantage illustrates the relevance of this perspective in contemporary research.

\section{Social Disorganization and Assaults on Law Enforcement Officers}

As previously explained, social disorganization increases crime through weakened informal social controls (Bursik, 1988; Bursik \& Grasmick, 1993; Chamlin \& Cochran, 1994; Sampson \& Groves, 1989). Despite this well-researched concept, very little research has been completed that has examined community characteristics and assaults on law enforcement officers (Gibbs et al., 2018; Kaminski \& Sorensen, 1995; Kaminski et al., 2003; Morrison \& Meyer, 1974; Regens et al., 1974; Wilson \& Zhao, 2008). One study did examine structural characteristics at the county level for a southeastern state and determined that assaults on law enforcement officers are more likely in counties with higher rates of family disruption and lower levels of poverty (Redman, 2018). However, this research was performed on a unit of analysis (county) that does not take into account variance across communities.

The research that does exist on social disorganization and assaults on law enforcement officers has shown that specific indicators offer the ability to explain the occurrence of assaults on law enforcement officers in certain areas. For example, research has demonstrated that the areas with high levels of the following characteristics are associated with higher levels and spatial concentrations of assaults on law enforcement officers: 
- Alcohol and drug abuse (Barrick et al., 2014; Caplan et al., 2014; Johnson, 2011; Kaminski et al., 2003; Wilson \& Zhao, 2008)

- Calls for service (Barrick et al., 2014; Gibbs et al., 2018)

- Family disruption (divorce and single parent households) (Barrick et al., 2014; Caplan et al., 2014; Gibbs et al., 2018; Kaminski et al., 2003; Redman, 2018; Uchida et al., 1987; Wilson \& Zhao, 2008)

- Gang territory (Caplan et al., 2014)

- Illegal drug markets (Caplan et al., 2014)

- Population density (Wilson \& Zhao, 2008)

- Poverty and/or concentrated disadvantage (Kaminski et al., 2003; Willits, 2014)

- Racial heterogeneity (Barrick et al., 2014; Caplan et al., 2014; Johnson, 2011; Kaminski et al., 2003; Wilson \& Zhao, 2008)

- Residential foreclosures (Caplan et al., 2014)

- Residents with prior criminal offenses (Barrick et al., 2014; Caplan et al., 2014; Johnson, 2011; Kaminski et al., 2003; Wilson \& Zhao, 2008)

- Unemployment (Barrick et al., 2014; Caplan et al., 2014; Johnson, 2011; Kaminski et al., 2003; Wilson \& Zhao, 2008)

- Violent crime (Caplan et al., 2014)

This is a significant area of research because it is important to understand those community characteristics that may be associated with a higher risk of assaults on law enforcement officers (Gibbs et al., 2018). The practical implications of this research are self-evident in that if information can be provided on what factors increase the likelihood of assaults on law enforcement officers it may be possible to reduce the numbers of these 
assaults and the physical consequences that follow for individual officers. These characteristics can be as simple as those characteristics that define social disorganization to others that illustrate second and third order effects of social disorganization, such as high concentrations of foreclosures, gang members, and illicit drug markets (California Commission on Peace Officer Safety Training, 2001; Caplan et al., 2014; Gibbs et al., 2018; Kaminski et al., 2003; Kaminski \& Coleman, 2007; Meyer \& Carroll, 2013).

\section{Review of Analysis}

\section{Level of Analysis}

Presently, the assault on law enforcement officers literature contains numerous studies that examines the issue at the city (Caplan et al. 2014; Fridell \& Pate, 1995; Gibbs et al., 2018; Kaminski, 2002; Kaminski et al., 2003; Kent 2010; Lott, 2000; Regens et al., 1974; Willits 2014), county (Gibbs et al., 2018; Kaminski et al., 2000; Kaminski et al., 2003; Kaminski 2008; Redman, 2018), state (Bailey 1982; Bailey \& Peterson, 1987; Chamlin 1989; Gibbs et al., 2018; Peterson \& Bailey, 1988), and national levels (Bailey \& Peterson, 1994; Batton \& Wilson 2006; Gibbs et al., 2018; Kaminski \& Marvell, 2002; Kaminski et al., 2003; Quinet et al., 1997; Southwick, 1998). As noted earlier, the current research also includes examination of the characteristics of social disorganization, but there is a lack of research at a level of analysis below the city level (Bierie, 2017; Gibbs et al., 2018; Kaminski et al., 2003). Therefore, analysis of assaults on law enforcement officers at levels such as census tracts, patrol precincts, and patrol beats is lacking (Bierie, 2017; Gibbs et al., 2018; Kaminski et al., 2003). This illustrates the advantage of the focus of the present study (census tracts) and the theoretical perspective (social disorganization). Ultimately, social disorganization is ideal for explaining 
variation of crime within and/or across a city and the use of census tracts enables the comparison of geographical areas.

\section{Type of Analysis}

When examined holistically, the current literature on assaults on law enforcement officers primarily examines individual, situational, or environmental aspects as opposed to characteristics associated with social disorganization or other community and neighborhood aspects. Although much is known about the distribution of the events and assailant characteristics, less is known about the social and ecological elements and processes that may impact the possible risk of an assault on a law enforcement officer (Caplan et al., 2014; Chamlin \& Cochran, 1994). Further, little research has been completed using spatial analysis techniques (for exceptions see Caplan et al., 2014; Kaminski et al., 2000; Kaminski et al., 2003). Spatial analysis techniques provide a visual aspect to the statistical results and can further provide context to results and enable comparison of results (Caplan et al., 2014; Gibbs et al., 2018; Johnson, 2011).

\section{Summary}

When viewed comprehensively, the varying perspectives taken are useful to understanding assaults on law enforcement officers. Particularly, assault on law enforcement officer data reveal most assaults are concentrated within areas associated with social disorganization characteristics. Not only does the theoretical perspective of social disorganization provide insight to why assaults on law enforcement officers are spatially concentrated, but this also is consistent with the law of crime concentration. However, the current literature is lacking in several key areas as identified below: 
- Research has not examined the effects of characteristics associated with social disorganization on the odds of an assault against law enforcement officers;

- Analyses at the census tract level are missing from the literature; and

- The use of spatial analysis techniques to statistically analyze and visualize data are sparse in the literature.

Therefore, a cogent study would attempt to address each of the aforementioned areas in a comprehensive study. This is what the present study attempted to accomplish as described in the following section.

\section{Present Study}

Logically, the constructs of the law of crime concentration and social disorganization are applicable to assaults on law enforcement officers. As previously noted, the current literature points to a noticeable lack of not only spatial research on assaults of law enforcement officers, but also research with a level of analysis at the community level that examines specific social and ecological aspects that may influence assaults on law enforcement officers. Therefore, a cogent study is one that applies a spatial analysis of assaults on law enforcement officers to determine if assault incidents are consistent with the law of crime concentration and social disorganization constructs. The present study attempted to fill this void by examining whether assaults on law enforcement officers are spatially concentrated and whether measures of social disorganization can explain why they are concentrated.

Accordingly, this study analyzed data on assaults on law enforcement officers in a major metropolitan area located in a southeastern state. These data were merged with U.S. Census Bureau data for census tracts within the metropolitan area. From the data, 
measures of social disorganization were created to explain potential geographical causes of assaults on law enforcement officers at the census tract level. Therefore, the three main hypotheses tested within the present study were as follows:

$\mathrm{H}_{1}$ : Assaults on law enforcement officers will be spatially concentrated in which half (50 percent) of all incidents occur within four percent of all street segments within the metropolitan area.

$\mathrm{H}_{2}$ : Assaults on law enforcement officers will be spatially concentrated in and around the downtown urban core with decreasing incidents away from the downtown urban core.

$\mathrm{H}_{3}$ : The presence of social disorganization characteristics (economic segregation, racial heterogeneity, residential instability, population density, and educational attainment) within census tracts will be both positively and significantly correlated with incidence of assaults on law enforcement officers.

Further, the specific characteristics of social disorganization examined within $\mathrm{H}_{3}$ of the present study were identified in the following sub-hypotheses, which were grouped by the foundational elements of social disorganization associated with higher incidence of crime.

\section{Economic Segregation}

$\mathrm{H}_{3 \mathrm{~A}}$ (Poverty): The percent of individuals earning below the poverty line within a census tract will be both positively and significantly correlated with incidence of assault on law enforcement officers. 
$\mathrm{H}_{3 \mathrm{~B}}$ (Family Disruption): The percent of female-headed households within a census tract will be both positively and significantly correlated with incidence of assault on law enforcement officers.

$\mathrm{H}_{3 \mathrm{C}}$ (SNAP Benefits): The percent of households within a census tract receiving Supplemental Nutrition Assistance Program (SNAP) benefits within a census tract will be both positively and significantly correlated with incidence of assault on law enforcement officers.

\section{Racial Heterogeneity}

$\mathrm{H}_{3 \mathrm{D}}$ (Racial Heterogeneity): The measure of racial heterogeneity within a census tract will be both positively and significantly correlated with incidence of assault on law enforcement officers.

\section{Residential Instability}

$\mathrm{H}_{3 \mathrm{E}}$ (Vacant Housing): The percentage of vacant housing units within a census tract will be both positively and significantly correlated with incidence of assault on law enforcement officers.

$\mathrm{H}_{3 \mathrm{~F}}$ (Rental Housing): The percentage of renter-occupied housing units within a census tract will be both positively and significantly correlated with incidence of assault on law enforcement officers.

$\mathrm{H}_{3 \mathrm{G}}$ (Resident Mobility): The percentage of individuals who have moved into the census track since 2015 will be both positively and significantly correlated with incidence of assault on law enforcement officers. 


\section{Population Density}

$\mathrm{H}_{3 \mathrm{H}}$ (Population Density): The population density within a census tract will be both positively and significantly correlated with incidence of assault on law enforcement officers.

\section{Educational Attainment}

$\mathrm{H}_{3 \mathrm{I}}$ (Education Attainment): The percent of individuals aged 25 years and older without a Bachelor's degree or higher within a census tract will be both positively and significantly correlated with incidence of assault on law enforcement officers.

Overall, the results from the present study may assist law enforcement agencies in ensuring officer on-scene safety by developing policies, procedures, training, and best practices when responding to calls for service in specific locations where the risk for assault is higher (Caplan et al., 2014). The specific methods used for the present study are detailed in the following section. 


\section{CHAPTER III}

\section{METHODS}

\section{Study Location Contextual Background}

Prior to providing the detailed methods, background information on the selected metropolitan area is needed to provide the necessary context to understand the results. It is important to note the selected metropolitan area is a consolidated city-county area. As such, a single government structure is present in the consolidated county and one law enforcement agency serves the majority of the jurisdiction. However, there are some semi-autonomous/smaller class cities located in the county that are policed by smaller law enforcement agencies. For this study, data are derived from the law enforcement agency that patrols the majority of the county. Specific parameters of the selected metropolitan as compared to state and national averages are provided in Table 1. Further, the selected metropolitan areas is comprised of 191 census tracts (see Figure 2), which are defined by the U.S. Census Bureau (2018) as "small geographic areas—with an average of about 4,000 people each — that are commonly used to present information for small towns, rural areas, and neighborhoods" (p. 12).

For the present study, all 191 census tracts were used. The utilization of all 191 census tracts resulted in some drawbacks due to the presence of law enforcement agencies in semi-autonomous/smaller class cities within the county that serve their citizens for which assault on officer data is not available. This created concerns in which 
the totals for these census tracts could be overrepresented as the main law enforcement agency would typically be called for assistance on more serious/violent call as well as possibly underrepresented because assaults in those jurisdictions will not be included in the provided law enforcement agency data. To help determine possible impacts, all smaller class cities with law enforcement agencies were identified. The geographical boundaries of these cities were then determined via a review of detailed census tract reference maps produced by the U.S. Census Bureau (2010). Through this review, it was determined that four (4) individual census tracts did not include geography under the law enforcement services of the selected metropolitan law enforcement agency. The law enforcement agency for the selected metropolitan area also provides law enforcement support to other law enforcement agencies in smaller class cities. Therefore, assaults on law enforcement officers are recorded for these census tracts. Overall, these four census tracts totaled 72 assaults on law enforcement officers between 2010 and 2019. Since this total number of assaults represents less than one (1) percent of all assaults of law enforcement officers over the 10-year period and only two census tracts within the metropolitan areas recorded zero (0) assaults, it was determined these census tracts would remain in the present study. Ultimately, the 191 census tracts serve as the unit/level of analysis for the present study. Identification of the downtown urban core and oldest section of the selected metropolitan area is provided in Figure 3. Lastly, the complete western border of the selected metropolitan area is comprised of a natural river serving as a state boundary. The remaining borders of the selected metropolitan area abut five other counties within the state. 
As for the organization of analysis, the municipal law enforcement agency of the selected metropolitan area was established in the early 2000s with the merger of the former county and city law enforcement agencies. Although the yearly number of sworn officers varies, the current budget for the municipal law enforcement agency provides funding for 1,250 officers. Structurally, the law enforcement agency is organized into nine patrol divisions across the metropolitan area as well as eight operational divisions for Administrative Services, Community Services, Major Crimes, Narcotics, Special Investigations, Special Operations, and Training.

\section{Data}

Data analyzed in this study were derived from three sources. The first data source was information on assaults on law enforcement officers for the years 2010 through 2019 from the law enforcement agency providing services to the selected metropolitan area. The second data source was social and ecological characteristics of all census tracts within the metropolitan area from the U.S. Census Bureau 2018 American Community Survey. The third and final data source was various shapefiles for the metropolitan area to enable advanced spatial analyses. Each of these elements are further discussed in the subsequent sections.

\section{Dependent Variables}

The dependent variable in the present study was an officially reported assault on a law enforcement officer occurring between 2010 and 2019 in the metropolitan area. Official records from the associated law enforcement agency on incidents of assaults on law enforcement officers were obtained through official requests for said years. Structured data were obtained that provided the year, exact address (to include street 
number, street name, city, and zip code); and geographical location (XY coordinate location data based on the Kentucky State Plane Coordinate System) for each assault on a law enforcement officer for the years 2010 through 2019. These data points provided rich detail regarding assaults on law enforcement officers. Further, the exact geographical location of the assaultive incident enabled detailed spatial analyses.

\section{Independent and Predictor Variables}

The second data element utilized in the study was the community characteristics for all census tracts within the metropolitan area. The term "community" is loosely applied in this instance as one of the main issues facing communities and crime literature is the lack of an accepted definition of a community (or neighborhood) (Logan, 2018; Sperling, 2012). For example, one could define community simply as "a group of people organized around certain commonly held interests and attributes that help create a sense of shared identity" rather than defined by geographical boundaries (Brown \& Schafft, 2011, p. 35). The shared identity concept is an important life element, especially in urban areas, in terms of formal and informal resources, control, and personal identity (Brown \& Schafft, 2011; Logan, 2018; Sperling, 2012). Both shared identity and personal identity also affect the social cohesion and social bonds within communities and how communities emerge, change, and persist (Brown \& Schafft, 2011; Buslik, 2012; Logan, 2018). However, even this descriptive definition may not be of use in specific research endeavors. This is because the content and definition of a community can include both geographic/place-oriented and social/people-oriented components (Logan, 2018; Sperling, 2012). 
In the absence of a universally accepted definition, census tracts have become an accepted proxy for a community within community crime research (Logan, 2018; Sperling, 2012). Although census tracts are not actual communities per se, using these terms allow for a more general understanding of census data (Logan, 2018; Sperling, 2012). Although the metropolitan area of the present study consists of numerous official communities, data is more reliable and available for census tracts (Gibbs et al., 2018). Specifically, data was used from 2018 American Community Survey five-year estimates (2014-2018) publicly available through the U.S. Census Bureau Explore Census Data portal (https://data.census.gov/). The five-year estimates were used as opposed to oneyear estimates or the most recent decennial census due to the larger sample sizes (60 months of collected data), smaller margin of error (due to larger sample size), and increased reliability of multiyear estimates for small geographical areas and populations such as census tracts (U.S. Census Bureau, 2018). Further, five-year estimates are preferred when precision is more important than currency as was the case for the present study (U.S. Census Bureau, 2018).

Following previous research performed by Kaminski et al. (2003) and Gibbs et al. (2018), the present study utilized specific theoretical indicators, which are consistent with constructs of social disorganization. Further, in an effort to maintain community-level variation, data for the theoretical indicators were collected at the census-tract level rather than more commonly used larger levels of aggregation such as cities. The theoretical indicators were grouped by the community characteristics of social disorganization. Overall, the use of these data points enabled analysis that covers various dimensions of social disorganization. 
Economic Segregation. Three theoretical indicators comprised this structural characteristic as similarly used in previous assault on law enforcement officer research (Hughes et al., 2020; Kaminski et al., 2003; Willits, 2014). The first indicator was poverty. This indicator was measured by the percent of individuals within the population of a census tract earning below the poverty line ( 0 percent to 100 percent). The second indicator was family disruption, which was associated with female-headed households. This measurement was the percent of households within a census tract that were femaleheaded ( 0 percent to 100 percent). The percent of female-headed households is an important measure as it is a common variable within previous social disorganization research, including previous assault on law enforcement officers research (Barrick et al., 2014; Caplan et al., 2014; Gibbs et al., 2018; Kaminski et al., 2003; Uchida et al., 1987; Wilson \& Zhao, 2008). The third indicator was SNAP benefits, which has been utilized as a variable in previous policing research (Hughes et al., 2020). Specifically, this measure was the percentage of households within a census tract that have received SNAP benefits.

Racial Heterogeneity. One theoretical indicator was used to measure this community characteristic, which is a common measure in assault on law enforcement officers research (Barrick et al., 2014; Caplan et al., 2014; Johnson, 2011; Kaminski et al., 2003; Wilson \& Zhao, 2008). Specifically, racial heterogeneity was operationally measured using Blau's (1977) index, which is an often used dissimilarity measure (Biemann \& Kearney, 2010). Blau's (1977) index utilized the squared fractions of all groups within a specific population $\left(1-\Sigma p_{i}^{2}\right)$ to achieve an overall heterogeneity score. Similar to Warner et al. (2015), the present study used two (2) racial groups-White and 
African-American — due to the fact that over 93 percent of residents within the selected metropolitan area fell into these two racial categories based on estimates from the U.S. Census Bureau 2018 American Community Survey. When examining heterogeneity, Blau (1977) states that "heterogeneity is at a maximum for a given number of groups when the population is evenly divided among them, and it increases with the number of groups" (p. 78). Therefore, when using two racial groups, the dissimilarity measure for each census tract can range from 0.0 (complete homogeneity) to 0.50 (maximum heterogeneity).

Residential Instability. Three theoretical indicators comprised this community characteristic, which has been utilized in previous assault on law enforcement officer research (Caplan et al., 2014). The first indicator was rental housing. This indicator was a measurement of the percent of individuals within a census track living in rental properties ( 0 percent to 100 percent). This indicator was an important measure as rental properties can produce residential instability that can affect informal social control mechanisms. As for a more specific measure of residential instability, residential mobility was a measurement of the percentage of individuals within the population of a census track who have moved into the census tract since 2015 ( 0 percent to 100 percent). Another indicator of residential instability was vacant housing, which was the percent of residential housing units within a census tract that are vacant ( 0 percent to 100 percent).

Other Indicators. In addition to the common community characteristics of social disorganization previously discussed, two additional theoretical indicators of social disorganization were used. The first indicator was educational attainment, which was measured by the percent of individuals aged 25 years or older within the population of a 
census track without a bachelor's degree ( 0 percent to 100 percent $)$. This was an important measure as it is firmly established that individuals with college degrees tend to commit less crime and develop more social capital compared to those without a college degree. The second indicator was population density. This was a measure of the number of people per square mile within a census tract (total population of a census track divided by the square mileage of a census track). Although population density is not seen as strong predictor of social disorganization, assault on law enforcement officer research does reveal a positive correlation between population density and the level of assaultive events (Wilson \& Zhao, 2008).

\section{Spatial Data}

A full understanding of the independent and dependent variables needed the spatial data elements, which was the third and final piece of the data triangle. In addition to the assaults on law enforcement data and the census tract data, the present study utilized shapefiles to enable spatial analysis, which are described below.

Point Data: A discrete location usually depicted by a symbol or label. It is like a pin placed on a paper wall map. Different symbols are used to depict the location of crimes, motor vehicle crashes, traffic signs, buildings, police stations, cell towers, etc.

Line Data: A geographic feature that can be represented by a line or set of lines, such as railways, streets, rivers, powerlines, bus routes, etc.

Polygon Data: A multisided figure represented by a closed set of lines, such as city boundaries, census tracts or blocks, patrol beats, neighborhood boundaries, and gang turf. Polygon features may be as large as countries or as small as a 
single place (like a park or cemetery) or even a single building (such as a school). (Hill \& Paynich, 2014, p. 14)

Specifically, publicly-available shapefiles for census tracts (polygon data) and street centerlines (line data) were utilized for the present study. The shapefiles were obtained from an open access online data portal maintained by the metropolitan area of the present study. These shapefiles enabled the ability to spatially analyze and visualize structured data. This ability provided additional data analysis techniques beyond traditional statistical analysis. Lastly, the point data was created from the official assaults on law enforcement office data from the metropolitan law enforcement agency. Converting the structured assault on law enforcement officer data to spatial point data was possible due to the provided geographical coordinates of the location of each assault.

\section{Design}

The present study utilized a confirmatory analysis design (also termed basic research or theory testing) to assess both the spatial concentration of assaults on law enforcement officers and correlation with theoretical constructs of social disorganization. This design was used to test three specific hypotheses:

$\mathrm{H}_{1}$ : Assaults on law enforcement officers will be spatially concentrated in which half (50 percent) of all incidents occur within four percent of all street segments within the metropolitan area.

$\mathrm{H}_{2}$ : Assaults on law enforcement officers will be spatially concentrated in and around the downtown urban core with decreasing incidents away from the downtown urban core. 
$\mathrm{H}_{3}$ : The presence of social disorganization characteristics within census tracts will be both positively and significantly correlated with incidence of assaults on law enforcement officers.

As a whole, the research design and evaluated data provided a greater understanding of the spatial, ecological, and social patterns of assaults on law enforcement officers and whether these patterns are consistent with previous research.

\section{Data Analysis Plan}

In order to assess the spatial and temporal patterns of assaults on law enforcement officers in the selected metropolitan area, the present study utilized multiple analysis steps through various software platforms to include CrimeStat III, ESRI ArcMap 10.5.1, IBM SPSS Statistics 24, and Microsoft Excel 2016. The steps focused on spatial analysis and quantitative analysis, which are detailed within the subsequent sections.

\section{Spatial Analysis Steps}

The first step was spatially plotting the assault on law enforcement point data via ArcMap 10.5.1 with reference to a shapefile of all census tracts for the selected metropolitan area. Once spatially plotted, the second step spatially joined the assault on law enforcement officer point data and the 2018 American Community Survey data with the census tracts of the selected metropolitan area. Joining point data (assault incident) with polygon data (census tracks) enabled counting of points within each polygon. Further, the joining of census tract data enabled analysis with the community characteristic independent variables. Within the context of the present study, this step resulted in identifying the total number of assaults on law enforcement officers for each census track between the years of 2010 and 2019 and the aggregation of the 2018 
American Community Survey data. After joining the data, multiple maps were produced providing graphical representation of point data and thematic/choropleth maps to illustrate the various community characteristics. These maps enabled visual interpretation analyses (Harris, 1999). Despite the benefits of maps, there are some drawbacks. For example, visual analysis can result different interpretations by individuals and simple point data mapping does not account for overlapping or stacked points thereby masking the true number of incidents (Harris, 1999). As such, other spatial analysis techniques were utilized.

After the data were aggregated to enable analysis beyond visual interpretation analysis, the first advanced spatial analysis test was spatial autocorrelation to statistically determine if a pattern of assaults on law enforcement officers is present. This specific test was performed first to determine whether assaults on law enforcement officers were spatially clustered/concentrated. Specifically, spatial autocorrelation determined whether the spatial distribution of a measure (in the present study assaults on law enforcement officer) across space is nonrandom, or that a specific pattern is present in which a measures are similar in both value and location (Anselin et al., 2000; Bernasco \& Elffers, 2010). Therefore, spatial autocorrelation looked for groupings of similar values and is considered positive when nearby locations are more similar to adjacent locations than locations that are afar (Bernasco \& Elffers, 2010; Eck et al., 2005). Essentially, the spatial point data formed groupings and choropleth maps were able to be developed to graphically indicate spatial patterns (Bernasco \& Elffers, 2010). Overall, spatial autocorrelation tested whether the distributions of single assaults on law enforcement officers are related to other assaults (Eck et al., 2005). 
Moran's I was used to determine if spatial autocorrelation exists, which is one of the most commonly used spatial concentration tests (Bernasco \& Elffers, 2010; Eck et al., 2005; Carrijo \& Silva, 2017; Quick \& Law, 2013). This was due to the adaptability of Moran's I and its simple variance-covariance structure that is used in other common statistical tests (Bernasco \& Elffers, 2010; Carrijo \& Silva, 2017). In fact, Moran's I was the most appropriate spatial autocorrelation measure because the point data had been aggregated to specific polygons/geographical areas, or census tracts (Eck et al., 2005). Fundamentally, Moran's I compared the value of a single location/census tract with those in all other locations/census tracts based on an intensity level, which in the present study was the number of points (assaults on law enforcement officers) within a polygon (census tract) (Levine, 2013; Eck et al., 2005). Similar to correlation coefficient, results of Moran's I can range between -1.0 and +1.0 with a higher positive result indicating spatial clustering or spatial autocorrelation (Eck et al., 2005). In order words, spatial clustering occurred when specified geographical areas (census tracts) have similar characteristics (assaults on law enforcement officers) to neighboring locations and dissimilar characteristics to locations father away, or that high-crime areas/rates are clustered together (Anselin et al., 2000; Bannister et al., 2018; Levine, 2013). Overall, Moran’s I was exploratory spatial data analysis that attempted to identify spatial clusters—of high or low risk — statistically rather than through visual interpretation analysis (Quick \& Law, 2013).

Following spatial autocorrelation analysis, street centerline data (line data) for the selected metropolitan area was utilized to spatially join the assault on law enforcement officer point data with street centerlines. This spatial joining enabled the counting of the 
number of assaults on law enforcement officers for each street segment. This analysis was important in supporting the Moran's I results of spatial autocorrelation by providing another test of spatial concentration of assaults on law enforcement officers.

The final set of spatial analyses involved hot spots, which are generally understood as areas where crime is concentrated (Eck et al., 2005; Weisburd \& Green, 1994). This concentration could be individual crime types (e.g., assaults on law enforcement officers) or areas that experience large amounts of crime or disorder (Eck et al., 2005). Although no common definition of the term hot spot exists, for the present study the underlying understanding was that hot spots are considered "an area with a greater than average number of criminal or disorder events, or an area where people have a higher than average risk of victimization" (Eck et al., 2005, p. 2).

In order to perform hot spot analysis of assaults on law enforcement offices, three specific tests were performed. First, optimized hot spot analysis was performed to determine where assaults on law enforcement officers are concentrated if first determined to be spatially clustered via Moran's I. Therefore, optimized hot spot analysis determined spatial locations where incident rates of assaults on law enforcement officers were high both in a single location and its neighbors (Anselin et al., 2000; Harris, 1999). The second test was a fishnet grid (or grid cell analysis) using 2,500-foot grids overlaid onto the selected metropolitan area. A grid cell analysis enables the counting of assaults per grid cell to determine hot spots (Anselin et al., 2000; Harris 1999). The third test was kernel density estimation hotspot analysis, which is considered an extension of the optimized hot spot and fishnet grid analyses (Anselin et al., 2000). The kernel density analysis removed the restrictive fishnet grid and produced a map with smooth edges 
(rather than square edges) and spatially displayed many overlapping circles of variables size where clusters/concentrations/hot spots were present (Anselin et al., 2000). Kernel density estimation (or kernel smoothing) is a commonly used method for analysis to estimate how incident levels may vary continuously across a geographical area based associated point data (Anselin et al., 2000). The result was a heat map in which coloring was used to reflect both the point data pattern for the location and the immediate surrounding area (Anselin et al., 2000).

\section{Quantitative Analysis Steps}

Similar to spatial analysis, the quantitative analysis included several steps to examine the independent and predictor variables. The first step was to calculate a 10year mean of assaults on law enforcement officers for each census tract based on the provided data from 2010-2019. Once the 10-year mean was calculated, the resulting mean was used to determine the rate of assaults on law enforcement officers for each census tract for the 10-year period. A rate, whether a crime rate or a rate of assaults on law enforcement officers, describes the number of crimes per a specific size of total population, such as per 100,000 individuals. Therefore, the rate of assaults on law enforcement officers per census tract was calculated by dividing the 10-year mean of assaults on law enforcement officers by the census tract total population (based on the five-year 2018 American Community Survey data estimates) and multiplying the result by 1,000 . This provided a 10-year mean rate of assaults on law enforcement officers per 1,000 individuals within each census tract (herein referred to as assault rate). The mean assault rate was preferred to using the aggregate 10-year data total to help control for variances across multiple years and to better align with the 2018 American Community 
Survey data which was based on five-year estimates. Further, crime rates are considered one of the best methods to compare crime across locations and to provide an accurate reflection of crime (Vellani, 2020). This resulted in statistical analyses based on means that covered several years.

The second step was the production of descriptive statistics for all variables. For each of the variables, measures of central tendency and standard deviations were established. These measures indicated the distribution of each variable. The third step was the production of a correlation matrix through the use of the Pearson correlation coefficient. The correlation matrix included the dependent variable and the independent variables associated with social disorganization. This bivariate analysis was used to confirm the direction and strength of the correlation between each of the variables independently. This step enabled a preliminary determination of whether the theoretical aspects of social disorganization are associated with assaults on law enforcement officers.

The fourth step used the independent variables and regressed them on the assault rate per census tract using multiple linear regression. In more simplistic terms, multiple linear regression attempted to explain the amount of variation in the dependent variable through multiple independent variables. This statistical analysis determined whether variance in assaults on law enforcement officers per census tract is impacted by the independent variables associated with social disorganization. Further, multiple linear regression enabled the determination of which specific variables had the greatest impact on assaults of law enforcement officers. Within the present study, the objective was to explain variation within assaults on law enforcement officers in each census tract through multiple social disorganization indicators. Results of the multiple linear regression 
determined to be statistically significant were subjected to sensitivity analysis to ensure the results are stable during alternative testing of the effects.

The fifth step involved testing of additional models with composite scales for groupings of specific variables to further analyze results. Specifically, principal components analysis was performed on the independent variables related to economic segregation (poverty, family disruption, and SNAP benefits) and residential instability (vacant housing, rental housing, and residential mobility) to determine if composite scales could be developed. After principal components analysis, previous statistical analysis steps were repeated (descriptive statistics, correlation matrix, and multiple linear regression) to determine the statistical significance of the composite scales.

\section{Summary}

Overall, the methods outlined above enabled detailed analysis of the provided assault on officer data. Not only were statistical analyses performed, but also detailed spatial analyses. Further, the statistical and spatial analyses built on each other thereby providing multiple avenues to examination the data. Although additional testing could be completed (see Limitations section), the analyses performed were sufficient to determine if the stated hypotheses were supported. Detailed analysis results are provided in the next section followed by a detailed discussion of the results. 


\section{CHAPTER IV}

\section{RESULTS}

\section{Descriptive Statistics}

\section{Assaults on Law Enforcement Officers (Dependent Variable)}

A full summary of the descriptive statistics associated with the dependent variable can be found in Table 2. Overall, 9,150 assaults on law enforcement officers occurred between 2010 and 2019. The data displayed an annual mean $(\bar{x})$ of 915.0 assaults. Although the overall mean is important, a longitudinal examination of the assault data reveals significant variation in the number of assaults per year (see Figure 4). Specifically, the number of assaults on law enforcement officers ranged from a high of 1,122 (in 2012) to a low of 568 (in 2016), which is close to a 100 percent difference.

When examining assault data at the census tract level, there were an average of 48.0 incidents per census tract for the evaluation time-period. Approximately half (49.7 percent) of all census tracts recorded 26 or less incidents during the time frame. Similar to the yearly totals, the number of assaults per census tract revealed significant variance with a range from 0 incidents (within two census tracts) to 755 incidents (within one census tract). Therefore, a single census tract accounted for approximately 8.3 percent of all assaults on law enforcement officers during the evaluation time frame. Further, the five census tracts with the highest number of recorded assaults during the evaluation time frame accounted for 1,794 incidents, or 19.6 percent of all incidents. As for the assault 
rate per 1,000 residents, the 10 -year mean $(\bar{x})$ across all census tracts was 1.46 assaults per 1,000 individuals. Mirroring the aggregate data, the assault rate per census tract revealed significant variance with a range from a rate of zero (0) in two census tracts to a rate of 18.47 within one census tract. To better visualize the data and spatial variance, Figures 5 and 6 provide choropleth maps with thematic shading in relation to assaults rates and overall number of assaults per census tract.

Removal of Outlier Census Tract for Statistical Analyses. Upon review of the descriptive statistics, an outlier census tract was noted within the data (see Figure 7 for identification of census tract). This census tract recorded the most assaults on law enforcement officers during the study timeframe $(n=755)$, which was 136 percent higher than the census tract with the next highest number of assaults $(n=320)$. Therefore, the number and average of assaults on law enforcement officers per census tract had skewness (5.82 and 3.80 respectively) and kurtosis (50.27 and 23.65 respectively) scores outside of the acceptable skewness (+/- 3) and kurtosis (+/- 10) ranges for normal distributions. Further, when comparing the community characteristics of this census tract to overall metropolitan averages, the census tracts exhibits much higher percentages for noted community characteristics as compared to the overall metropolitan area (see Table 3). For example, percentages for vacant housing, poverty, rental housing, and SNAP benefits are twice as high compared the metropolitan average. The racial heterogeneity index of the census track is also approximately twice the metropolitan average. However, there are individual census tracts that have higher percentage levels of community characteristics than the outlier census tract. Therefore, the outlier census tract 
is not unique by itself, but rather one of multiple census tracts that exhibit high levels of social disorganization community characteristics.

Upon further review of the census tract, it was determined that community characteristics may not accurately reflect overall assaults on law enforcement officers. This is due to several aspects of the census tract. First, the census tract is the main entertainment district of the metropolitan areas that is heavily visited for daily entertainment as well as for special events. As such, the census tract includes numerous bars and restaurants, adult-themed businesses, and facilities for sporting events, concerts, plays, conferences, and other events. Therefore, the census tract is heavily frequented by individuals who do not live within the census tract who may engage in an assault on law enforcement officer. Second, the adult and juvenile correctional facilities for the selected metropolitan area are located within the census tract. Therefore, transporting of arrested individuals to correctional facilities provides additional opportunities for assaults on law enforcement officers. As such, the high number of assaults on law enforcement officers may be significantly influenced by the aspects of the built environment of the census tract in addition to the community characteristics.

Due to the identification of the outlier census tract, descriptive statistics were computed with the removal of the census tract. Upon the omission of the census tract, the number and average of assaults on law enforcement officers per census tract had acceptable skewness (2.33 and 1.72 respectively) and kurtosis (7.60 and 2.74 respectively) scores as detailed in Table 2 . These results supported the decision to remove the outlier census tract in all statistical analyses, but include it in all spatial analyses, which is a common method used in research (Osborne \& Overbay, 2008; Van 
Selst \& Jolicoeur, 1994). Removal of the outlier census tract was important for the statistical analyses as regression analysis employs the assumption that the data is normally distributed. Therefore, removal of the outlier census tract ensured the regression analyses adhered to the normal distribution assumption.

\section{Social Disorganization Statistics (Independent Variables)}

A full summary of the descriptive statistics associated with each independent variable can be found in Table 2. Although the range of the variables is large, this is not unexpected due to the number of census tracts (191) and the size and diversity of the selected metropolitan area. Despite the variation, the skewness and kurtosis of the variables were in acceptable ranges (between $+/-3$ and +/- 10 respectively) and should not influence the overall results of the present study. Significant variable ranges of note included vacant housing ( 0.0 percent to 38.0 percent), education attainment (20.6 percent to 98.4 percent), poverty ( 0.9 percent to 81.0 percent), rental housing (1.7 percent to 100.0 percent), SNAP benefits ( 0.0 percent to 71.1 percent), and population density (per square mile) (184.8 to $24,525.6)$.

\section{Spatial Analysis}

Spatial mapping of all assaults on law enforcement officers between 2010 and 2019 is provided in Figure 8, which utilized all reported. The spatial mapping revealed a noticeable geographic concentration within and near the downtown urban core with decreasing occurrences further away from the downtown urban core. Although not as noticeable, there is also a geographic concentration in the area immediately south of the downtown urban core. In addition to assaults on law enforcement officers, Figures 9 through 17 provide choropleth maps for each independent variable with thematic shading 
indicating the overall measure of the variable within each census tract. These figures also illustrate geographic concentration of social disorganization indicators, such as poverty, family disruption, SNAP benefits, vacant housing, rental housing, and education attainment. The significance of the visually present concentration of assaults on law enforcement officers cannot be determined until after the completion of additional spatial analyses, which are discussed in the following sections.

\section{Spatial Autocorrelation}

The first spatial analysis test performed was Moran's I, which is one of the most commonly performed spatial autocorrelation tests (Hill \& Paynich, 2014; Levine, 2013). Spatial autocorrelation is based on the assumption that criminal incidents (such as assaults on law enforcement officers) occurring in different, but proximal, locations are related more to each other than incidents that occur father away (Hill \& Paynich, 2014). To determine spatial autocorrelation, Moran's I compared the crime rate in one defined area (census tract) to crime rates in all other defined areas (Hill \& Paynich, 2014). Therefore, Moran's I determined whether assaults on law enforcement officers were clustered/concentrated. For this test, all assaults on law enforcement officers between 2010 and 2019 were spatially joined to census tracks allowing Moran's I to be based on aggregate data over 10 years, which provided a much more reliable reflection of assaults as compared to single year statistics (Spelman, 1995; Vellani, 2020). The results of Moran's I suggested that the pattern of assaults on law enforcement officers was clustered or concentrated (Moran's $\mathrm{I}=.395, \mathrm{p}=.00, \mathrm{z}$-score $=20.93$ ). This result illustrated that there was less than a one percent likelihood that the concentrated pattern of assaults on law enforcement officers was random chance. 


\section{Street Segment Spatial Concentration}

In addition to spatial autocorrelation testing, additional spatial testing utilized street centerline data for the selected metropolitan areas to identify the number of assaults on law enforcement officer per each street segment. This procedure was a direct test of the first hypothesis of the present study, which posits half (50 percent) of all assaults on law enforcement officers will occur within four percent of all street segments $\left(\mathrm{H}_{1}\right)$. Therefore, it was hypothesized that assaults on law enforcement officers will be spatially concentrated consistent with the law of crime concentration. To be consistent, 50 percent of assaults on law enforcement officers would need to be concentrated within four percent or less of all street segments within the selected metropolitan area as well as 25 percent of incidents concentrated in less than 1.5 percent of all street segments.

Within the selected metropolitan area, there were 34,261 street segments. Street segments can be simply defined as an individual street and its two sides segmented between two intersections, which provides address ranges to enable geocoding integrity (Kim, 2018; Weisburd et al., 2004). Using ArcMap 10.5.1 and a street centerlines shapefile for the selected metropolitan area, all assaults on law enforcement officers were joined to the relative street segment based on spatial location. The spatially joined data revealed all assaults on law enforcement officers occurred within 3,060 street segments, or 8.9 percent of all street segments. The bullets below provide the percentage of street segments where the relative proportion of assaults take place (see Figure 18 for graphical representation).

- 90 percent of all assaults $(\mathrm{n}=8,235)$ occurred in 6.0 percent of street segments $(n=2,061)$ 
- 75 percent of all assaults $(\mathrm{n}=6,863)$ occurred in 3.2 percent of street segments $(\mathrm{n}=1,113)$

- 50 percent of all assaults $(n=4,575)$ occurred in 1.1 percent of street segment $(\mathrm{n}=389)$

- 25 percent of all assaults $(\mathrm{n}=2,287)$ occurred in 0.3 percent of street segments $(\mathrm{n}=120)$

Overall, the results were consistent with the law of crime concentration (50 percent of crime occurs within four percent or less of street segments).

As for range, the highest number of assaults on law enforcement officer for a single street segment was 47 . This is in comparison to 31,201 street segments that experienced no assaults on a law enforcement officer and 1,395 street segments that experienced a single assault on a law enforcement officer, which represented 95.1 percent $(n=32,596)$ of all street segments. Therefore, the range of assaults on law enforcement officers per street segment was significantly skewed towards lower numbers of occurrences.

\section{Hot Spot Analysis}

In addition to statistical measures of concentration, additional spatial analyses were performed to identify specific areas of concentration. The first hot spot analysis utilized optimized hot spot analysis to identify hot and cold spots for assaults on law enforcement officers based on census tracts. Subsequent tests used fishnet grid hot spot analysis and kernel density hot spot analysis to provide a more detailed level of analysis of hot spots. The results of these tests are discussed in the following sections. 
Optimized Hot Spot Analysis. In order to identify hot spots for assaults on law officers, optimized hot spot analysis was conducted to identify statistically significant spatial clusters of high values (hot spots) and low values (cold spots). When assaults on law enforcement officers were aggregated to census tracts, visual interpretation analysis revealed that hot spots were located within and immediately surrounding the downtown urban core area with cold spots to the east in suburban areas (see Figure 19). This illustrated geographic concentration of assaults on law enforcement officers within and immediately surrounding the central business district or the downtown urban core. Further, the identified hot spots overlapped the concentrations of the community characteristics or social disorganization.

Fishnet Hot Spot Analysis. To analyze spatial locations at smaller units of analysis than census tracts, a fishnet hot spot analysis was performed using a grid of 2,500 square foot cells. This resulted in 2,013 grid cells within the selected metropolitan area. The total number of assaults occurring within each grid cell was aggregated and displayed using a color ramp (see Figure 20). Data analysis revealed all assaults on officers occurred in 33.5 percent $(n=674)$ of grid cells. Further, approximately half of all assaults on law enforcement officers ( $\mathrm{n}=4,565 ; 49.9$ percent) occurred in 2.8 percent $(\mathrm{n}=56)$ of grids with three-quarters $(\mathrm{n}=6,857 ; 74.9$ percent $)$ occurring in 7.4 percent $(n=148)$ of grids. Visual interpretation analysis of the thematic shading of the fishnet hot spot analysis results in Figure 20 revealed that the largest concentration of assaults on law enforcement officers was concentrated in the areas in and immediately surrounding the central business district or the downtown urban core. This spatial analysis further 
supported the results that assaults on law enforcement officers are spatially concentrated and was consistent with the results of the optimized hot spot analysis results.

Kernel Density Hot Spot Analysis. In addition to the grid cell analysis, kernel density hot spot analysis was performed using a combination of ArcMap 10.5.1 and CrimeStat III. This analysis calculated the density of assault incidents through statistical analysis in order to define areas of high versus low occurrence. The visual result was a heat map with areas with red shading indicating the most likely areas for assaults. When this analysis was applied to the assault on law enforcement officer data, the results mimicked the optimized hot spot analysis and the fishnet analysis results in terms of spatial concentration (see Figure 21). The analysis illustrated concentration of assaults on law enforcement officers in the downtown urban core and immediately surrounding areas much like the community characteristics of social disorganization.

\section{Bivariate Analysis}

As indicated in Table 4, seven of the nine independent variables within the present study emerged as being significantly correlated with assaults on law enforcement officers within census tracts at the $\mathrm{p}<0.01$ level. Although the correlation strength for the variables can be traditionally considered weak for some (e.g., 0.3) and strong for other, (e.g., 0.7) (Salkind, 2000), the fact that all correlations were above 0.3 indicated each of the variables had a more contemporarily viewed strong effect (Gignac \& Szodorai, 2016; Hemphill, 2003). Further, the direction of the correlations was consistent with the expected relationship within the sub-hypotheses in which higher levels of a community characteristic was associated with higher levels of assaults on officers. Overall, the strongest correlation with assaults on law enforcement officers was percent 
of vacant housing units within a census tract $(r=0.76)$ followed by percent of individuals receiving SNAP benefits $(r=.73)$ and percent of individuals with income below the poverty line $(\mathrm{r}=.73)$. The weakest, but significant, correlation with assaults on law enforcement officers was residential mobility $(r=0.31)$. The independent variables not significantly correlated with assaults on law enforcement officers were racial heterogeneity and population density. In order to further evaluate the significantly correlated variables, multivariate testing via regression was required to better understand the factors that condition the relationship between social disorganization and assaults on law enforcement officers.

\section{Multivariate Analysis}

Following bivariate testing, multivariate testing was completed using the seven independent variables that illustrated significant correlation with assaults on law enforcement officers. The specific multivariate test used was multiple linear regression. Overall, the regression model (see Table 5) illustrated good fit $(\mathrm{F}=39.5, \mathrm{p}<0.01)$.

Further, the combination of independent variables explained 68 percent $\left(R^{2}=0.68\right)$ of the variation in assaults on law enforcement officers per census tract. This result was considered significant due to an $\mathrm{R}^{2}$ value above 0.30 and is based on comprehensive data covering several years. Therefore, the independent variables within the model were positively and significantly associated with assaults on law enforcement officers and can be considered significant predictors. More specifically, as the rate/percentage of vacant housing, SNAP benefit receivership, and family disruption increases in a census tract, so does the rate of assaults on law enforcement officers. 
Conversely, four of the seven independent variables included in the model were not significantly correlated with assaults on law enforcement officers. Similar to bivariate testing, common indicators of social disorganization were not significant. Specifically, poverty, rental housing, education attainment, and residential mobility were not significantly associated with assaults on law enforcement officers (see Table 5).

\section{Additional Model Testing}

Based on the results of the full model of dependent and independent variables, an additional model was tested to distill the most influential independent variables. To begin, poverty, rental housing, education attainment, and residential mobility were removed due to insignificant results in the multiple regression analysis of the fully tested model. The resulting model (see Table 6$)$ still illustrated good fit $(\mathrm{F}=111.1, \mathrm{p}<0.01)$ and the combination of independent variables explaining 67 percent $\left(R^{2}=0.67\right)$ of the variation in assaults on law enforcement officers per census tract. Further, all independent variables in the model remained significant thereby further illustrating their correlation to assaults on law enforcement officers.

\section{Composite Scale Model Testing}

In addition to the full model testing with all individual variables, additional testing of models with composite scales was completed. Specifically, two composite scales were created based on general aspects of social disorganization and with multiple independent/predictor variables related to economic segregation (poverty, SNAP benefits, and family disruption) and residential instability (vacant housing, rental housing, and resident mobility). To develop the composite scale, a principal components analysis was used to determine if the possible scale was sufficient. For both of the proposed 
composite scales, the results of the principal components analysis indicated a one-factor solution with sufficient factor scores above 0.5 and an eigenvalue above 1.0 as indicated in Table 7. After the principal components analysis indicated sufficient scales, the percentages of each individual variable in the scale were summed to produce the operational measure for the two composite scales. These composite scales were then subjected to the same bivariate and multivariate testing as the full model with all individual independent/predictor variables.

Bivariate Composite Scale Testing. As indicated in Table 8, both composite scales were significantly correlated with assaults on law enforcement officers within census tracts at the $\mathrm{p}<0.01$ level. In fact, both composite scales illustrated strong correlations with economic segregation $(r=0.72)$ resulting in a slightly higher correlation than residential instability $(r=.70)$. Further, the direction of the correlations was consistent with the expected theoretical relationship in which higher levels of a community characteristic was associated with higher levels of assaults on officers.

Multivariate Composite Scale Testing. Following bivariate testing, multivariate testing was completed using the two composite scales. The specific multivariate test used was again multiple linear regression. Overall, the regression model (see Table 9) illustrated good fit $(F=114.0, p<0.01)$. Further, the combination of two composite scales explained 59 percent $\left(\mathrm{R}^{2}=0.59\right)$ of the variation in assaults on law enforcement officers per census tract. This result was considered significant due to an $\mathrm{R}^{2}$ value above 0.30 and is based on comprehensive data covering several years. Additionally, multicollinearity was determined to not be an issue after review of tolerance statistics as both variables are above 0.20 (Weisburd \& Britt, 2013). Therefore, the independent 
variables within the model can be considered significant predictors of assault on law enforcement officers. Additionally, a review of the standardized coefficients revealed that the economic segregation was the most influential predictor within the model compared to residential instability.

\section{Results Summary}

\section{Spatial Analysis Summary}

Overall, the spatial analysis resulted into two major findings. First, the street segment analysis revealed support for two of the main hypotheses of the study. First, the street segment analysis found that 90 percent of all assaults $(n=8,235)$ occurred in 6.0 percent of street segments $(n=2,061)$. This is well above the threshold of the law of crime concentration which posits that 50 percent of crime is geographically concentrated in four percent of city. Continuing with concentration, additional mapping of both dependent and independent variables illustrated concentrations of both assaults on law enforcement officers and higher levels of social disorganization community characteristics within and near the downtown urban core. These results were consistent with theoretical foundations of social disorganization and similar research. Additional statistics testing was required to determine if the noted concentrations were significant and which community characteristics were the most influential, which is discussed in the next section.

\section{Statistical Analysis Summary}

Overall, the statistical analysis produced multiple notable findings. First, the community characteristics associated with social disorganization were indeed significantly positively correlated with assaults on law enforcement officers and were 
consistent with theoretical assumptions and previous research. Second, the community characteristics explained a significant amount of variance in assaults of law enforcement officers throughout census tracts $\left(\mathrm{R}^{2}=0.68\right)$. Despite this finding, bivariate and multivariate testing revealed that common community characteristics within social disorganization research — as well as some used in more general crime research-were not significant. Specifically, the community characteristics of education attainment, population density, poverty, racial heterogeneity, rental housing, and residential mobility were not significant. This left vacant housing, SNAP benefits, and family disruption as the three community characteristics that held significance throughout the statistical testing. In fact, these three community characteristics by themselves explained a significant amount of variance in assaults of law enforcement officers throughout census tracts $\left(\mathrm{R}^{2}=0.67\right)$, which was only one percent less than all community characteristic together. Third, the statistical analysis further revealed that the community characteristics can be effectively used to develop composite scales for groups of community characteristics such as economic segregation and residential instability. Further, the use of these scales can explain a significant amount of variance in assaults of law enforcement officers throughout census tracts $\left(\mathrm{R}^{2}=0.59\right)$. Lastly, the statistical testing revealed that SNAP benefits receivership within a community was the most significant predictor of assaults on law enforcement officers and not more traditional community characteristics such as poverty. 


\section{CHAPTER V DISCUSSION}

The current literature on assaults on law enforcement officers points to a lack of analysis in three general areas: analysis below the city level, analysis beyond descriptive and explanatory, and spatial data analysis (Bierie, 2017; Caplan et al., 2014; Chamlin \& Cochran, 1994; Gibbs et al., 2018; Kaminski et al., 2000; Kaminski et al., 2003). To better understand assaults on law enforcement officers and to inform future research, the present study utilized comprehensive data from the years 2010-2019 to analyze occurrences of assaults on law enforcement officers via census tracts and social disorganization indicators. The objectives of the present study tested three main hypotheses:

$\mathrm{H}_{1}$ : Assaults on law enforcement officers will be spatially concentrated in which half (50 percent) of all incidents occur within four percent of all street segments within the metropolitan area.

$\mathrm{H}_{2}$ : Assaults on law enforcement officers will be spatially concentrated in and around the downtown urban core with decreasing incidents away from the downtown urban core.

$\mathrm{H}_{3}$ : The presence of social disorganization characteristics within census tracts will be both positively and significantly correlated with incidence of assaults on law enforcement officers. 
Using census track data from the 2018 American Community Survey five-year estimates (2014-2018) and relative shapefiles for a major metropolitan area within a southeastern state, the present study was able to test the hypotheses at the census track level. This was an important area of study as the current literature indicates a lack of structured and spatial research on assaults on law enforcement officers to this level (Bierie, 2017; Caplan et al., 2014; Chamlin \& Cochran, 1994; Gibbs et al., 2018; Kaminski et al., 2000; Kaminski et al., 2003). Overall, the present study revealed support for all three hypotheses as discussed in the following sections.

\section{Number of Assaults on Law Enforcement Officers Per Year}

Before discussing hypothesis support, a notable aspect of the data was the significant variation in the number of assaults in each year of the study period, which ranged from 1,122 (in 2012) to 568 (in 2016). In fact, the lowest number of assaults on law enforcement officers occurred after two exogenous shocks to law enforcement. The first shock was the so-called Ferguson effect after the officer involved shooting in Ferguson, Missouri in 2014. Second, the law enforcement agency in the selected metropolitan area implemented body-worn cameras in 2015. These two shocks coincided with the drop in recorded assaults on law enforcement officers in the selected metropolitan area. In fact, previously conducted research post-implementation of bodyworn cameras within the law enforcement agency revealed decreases not only in assaults on officers, but also officer-initiated activity, use of force incidents, and complaints against officers (Schaefer et al., 2016). Possible impact on the data could not be specifically determined, but recent research provides come context. For example, research has indicated the Ferguson effect was not correlated with increases in assaults 
(injurious or non-injurious) on or killings of law enforcement officers (Maguie, et al., 2017; Shjarback \& Maguire, 2019). However, evidence of de-policing has been revealed in research, especially in cities in the months that followed a highly visible officer involved shooting (Maguie, et al., 2017). As for body-worn cameras, this is a relatively new area of research similar to the Ferguson effect. Overall, the current research findings have been mixed in which some studies revealed decreases in assaults on law enforcement officers post-body-worn camera implementation while others revealed increases in assaults as well as no effect on assault rates (Ariel et al., 2016; Ariel et al., 2018).

\section{Spatial Concentration}

As for spatial concentration, assaults on law enforcement officers within the selected metropolitan area were spatially concentrated per the law of crime concentration as well as per social disorganization. After spatially joining all assaults on law enforcement officers to individual street segments, the results revealed that more than 50 percent of all assaults on law enforcement officers occurred in less than four percent of street segments. In fact, over 75 percent of all assaults on law enforcement officers occurred in less than four percent of street segments. This result directly supported the hypothesis that $\left(\mathrm{H}_{1}\right)$ assaults on law enforcement officers will be spatially concentrated in which half (50 percent) of all incidents occur within four percent of all street segments within the metropolitan area.

In addition to street segments, analysis via Moran's I revealed with statistical significance assaults on law enforcement officers are spatial concentrated/clustered throughout the selected metropolitan area. Additional optimized hot spot analysis, 
fishnet grid analysis, and kernel density hot spot analysis visually identified where assaults on law enforcement offices predominately occur and the results are visually correlated with each other. Lastly, visual interpretation analysis of the point data for census tract rates of assaults on law enforcement officers revealed spatial concentrations.

When spatially displayed, there were noticeable concentrations of assaults on law enforcement officers in areas within and immediately surrounding the downtown urban core. Further joining of assault on law enforcement officer data to census tracts also illustrated higher incident occurrence within census tracts near and around the downtown urban core. Therefore, mapping of assaults on law enforcement officers revealed a noticeable geographic concentration within and near the downtown urban core with decreasing occurrences further away from the downtown urban core. Using social disorganization as the theoretical basis, this result was consistent with theoretical constructs that posit more crime occurs in areas surrounding the central business district with decreasing rates farther away (Shaw \& McKay, 1942). Overall, these results supported the hypotheses that $\left(\mathrm{H}_{2}\right)$ assaults on law enforcement officers will be spatially concentrated in and around the downtown urban core with decreasing incidents away from the central business district. Further, the results supported research conclusions drawn close to 80 years ago using data for a different type of crime by Shaw and McKay (1942).

In addition to spatial concentrations of assaults on law enforcement officers, additional concentrations of social disorganization indicators were revealed. After spatially projecting the 2018 American Community Survey five-year estimate data for each census tract, the following spatial concentrations were revealed. 
- Poverty: Individuals earning below the poverty line were spatially concentrated in and around the downtown urban core with decreasing percentages father away from the downtown urban core.

- Family Disruption: These households were spatially concentrated in and south of the downtown urban core with decreasing percentages away from the downtown urban core to the east.

- SNAP Benefits: Percentage of families receiving SNAP benefits was spatially concentrated in and south of the downtown urban core.

- Vacant Housing: Percentage of vacant housing units was spatially concentrated in and around the downtown urban core with decreasing percentages father away from the downtown urban core.

- Rental Housing: Percentage of renter-occupied housing was spatially concentrated in and around the downtown urban core as well as some concentration east of the downtown urban core.

- Education Attainment: Individuals aged 25 and older without a college degree were spatially concentrated in and south of the downtown urban core with decreasing percentages away from the downtown urban core to the east.

Due to the concentrations of high levels of the social disorganization community characteristics noted above overlapping the spatial concentrations of assaults on law enforcement officer, the hypothesis that $\left(\mathrm{H}_{3}\right)$ the presence of social disorganization characteristics within census tracts will be both positively and significantly correlated with incidence of assault on law enforcement officers is partially supported. Partial support was determined due to certain community characteristics illustrating no visual 
spatial concentration (racial heterogeneity, resident mobility, and population density) and others determined to be statistically not significant (racial heterogeneity, population density, poverty, rental housing, education attainment, and resident mobility), which is discussed next.

\section{Theoretical Support}

One of the main hypotheses within the present study was the presence of social disorganization characteristics within census tracts will be both positively and significantly correlated with incidence of assault on law enforcement officers $\left(\mathrm{H}_{3}\right)$. Particularly, higher occurrences of assaults on law enforcement officers could be predicted through indicators of social disorganization within census tracts. Overall, both bivariate and multivariate testing revealed partial support for the hypothesis. Although many indicators of social disorganization were significantly significant and in the theoretically expected direction, a few community characteristics associated with social disorganization did not reach significance.

To begin, seven of the nine independent variables (vacant housing, SNAP benefits, poverty, rental housing, family disruption, education attainment, and resident mobility) were significantly and positively correlated to assaults on law enforcement officers and supported the notion that the assaultive events tend to occur within census tracts with higher levels of social disorganization indicators. In fact, the resulting regression model using these seven independent variables was able to account for 68 percent $\left(R^{2}=0.68\right)$ of the variation in assaults on law enforcement officers per census tract. This was despite the model not including the independent variables of racial heterogeneity and population density, which were not significantly correlated to assaults 
on law enforcement officers in bivariate analysis. Further, the regression model revealed that poverty, rental housing, education attainment, and residential mobility were not significant predictors of assaults on law enforcement officers. These results were surprising due to many of the independent variables being foundational elements of community crime literature (e.g., poverty, residential mobility), general crime literature (e.g., education attainment), and contemporary crime literature (e.g., population density).

Due to the noted insignificancies, additional regression models were performed without these independent variables. The subsequent regression model included three independent variables and revealed that higher levels of social disorganization in terms of percent of vacant housing, SNAP benefit receivership, and family disruption were the strongest predictors of assaults on law enforcement officers and can explain assault concentration in those areas with high levels. In fact, these three independent variables explained 67 percent $\left(\mathrm{R}^{2}=0.67\right)$ of the variation in assaults on law enforcement officers. Although containing fewer variables, this model explained a similar amount of variation compared to the model with seven variables $\left(\mathrm{R}^{2}=0.68\right)$. This illustrates that the percent of vacant housing units, SNAP benefit receivership, and family disruption are highly influential community characteristics related to assaults on law enforcement officers. Further, review of the standardized coefficients revealed that SNAP benefits was the most influential community characteristic followed by vacant housing and family disruption. The fact that SNAP benefits was determined to be the most influential community characteristic was a very interesting finding, especially in light of more prominent community characteristics - poverty, racial heterogeneity, education attainment - not receiving statistical significance. 
The influence of the significant variables noted above continued when multiple variables were combined to create composite scales of economic segregation (poverty, family disruption, and SNAP benefits) and residential instability (vacant housing, rental housing, and residential mobility). The results of the testing revealed that a model with both composite scales was significant and can explain 59 percent $\left(\mathrm{R}^{2}=0.59\right)$ of the variation in assaults on law enforcement officers per census tract. Further, the tested model illustrated the economic segregation composite scale had the larger influence compared to the residential instability composite scale. Therefore, the results of the statistical analysis revealed that economic segregation variables tend to have the most influence on assaults on law enforcement officers.

\section{Findings Summary}

The findings of the present study were consistent with previous research, the law of crime concentration, and theoretical constructs of social disorganization theory. Specifically, assaults on law enforcement officers were concentrated in areas within, near, and in the immediate vicinity of the central business direct, or the downtown urban core. This spatial concentration was very apparent in the point data, census tract choropleth maps, and hot spot analysis maps depicting where assaults on law enforcement officers occur. Consistent with various views of social disorganization, assaults on law enforcement officers were spatially concentrated within those areas (downtown urban core) that typically have characteristics of social disorganization, particularly in those census tracts exhibiting high levels of vacant housing, SNAP benefits, and family disruption. Therefore, the present study revealed full support for two hypotheses $\left(\mathrm{H}_{1}\right.$ and $\left.\mathrm{H}_{2}\right)$ and partial support for another hypothesis $\left(\mathrm{H}_{3}\right)$. Tables 10 and 11 
provide a detailed breakdown of the support for each main hypothesis and subhypotheses. In sum, it can be stated that a majority of assaults on law enforcement officers was generated by small, concentrated pockets of city geography that exhibited high levels of social disorganization indicators.

Lastly, the percent of SNAP benefit receivership emerged as the strongest predictor variable of assaults on law enforcement officers. This finding was significant as it identified a very specific type of community characteristic associated with assaults on law enforcement officers. This is in addition to the influence of family disruption. In addition to these economic segregation variables, the percent of vacant housing units was revealed to be a strong predictor of assaults on law enforcement officers, which identifies a specific type of place. Therefore, a general conclusion can be drawn that census tracts with high percentages of SNAP benefit receivership, family disruption, and vacant housing tend to produce more assaults on law enforcement officers compared to census tracts with lower percentages of these community characteristics. Although poverty was significantly correlated to assaults on law enforcement officers, its significant was not replicated in the multivariate analysis. Despite this result, poverty is very important in community crime research and an insignificant result in a regression test should not diminish its influence. Specifically, high levels of SNAP benefits receivership and vacant housing units can be easily traced to poverty present within the community. Overall, the present study provided additional insight into the spatial concentration and theoretical understanding of assaults on law enforcement officers within a major metropolitan area within the southeast. The findings of the present study were consistent 
with previous research, the law of crime concentration, and theoretical constructs of social disorganization and provided support to all three hypotheses of the study.

\section{Policy Implications}

The findings from the present study have applications not only in the academic research realm, but also practical applications in the field. The most basic application from the research is identification of hot spots of assaults on law enforcement officers. Although law enforcement officers within the selected metropolitan area most likely have an informal knowledge of hot spots, the present study can help to confirm or contradict officers' informal knowledge. This is especially true if an officer's informal perception is incorrect and has improperly identified a specific area as low-risk when in fact it is a high-risk of an assaultive event. Further, commanding officers can utilize the findings in the same way to evaluate resource allocations to determine if changes are warranted based on areas that are identified as high-risk for an assaultive event. For example, commanding officers could change patrol assignments (e.g., from single-officer patrol vehicles to two-officer patrol vehicles), increasing the frequency of patrols in high-risk areas, and mandatory backup officers for all calls for service in high-risk areas among

others. The overall objective is to increase on-scene officer safety. Awareness of highrisk areas for assaultive events is especially true for specific built environment aspects that are highly-correlated with assaultive events, such as vacant housing units.

In addition to law enforcement agencies, the results of the present study also provide opportunities for public officials to implement programs and policies to help address the community characteristics that lead to assaults on law enforcement officers. Unfortunately, addressing community characteristics, some of which may be deeply 
entrenched akin to concentrated disadvantage, is more difficult to address and to implement effective policies because they are wicked problems (Hauss, 2014; Peters, 2017). Therefore, an effective policy effort cannot simply address one community characteristic because of the inherent interconnectedness of many community characteristics. For example, SNAP benefit receivership was determined to be the most influential community characteristic associated with assaults on law enforcement officers while poverty was determined to be insignificant in regression analysis. However, both poverty and SNAP benefit receivership are positively connected. Ultimately, policies directed at the community characteristics have to deal with wicked problems that have no easy answers and have second and third order causes and effects. The benefit of research is that it can help to inform and evaluate possible policy options.

Overall, the use of findings of the present study by law enforcement agencies or public officials is a form of public criminology (Braga \& Davis, 2014; Loader \& Sparks, 2010; Uggen and Inderbitzin, 2010). This refers to researchers completing research that can be provided to three important groups: (1) those who create crime policy (public officials), (2) those who oversee and implement crime and justice policies (law enforcement and other public agencies); and (3) those in the general public who are affected by implemented crime policies (Braga \& Davis, 2014). One of the most important benefits of public criminology is the ability for diverse teams to develop and implement research projects that help gain an understanding of local crime, develop specific interventions, and evaluate impacts (Brydon-Miller et al., 2003; Klofas et al., 2010). Although in many ways action research (Brydon-Miller et al., 2003), the intersection between research and practice can also be called translational criminology in 
which researchers and practitioners work together to leverage scientific research to gain knowledge to develop effective programs and policies in relation to specific community issues or policy dilemmas (Braga \& Davis, 2014, Laub, 2012). In sum, it is hopeful the law enforcement agency and public officials of the selected metropolitan area can use the findings of the study to enact necessary changes to increase on-scene officer safety (short-term goal) and to address community characteristics that lead to areas being highrisk for assaultive events (long-term goal). These can range from situational awareness training for officers related to areas with increased assaultive incidents to community initiatives to increase police/citizen relationships and public policies to address community characteristics.

\section{Limitations}

Although the present study provided insight into assaults on law enforcement officers, it was not without specific limitations. First, the census data used within the present study was based on five-year estimates. Although the data have less margin of error based on longitudinal data collection, the data were estimates based on samples. Therefore, it is unknown whether using the full decennial census information from 2010 could have impacted the results of the present study, but provided opportunities for future research. Further, using the five-year estimates did not account for any changes in the census tracts prior to collection of the five-year estimate data.

Additionally, the five-year estimate data was examined using census tracts as the unit of analysis. Although the use of census tracts in social science research was methodologically acceptable, the use of census tracts can impact data and subsequent results. More granular analysis could be achieved by using census block groups as the 
unit of analysis. Census block groups are divisions within census tracts and their use would significantly increase the number of cases within the present study, which numbered 191 census tracts. Use of block groups could also possibly eliminate the issue of outlier census tracts. Further, some census tracts within the selected metropolitan area were significantly larger in square miles as compared to others. Also, some census tracts were possibly underrepresented due to semi-autonomous/smaller class cities within the selected metropolitan areas having independent law enforcement agencies. Therefore, it is unknown if assaults on law enforcement officer data from the smaller class cities would have impacted the study results. Thus, the large geographical areas and missing data from other law enforcement agencies in semi-autonomous/smaller class cities could have masked potential pockets of difference. In addition to increasing the number of cases, external validity was limited due to the analysis of a single metropolitan area.

Another data limitation aspect was referencing the occurrence of assaults on law enforcement officers to some other type of data point to determine rates of occurrence. Based on available data, the present study completed a basic attempt at this by calculating a rate of assaults on law enforcement officers per 1,000 residents in each census tract. Immediate limitations were noted regarding this methodology as population density was determined to not be significantly correlated with assaults on law enforcement officers. Therefore, other statistical baselines for occurrence needed to be developed, such as determining a rate of assaults on law enforcement officers in comparison to calls for service in each census tract. This baseline is needed because an aggregate number of assaults for a limited geographical area—a census tract— does not provide the full context as to whether the level of occurrence is high, low, average, etc. 
The law enforcement agency-provided data also did not include offender data. As such, the present study was unable to control for or analyze these variables. The present study also did not include measures specific measures of informal social control, such as friendship/kinship ties. Despite the importance to social disorganization theory, the omission of informal social control measures was not considered a major limitation to the present study as informal social control measures were not a specific focus of the present study. Overall, the totality of the limitations of the study did not diminish the results, but instead provided opportunities for future research.

\section{Future Research}

Limitations of the present study as well as other aspects provide opportunities for future research. This includes replication research within other metropolitan areas to conduct comparative analyses. For example, an advanced statistical comparison study with data from another major metropolitan area in the same or different state could be performed to determine if results are consistent across both geographical areas. This is in addition to comparing the five-year American Community Survey data to 2010 decennial census data to identify possible differences in results. In addition to comparison across geographies and census datasets, comparative analysis across different crime types is warranted. For example, spatial comparison to assaults in general would determine if both assault types are similarly spatially concentrated. This is in addition to research into temporal concentration (e.g., day of week, time), officer characteristics (e.g., rank, years of service, etc.), initial call for service that preceded the assault (e.g., traffic stop, domestic disturbance, etc.), patrol type (e.g., single officer, two officers), etc. that can help to identify factors that increase the risk for an assaultive incident. 
Additionally, the present study could be replicated for each year of the timeframe of the present study to evaluate possible changes across separate years. This would also provide deeper insight into the significant decreases in certain years followed by returns to previous levels, some of which may be due exogenous shocks to policing such as the Ferguson effect and body-worn cameras. This is in addition to determining an appropriate baseline statistic to evaluate the level of occurrence of assaults on law enforcement officers. For example, using calls for service as a baseline measure can enable the determination of the rate of assaults per calls for service, which would provide a consistent baseline across a geographical area and its features such as census tracts. Future research also needs to utilize a much smaller unit of analysis than census tracts. Issues regarding the dissimilar geographical sizes of census tracts within the selected metropolitan area supports the need for future research at smaller units of analysis. For example, research at the census block group unit of analysis would provide more granular data on assaults on law enforcement officers.

Additional research is also warranted from the theoretical perspective. For example, future research could examine the independent variables identified as insignificant within the present study and whether this result hold true for other crime types. Future research could also examine concentrated disadvantage, which is part of social disorganization. Specifically, identification of areas considered to have concentrated disadvantage could be achieved through the examination of multiple decennial reports. Once identified, social and ecological factors can be examined in relation to assaults on law enforcement officers. In sum, despite the encouraging findings 
of the present study, additional research is warranted to better understand assaults of law enforcement officers both spatially and theoretically.

\section{Conclusion}

The findings of the present study revealed that assaults on law enforcement officers were spatially concentrated in the downtown urban core within census tracts that exhibit high levels of indicators of social disorganization. The findings were supported through statistical, spatial, and visual analyses. More specifically, assaults on law enforcement officers were spatially concentrated within those areas (downtown urban core) that had high levels of community characteristics of social disorganization in accordance with the theoretical perspectives and the vast majority (90 percent) occur in a very small percentage ( 6 percent) of the metropolitan area. Therefore, the study revealed support for the following hypotheses:

$\mathrm{H}_{1}$ : Assaults on law enforcement officers will be spatially concentrated in which half (50 percent) of all incidents occur within four percent of all street segments within the metropolitan area.

$\mathrm{H}_{2}$ : Assaults on law enforcement officers will be spatially concentrated in and around the downtown urban core with decreasing incidents away from the downtown urban core.

$\mathrm{H}_{3}$ : The presence of social disorganization characteristics within census tracts will be both positively and significantly correlated with incidence of assault on law enforcement officers.

Although the present study examined numerous predictor variables, SNAP benefit receivership within a census tract was revealed to have the largest influence on assaults 
on law enforcement officers followed by vacant housing and family disruption. Other common social disorganization indicators (e.g., poverty, racial heterogeneity) were correlated (via bivariate testing) with assaults on law enforcement officers, but their significant was not replicated in multivariate testing. At most, the present study can be viewed as an appropriate addition to the current literature as it attempted to address noted gaps in understanding, but much more research is still warranted. In conclusion, assault of law enforcement officers is an important area of study as officers are assigned the responsibility to protect the safety and security of all citizens regardless of what census tract, housing unit, or circumstances the officer finds him/herself in. 


\section{REFERENCES}

Alpert, G., \& Dunham, R. (1992). Policing urban America (2nd ed.). Prospect Heights, IL: Waveland Press.

Anderson, E. (1999). Code of the streets: Decency, violence, and the moral life of the inner city. New York, NY: W.W. Norton \& Company.

Anselin,L., Cohen, J., Cook, D., Gorr, W., \& Tita, G. (2000). Spatial analyses of crime. In D. Duffee (Ed.), Criminal justice 2000: Measurement and analysis of crime and justice (Vol. 4, pp. 213-262). Washington, DC: U.S. Department of Justice, National Institute of Justice.

Ariel, B., Sutherland, A., Henstock, D., Young, J., Drover. P., Sykes, J., Megicks, S., \& Henderson, R. (2016). Wearing body cameras increases assaults against officers and does not reduce police use of force: Results from a global multi-site experiment. European Journal of Criminology, 13(6), 744-755.

Ariel, B., Sutherland, A., Henstock, D., Young, J., Drover. P., Sykes, J., Megicks, S., \& Henderson, R. (2018). Paradoxical effects of self-awareness of being observed: testing the effect of police body-worn cameras on assaults and aggression against officers. Journal of Experimental Criminology, 14, 19-47.

Bailey, W. (1982). Capital punishment and lethal assaults against police. Criminology, 19(4), 608-625.

Bailey, W., \& Peterson, R. (1987). Police killings and capital punishment: The postFurman period. Criminology, 25, 1-26.

Bailey, W., \& Peterson, R. (1994). Murder, capital punishment, and deterrence: A review of the evidence and an examination of police killings. Journal of Social Issues, 50, 53-73.

Bannister, J., Bates, E., \& Kearns, A. (2018). Local variation in the crime drop: A longitudinal study of neighborhoods in greater Glasgow, Scotland. British Journal of Criminology, 58, 177-199.

Barrick, K., Hickman, M., \& Strom, K. (2014). Representative policing and violence towards the police. Policing, 8(2), 193-204. 
Barrick, K., Strom, K., \& Richardson, N. (2018). Individual and situational influences on injurious assaults against the police. Policing, 41(2), 202-214.

Batton, C., \& Wilson, S. (2006). An examination of historical trends in the killing of law enforcement officers in the United States, 1947 to 1998. Homicide Studies, 10(2), 79-97.

Bayley, D., \& Garofalo, J. (1989). The management of violence by police patrol officers. Criminology, 27, 1-23.

Bellair, P. (1997). Social interaction and community crime: Examining the importance of neighbor networks. Criminology, 35(4), 677-703.

Bellair, P., \& Browning, C. (2010). Contemporary disorganization research: An assessment and further test of the systemic model of neighborhood crime. Journal of Research in Crime and Delinquency, 47(4), 496-521.

Bernasco, W., \& Elffers, H. (2010). Statistical analysis of spatial crime data. In A. Piquero \& D. Weisburd (Eds.), Handbook of quantitative criminology (pp. 699724). New York, NY: Springer.

Biemann, T., \& Kearney, E. (2010). Size does matter: How varying group sizes in a sample affect the most commons measures of group diversity. Organizational Research Methods, 13(3), 582-599.

Bierie, D. (2017). Assault of police. Crime and Delinquency, 63(8), 899-925.

Bierie, D., Detar, P., \& Craun, S. (2013), Firearm violence directed at police. Crime \& Delinquency, 62(4), 501-524.

Blau, P. (1977). Inequality and heterogeneity: A primitive theory of social structure. New York, NY: The Free Press.

Braga, A., \& Davis, E. (2014). Implementing science in police agencies: The embedded research model. Policing, 8(4), 294-306.

Brandl, S. (2001). In the line of duty: A descriptive analysis of police assaults and accidents. Journal of Criminal Justice, 24, 255-264.

Brown, D., \& Schafft, K. (2011). Rural people and communities in the $21^{\text {st }}$ century: Resilience and transformation. Malden, MA: Polity.

Brydon-Miller, M., Greenwood, D., \& Maguire, P. (2003). Why action research? Action Research, 1(1), 9-28. 
Buroway, M. (2005). For public sociology: Contradiction, dilemmas, and possibilities. American Sociological Review, 70(1), 4-28.

Bursik, R. (1988). Social disorganization and theories of crime and delinquency. Criminology, 26, 519-551

Bursik, R. (1988). Social disorganization and theories of crime and delinquency: Problems and prospects. Criminology, 26(4), 521-539.

Bursik, R., \& Grasmick, H. (1993). Neighborhoods and crime. New York, NY: Lexington Books.

California Commission on Peace Officer Safety Training. (2001). A five-year study of law enforcement officers killed and assaulted in the line of duty: A 1995-1999 report. Sacramento, CA: California Commission on Peace Officer Safety Training.

Buslik, M. (2012). Dynamic geography: The changing definition of neighborhood. Cityscape, 14(2), 237-241.

Caplan, J., Marotta, P., Piza, E., \& Kennedy, L. (2014). Spatial risk factors of injury to law enforcement officers from felonious battery. Policing, 37(4), 823-838.

Carr, P. (2003). The new parochialism: The implications of the Beltway case for arguments concerning informal social control. American Journal of Sociology, 108(6), 1249-1291.

Carrijo, T., \& Silva, A. (2017). Modified Moran's I for small samples. Geographical Analysis, 49, 451-467.

Carter, J., Mohler, G., \& Ray, B. (2018). Spatial concentration of opioid overdose deaths in Indianapolis: An application of the law of crime concentration at place to a public health epidemic. Journal of Contemporary Criminal Justice, 35(2), 1-25.

Chamlin, M. (1989). Conflict theory and police killings. Deviant Behavior, 10, 353-368.

Chamlin, M., \& Cochran, J. (1994). Opportunity, motivation, and assaults on police: A bivariate ARIMA analysis. American Journal of Criminal Justice, 19, 1-19.

Cohen, L., \& Felson, M. (1979). Social change and crime rate trends: A routine activity approach. American Sociological Review, 44(4), 588-608.

Covington, M., Huff-Corzine, L., \& Corzine, J. (2014). Battered police: Risk factors for violence against law enforcement officers. Violence and Victims, 29(1), 34-52.

Craun, S., Detar, P., \& Bierie, D. (2013). Shots fired: Examining lethal force used against Deputy U.S. Marshals. Victims \& Offenders, 8, 56-69. 
Creamer, J., \& Robin, G. (1968). Assaults on police. Police, 1, 82-87.

Cullen, F., \& Wilcox, P. (2015). Introduction: The legacy of Ruth Rosner Koernhauser. In F. Cullen, P. Wilcox, R. Sampson, \& B. Dooley (Eds.), Challenging criminological theory: The legacy of Ruth Rosner Kornhauser (Advances in criminological theory, Vol. 19, pp. 1-22). New York, NY: Routledge.

Curman, A., Andresen, M., \& Brantingham, P. (2015). Crime and place: A longitudinal examination of street segment patterns in Vancouver, BC. Journal of Quantitative Criminology, 31(1), 127-147.

Dooley, B. (2015). Ruth Rosner Koernhauser's 1963 manuscript. In F. Cullen, P. Wilcox, R. Sampson, \& B. Dooley (Eds.), Challenging criminological theory: The legacy of Ruth Rosner Kornhauser (Advances in criminological theory, Vol. 19, pp. 4558). New York, NY: Routledge.

Eck, J., Chainey, S., Cameron, J., Leitner, M., \& Wilson, R. (2005). Mapping crime: Understanding hot spots (NCJ 209393). Washington, DC: U.S. Department of Justice, Office of Justice Programs, National Institute of Justice.

Eck, J., Gersh, J., \& Taylor, C. (2000). Finding crime hot spots through repeat address mapping. In V. Goldsmith, P. McGuire, J. Mollenkopf, \& T. Ross (Eds.), Analyzing Crime Patterns: Frontiers of Practice (pp. 49-64). Thousand Oaks, CA: Sage.

Ellis, D., Choi, A., \& Blaus, C. (1993, April). Injuries to police officers attending domestic violence: An empirical study. Canadian Journal of Criminology, 149-168.

Engel, R. (2003). Explaining suspects' resistance and disrespect toward police. Journal of Criminal Justice, 31, 475-492.

Fridell, L., \& Pate, A. (1995). Death on patrol: Felonious killings of police officers. Washington, DC: U.S. Department of Justice, National Institute of Justice.

Garner, J., \& Maxwell, C. (2001). Understanding the use of force by and against the police in six jurisdictions (NCJRS 196694). Washington, DC: U.S. Department of Justice, National Institute of Justice.

Gibbs, J., Lee, J., Moloney, J., \& Olson, S. (2018). Exploring the neighborhood context of serious assaults on police. Policing and Society, 28(8), 898-914.

Gibbs, J., Ruiz, J., \& Klapper-Lehman, S. (2014). Police officers killed on duty: Replicating and extending a unique look at officer deaths. International Journal of Police Science and Management, 16(4), 277-287. 
Gignac, G., \& Szodorai, E. (2016). Effect size guidelines for individual differences researchers. Personality and Individual Differences, 102, 74-78.

Harris, K. (1999). Mapping crime: Principle and practice (NCJ 178919). Washington, DC: U.S. Department of Justice, Office of Justice Programs, National Institute of Justice.

Hauss, C. (2014). Security 2.0: Dealing with global wicked problems. Lanham, MD: Rowman \& Littlefield.

Hemphill, J. (2003). Interpreting the magnitudes of correlation coefficients. American Psychologist, 58(1), 78-79.

Hill, B., \& Paynich, R. (2014). Fundamental of crime mapping ( $2^{\text {nd }}$ ed.). Burlington, MA: Jones \& Bartlett.

Hirschi, T. (2015). Ruth and me. In F. Cullen, P. Wilcox, R. Sampson, \& B. Dooley (Eds.), Challenging criminological theory: The legacy of Ruth Rosner Kornhauser (Advances in criminological theory, Vol. 19, pp. 87-104). New York, NY: Routledge.

Horstman, P. (1973). Assaults on police officers. The Police Chief, 40, 44-53.

Hughes, T., Campbell, B., \& Schaefer, B. (2020). The influence of body-worn cameras, minority threat, and place on police activity. Journal of Community Psychology, $48,68-85$.

Jacobs, D., \& Carmichael, J. (2002). Subordination and violence against state control agents: testing political explanations for lethal assaults against the police. Social forces, $80,1223-1251$.

Johnson, R. (1999). Phoenix project: Predictors of suspect use of force (NCJRS 187776). Washington, DC: U.S. Department of Justice.

Johnson, R. (2011). Predicting officer physical assaults at domestic assault calls. Journal of Family and Violence, 26, 163-169.

Kaminski, R. (2002). An opportunity model of police homicide victimization (doctoral dissertation). Albany, NY: University at Albany, State University of New York.

Kaminski, R. (2008). Assessing the county-level structural covariates of police homicides. Homicide Studies, 12(4), 350-380.

Kaminski, R., \& Coleman, L. (2007). South Carolina deaths in police custody: Final report. Columbia, SC: South Carolina Department of Public Safety, Office of Justice Programs. 
Kaminski, R., \& Marvell, T. (2002). A comparison of changes in police and general homicides: 1930-1998. Criminology, 40(1), 171-190.

Kaminski, R., \& Sorensen, D. (1995). A multivariate analyses of individual situational and environmental factors associated with police assault injuries. American Journal of Police, 14, 3-48.

Kaminski, R., Jefferis, E., \& Chanhatasilpa, C. (2000). A spatial analysis of American police killed in the line of duty. In L. S. Turnbull, E. H. Hendrix, \& B. D. Dent (Eds.), Atlas of crime: Mapping the criminal landscape (pp. 212-220). Phoenix, AZ: Oryx Press.

Kaminski, R., Jefferis, E., \& Gu, J. (2003). Community correlates of serious assaults on police. Police Quarterly, 6(2), 119-149.

Kasarda, J., \& Janowitz, M. (1974). Community attachment in mass society. American Sociological Review, 39, 328-339.

Kavanaugh, J. (1997). The occurrence of resisting arrest in arrest encounters: A study of police-citizen violence. Criminal Justice Review, 22, 16-33.

Kent, S. (2010). Killings of police in U.S. cities since 1980: An examination of environmental and political explanations. Homicide Studies, 14(1), 3-23.

Kim, Y. (2018). Examining the relationship between the structural characteristics of place and crime by imputing census block data in street segments: Is the pain worth the gain? Journal of Quantitative Criminology, 34, 67-110.

Klofas, J., Hipple, N., \& McGarrell, E. (2010). The new criminal justice: American communities and the changing world of crime control. New York, NY: Routledge.

Kornhauser, R. (1978). Social sources of delinquency. Chicago, IL: University of Chicago Press.

Kornhauser, A. (2015a). Ruth Rosner Kornhauser: A personal and intellectual history. In F. Cullen, P. Wilcox, R. Sampson, \& B. Dooley (Eds.), Challenging criminological theory: The legacy of Ruth Rosner Kornhauser (Advances in criminological theory, Vol. 19, pp. 23-44). New York, NY: Routledge.

Kornhauser, R. (2015b). Theoretical issues in the sociological study of juvenile delinquency. In F. Cullen, P. Wilcox, R. Sampson, \& B. Dooley (Eds.), Challenging criminological theory: The legacy of Ruth Rosner Kornhauser (Advances in criminological theory, Vol. 19, pp. 59-86). New York, NY: Routledge. 
Krivo, L., \& Peterson, R. (1996). Extremely disadvantaged neighborhoods and urban crime. Social Forces, 75(2), 619-648.

Krivo, L., \& Peterson, R. (2000). The structural context of homicide: Accounting for racial differences in process. American Sociological Review, 65(4), 547-559.

Laub, J. (2012). Strengthening NIJ: Mission, science and process. National Institute of Justice Journal, 268, 16-21.

Levine, N. (2013). CrimeStat IV: A spatial statistics program for the analysis of crime incident locations. Washington, DC: U.S. Department of Justice, Office of Justice Programs, National Institute of Justice.

Lilly, J., Cullen, F., \& Ball, R. (2015). Criminological theory: Context and consequences ( $6^{\text {th }} e d$.). Thousand Oaks, CA: Sage.

Loader, I., \& Sparks, R. (2010). Public criminology? New York, NY: Routledge.

Logan, J. (2018). Relying on the census in urban social science. City \& Community, 17(3), 540-564.

Lott, J. (2000). Does a helping hand put others at risk? Affirmative action, police departments, and crime. Economic Inquiry, 38, 239-277.

Lowenkamp, C., Cullen, F., \& Pratt, T. (2003). Replicating Sampson and Groves's test of social disorganization theory: Revisiting a criminological classic. Journal of Research in Crime \& Delinquency, 40(4), 351-373.

Maguire, E., Nix, J., \& Campbell, B. (2017). A war on cops? The effects of Ferguson on the number of U.S. police officers murdered in the line of duty. Justice Quarterly, 34(5), 739-758.

Malm, A. (2019). Promise of police body-worn cameras. Criminology \& Public Policy, 18(1), 119-130.

Margarita. M. (1980). Police as victims of violence. The Justice System Journal, 5, 218233.

McClusky, J., Mastrofski, S., \& Parks, R. (1999). To acquiesce or rebel: Predicting citizen compliance with police requests. Police Quarterly, 2, 389-416.

Meyer, C., Magedanz, T., Dahlin, D., \& Chapman, S. (1981). A comparative assessment of assault incidents: Robbery-related, ambush, and general police assaults. Journal of Police Science and Administration, 9, 1-18. 
Meyer, C., Magedanz, T., Feimer, S., Chapman. S., \& Pammer, W. (1986). Ambushrelated assaults on police: Violence at the street level. Springfield, IL: Charles C. Thomas.

Meyer, C., Magedanz, T., Kieselhorst, D., \& Chapman, S. (1979). Violence and the police: The special case of the police assailant. Journal of Police Science and Administration, 7, 161-171.

Meyer, S., \& Carroll, R. (2013). When officers die: Understanding deadly domestic violence calls for service. The Police Chief, 78(5), 24-27.

Morrison, P., \& Meyer, C. (1974). A microanalysis of assaults on police in Austin, Texas. Norman, OK: University of Oklahoma, Bureau of Government Research.

Mustard, D. (2001). The impact of gun laws on police deaths. Journal of Law \& Economics, 44, 635-657.

National Institute of Justice. (2004). Research for practice: Law enforcement technology - are small and rural agencies equipped and trained (NCJ 204609). Washington, DC: U.S. Department of Justice, Office of Justice Programs, National Institute of Justice.

Osborne, D., McCord, E., Higgins, G. (2016). The interactive influence of prosocial places, youth population, and poverty on incidents of violent assault. Deviant Behavior, 37(4), 385-400.

Osborne, J., \& Overbay, A. (2008). Best practices in data cleaning: How outliers and fringeliers can increase error rates and decrease the quality and precision of your results. In J. Osborne (Ed.), Best practices in quantitative methods (pp. 2052013). Thousand Oaks, CA: Sage.

Ozkan, T., Worrall, J., \& Piquero, A. (2016). Does minority representation in police agencies reduce assaults on the police? American Journal of Criminal Justice, 41, 402-423.

Pattillo, M. (1998). Sweet mothers and gangbangers: Managing crime in a Black middleclass neighborhood. Social Forces, 76(3), 747-774.

Peters, G. (2017). What is so wicked about wicked problems? A conceptual analysis and a research program. Policy and Society, 36(3), 385-396.

Peterson, R., \& Bailey, W. (1988). Structural influences on the killing of police: A comparison with general homicides. Justice Quarterly, 5(2), 207-233.

Pierce, G., Spaar, S., Briggs, L. (1988). The character of police work: Strategic and tactical implications. Boston, MA: Northeastern University, Center for Applied Social Research, 
Quick, M., \& Law, J. (2013). Exploring hotspots of drug offences in Toronto: A comparison of four local spatial cluster detection methods. Canadian Journal of Criminology and Criminal Justice, 55(2), 215-238.

Quinet, K., Bordua, D., \& Lassiter,W. (1997). Line of duty police deaths: A paradoxical trend in felonious homicides in the United States. Policing and Society, 6, 283296.

Rabe-Hemp, C., \& Schuck, A. (2007). Violence against police officers: Are female officers at greater risk? Police Quarterly, 10(4), 411-428.

Redman, V. (2018). Macrolevel predictors of assaults against police in Kentucky [Doctoral dissertation]. Louisville, KY: University of Louisville.

Regens, J., Meyer, C., Swanson, C., Chapman, S., \& Wilson, P. (1974). An analysis of assaults on municipal police officers in 46 south central cities. Norman, OK: University of Oklahoma, Bureau of Government Research.

Richardson, N., Barrick, K., \& Strom, K. (2019). Is policing safer today? The case for a more comprehensive definition of dangerousness. Criminology and Public Policy, $18,37-45$.

Rountree, P., \& Warner, B. (1999). Social ties and crime: Is the relationship gendered? Criminology, 37(4), 401-425.

Salkind, N. (2000). Statistics for people who (think they) hate statistics. Thousand Oaks, CA: Sage.

Sampson, R., \& Groves, W. (1989). Community structure and crime: Testing social disorganization theory. American Journal of Sociology, 94, 774-802.

Schaefer, B., Campbell, B., Hughes, T., \& Reed, J. (2016). [Omitted] wearable video system implementation: Year one report. Louisville, KY: University of Louisville, Southern Police Institute.

Schouten, R., \& Brennan, D. (2016). Targeted violence against law enforcement officers. Behavioral Sciences and the Law, 34, 608-621.

Shaw, C., \& McKay, H. (1942). Juvenile delinquency and urban areas. Chicago, IL: University of Chicago Press.

Sherman, L., Gartin, P., \& Buerger. M. (1989). Hot spots of predatory crime: Routine activities and the criminology of place. Criminology, 27(1), 27-56. 
Shjarback, J., \& Maguire, E. (2019). Extending research on the "war on cops:" The effects of Ferguson on nonfatal assaults against U.S. police officers. Crime and Delinquency.

Southwick, L. (1998). An economic analysis of murder and accident risks for police in the United States. Applied Economics, 30, 593-605.

Spelman, W. (1995). Criminal careers of public places. In J. Eck \& D. Weisburd (Eds.), Crime and place: Crime prevention studies (Vol. 4, pp. 115-140). Monsey, NY: Willow Tree Press.

Sperling, J. (2012). The tyranny of census geography: Small-area data and neighborhood statistics. Cityscape, 14(2), 219-223.

Stewart, E. A., \& Simons, R. L. (2010). Race, code of the street, and violent delinquency: A multilevel investigation of neighborhood street culture and individual norms of violence. Criminology, 48, 569-605.

Stewart, E., \& Simons, R. (2006). Structure and culture in African American adolescent violence: A partial tells of the "code of the street" thesis. Justice Quarterly, 23, 133.

Stewart, E., Schreck, C., Simons, R. (2006). "I ain't gonna let no one disrespect me": Does the code of the street reduce or increase violent victimization among African American adolescents? Journal of Research in Crime and Delinquency, 43, 427458.

Stobart, R. (1972). Serious assaults on police. Police Journal, 45, 108-126.

Taylor, R. (2012). Defining neighborhoods in space and time. Cityscape, 14(2), 225-230.

Tiesman, H., Gwilliam, M., Konda, S., Rojek, J., \& Marsh, S. (2018). Nonfatal injuries to law enforcement officers: A rise in assaults. American Journal of Preventive Medicine, 54(4), 503-509.

Tucker-Gail, K., Selman, D., Kobolt, J., \& Hill, T. (2010). Felonious line-of-duty officer deaths (1995-1999): The impact of tenure and age. International Journal of Police Science \& Management, 12(1), 119-133.

Uggen, C., \& Inderbitzin, M. (2010). Public criminologies. Criminology \& Public Policy, 9(4), 725-750.

U.S. Census Bureau. (2019, July 1). Quickfacts. Retrieved from https://www.census.gov/quickfacts/ 
U.S. Census Bureau. (2018). Understanding and using American Community Survey data: What all data users need to know. Washington, DC: U.S. Department of Commerce, U.S. Census Bureau.

U.S. Bureau. (2010). 2010 Census - census tract reference map: Jefferson County, KY. Washington, DC: U.S. Department of Commerce, U.S. Census Bureau.

Uchida, C., Brooks, L., \& Kopers, C. (1987). Danger to police during domestic encounters: Assaults on Baltimore County Police, 1984-86. Criminal Justice Policy Review, 2, 357-371.

Vellani, K. (2020). Strategic security management: A risk assessment guide for decision makers ( $2^{\text {nd }}$ ed.). Boca Raton, FL: CRC Press.

Van Selst, M., \& Jolicoeur, P. (1994). A solution to the effect of sample size on outlier elimination. Quarterly Journal of Experimental Psychology, 47(3), 631-650.

Warner, B., \& Rountree, P. (1997). Local social ties in a community and crime model: Questioning the systemic nature of informal social control. Social Problems, 44(4), 520-536.

Warner, B., Swartz, K., \& Hawk, S. (2015). Racially homophilous social ties and informal social control. Criminology, 53(2), 204-230.

Weisburd, D. (2015). The law of crime concentration and the criminology of place. Criminology, 53(2), 133-157.

Weisburd, D., \& Britt, C. (2013). Statistics in criminal justice (4 ${ }^{\text {th }}$ ed.). New York, NY: Springer.

Weisburd, D., \& Green, L. (1994). Defining the drug market: The case of the Jersey City DMA system. In D. MacKenzie \& C. Uchida (Eds.), Drugs and crime: Evaluating public policy initiatives (pp. 61-76). Newbury Park, CA: Sage.

Weisburd, D., \& Mazerolle, L. (2000). Crime and disorder in drug hot spots: Implications for theory and practice in policing. Police Quarterly, 3, 331-49.

Weisburd, D., Bushway, S., Lum, C., \& Yang, S. (2004). Trajectories of crime at place: A longitudinal study of street segments in the city of Seattle. Criminology, 42, $283-322$.

Wilcox, P., Cullen, F., \& Feldmeyer, B. (2018). Communities and crime: An enduring American challenge. Philadelphia, PA: Temple University Press. 
Willits, D. (2014). The organisational structure of police departments and assaults on police officers. International Journal of Police Science and Management, 16(2), 140-154.

Wilson, L., \& Meyer, K. (1990). Violence at the street level: Police causalities and fatalities. Police Journal, 64, 28-45.

Wilson, L., Brunk, G., \& Meyer, C. (1990). Situational effects in police officer assaults: The case of patrol unit size. Police Journal, 63, 260-271.

Wilson, S., \& Zhao, J. (2008). Determining the correlates of police victimization: An analysis of organizational level factors on injurious assaults. Journal of Criminal Justice, 36, 461-468.

Wilson, W. (2012). The truly disadvantaged: The inner city, the underclass, and public policy $\left(2^{\text {nd }} e d.\right)$. Chicago, IL: University of Chicago Press. 
APPENDIX A

\section{FIGURES}




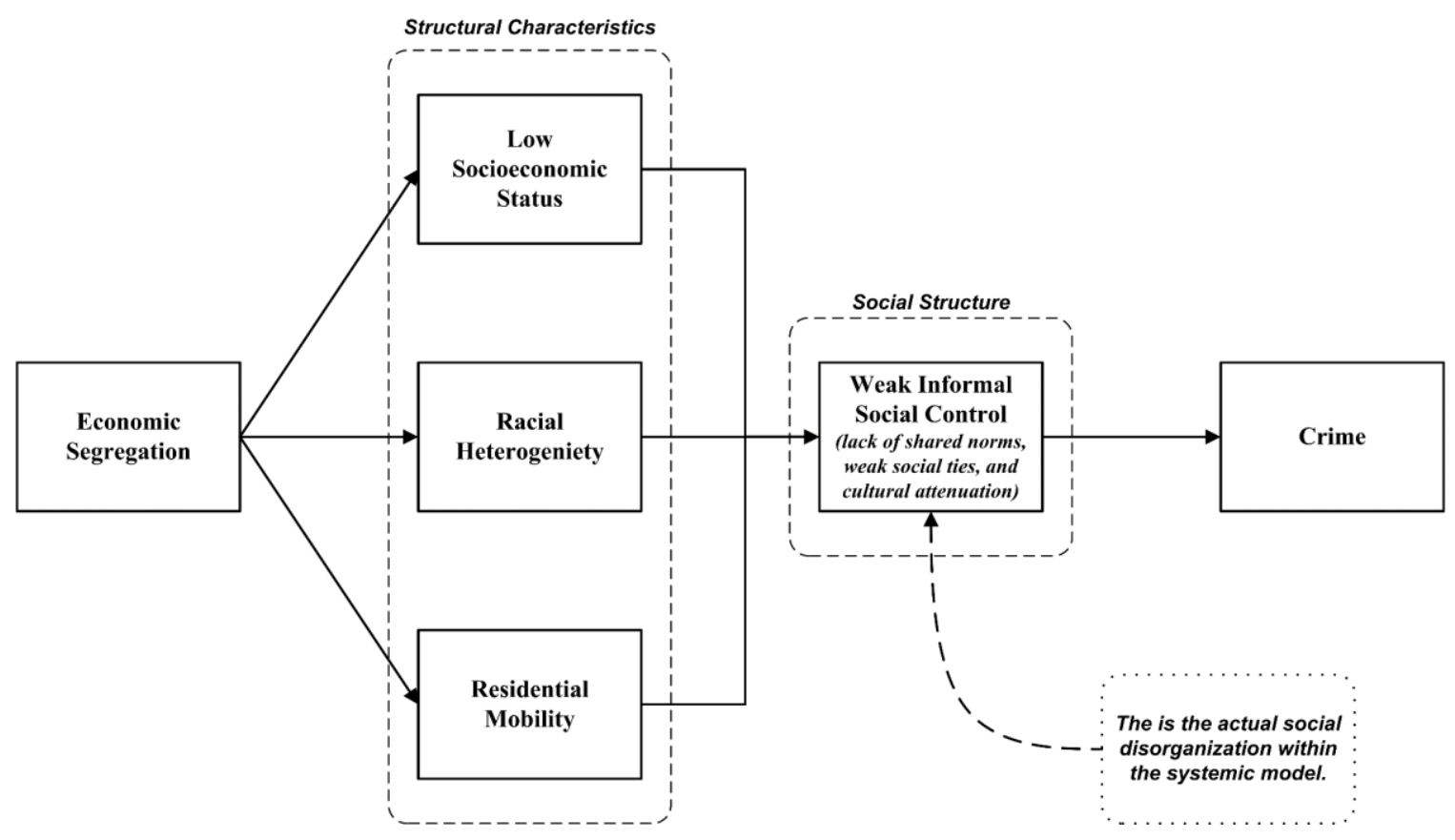

Figure 1. Graphical Representation of Systemic Model of Social Disorganization 


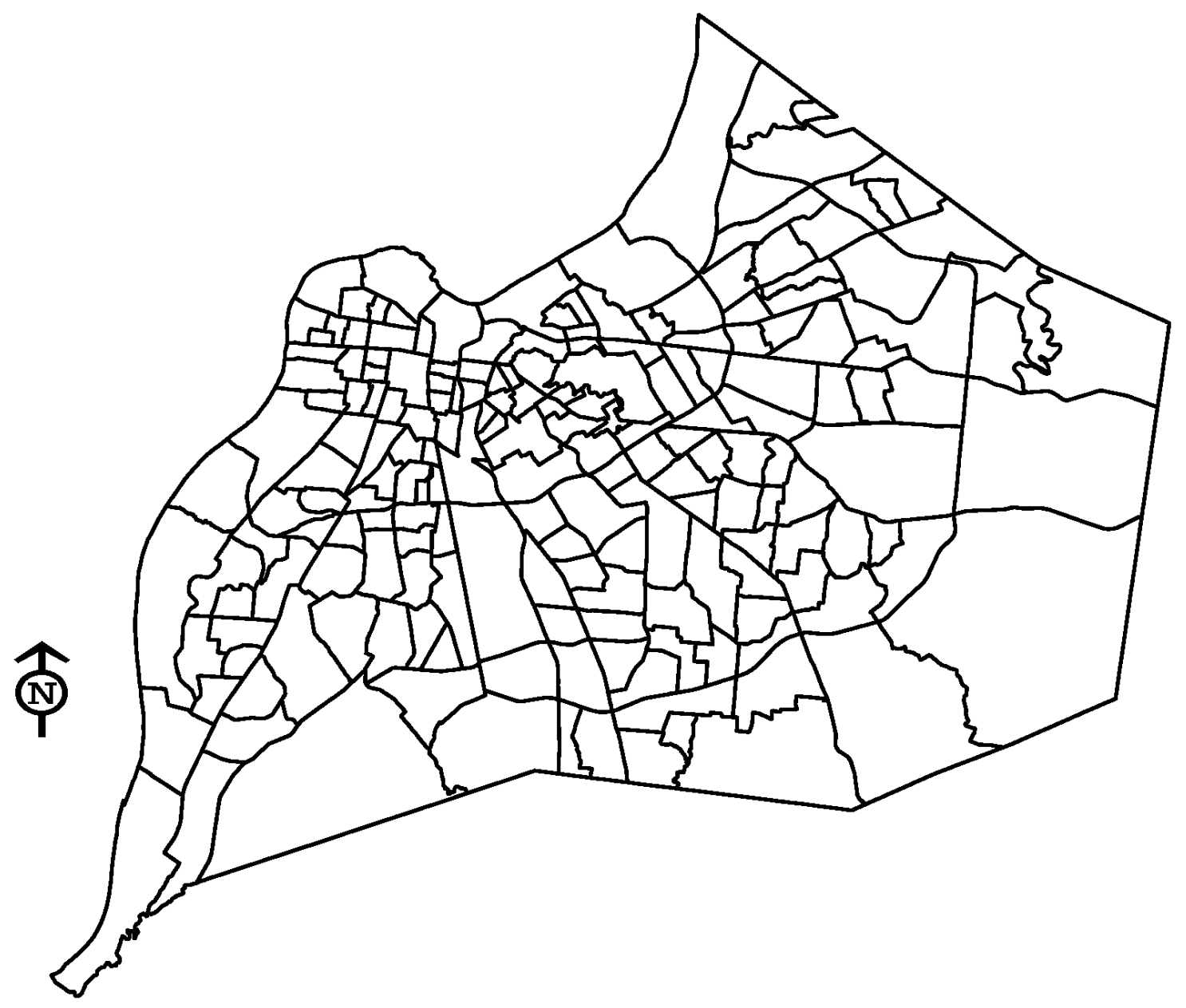

Figure 2. Census Tracts of Selected Metropolitan Area 


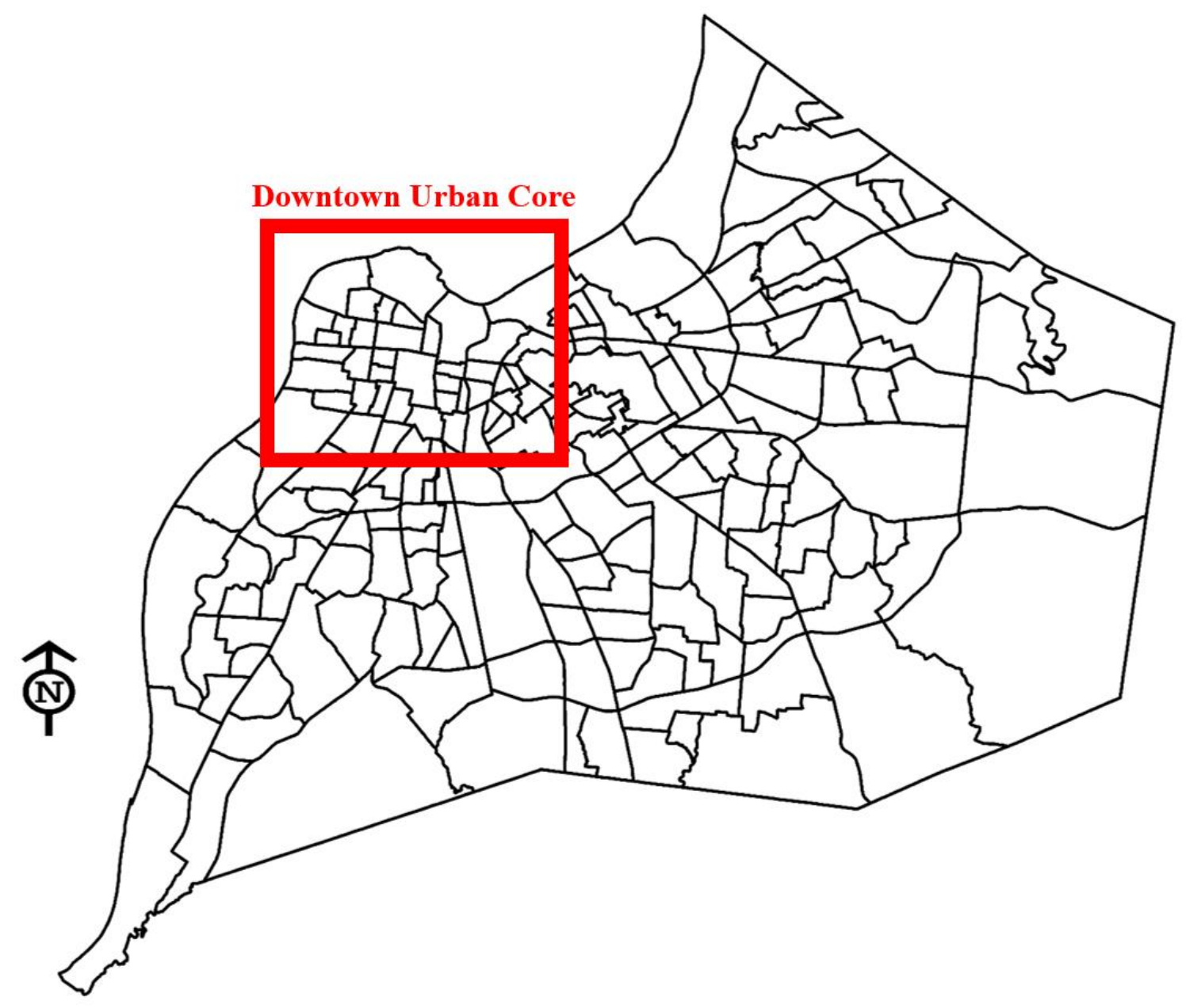

Figure 3. Downtown Urban Core of Selected Metropolitan Area 


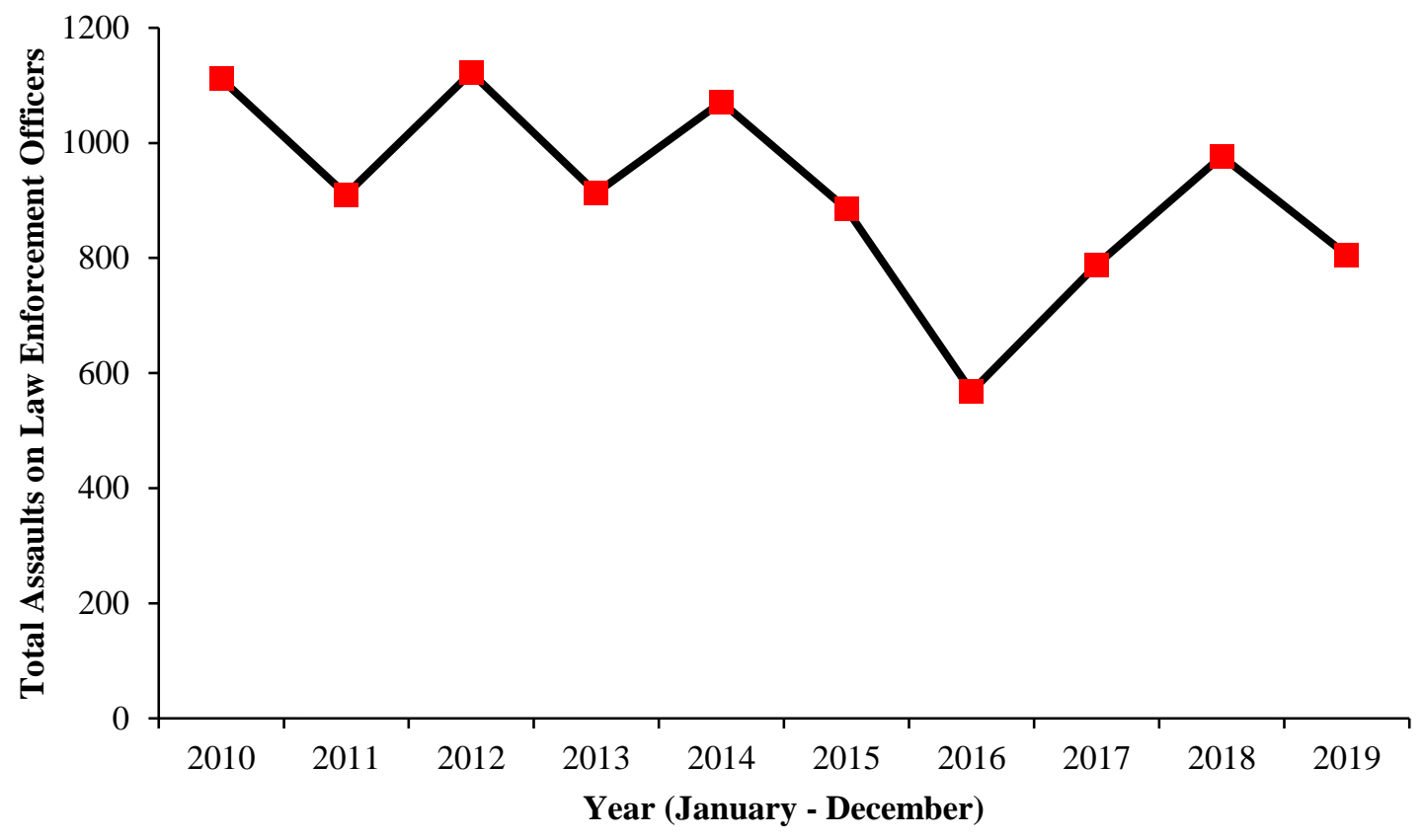

Figure 4. Total Assaults on Law Enforcement Officers per Year 


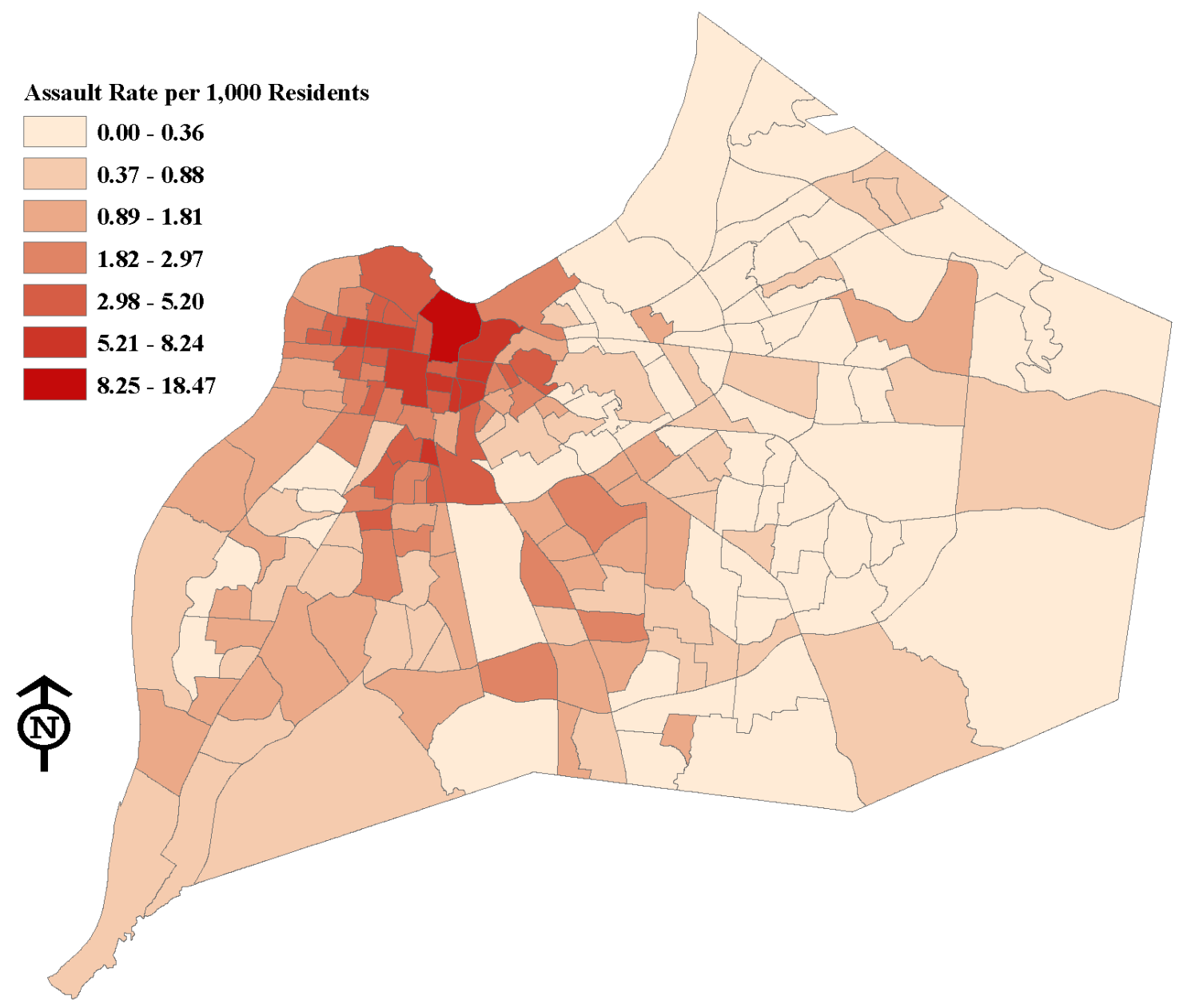

Figure 5. Assault Rate per 1,000 Residents per Census Tract 


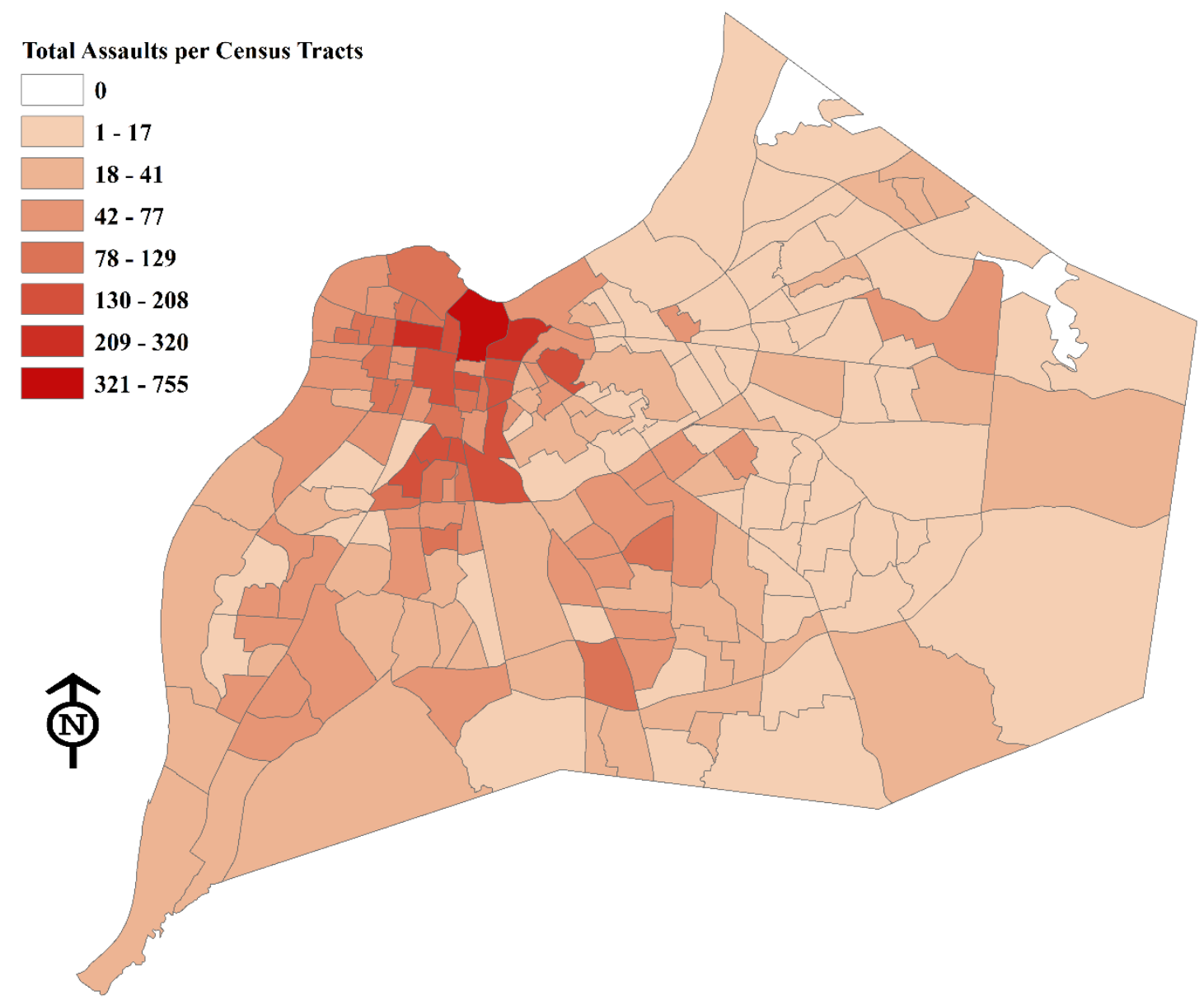

Figure 6. Total Assaults on Law Enforcement Officers per Census Tract (2010-2019) 


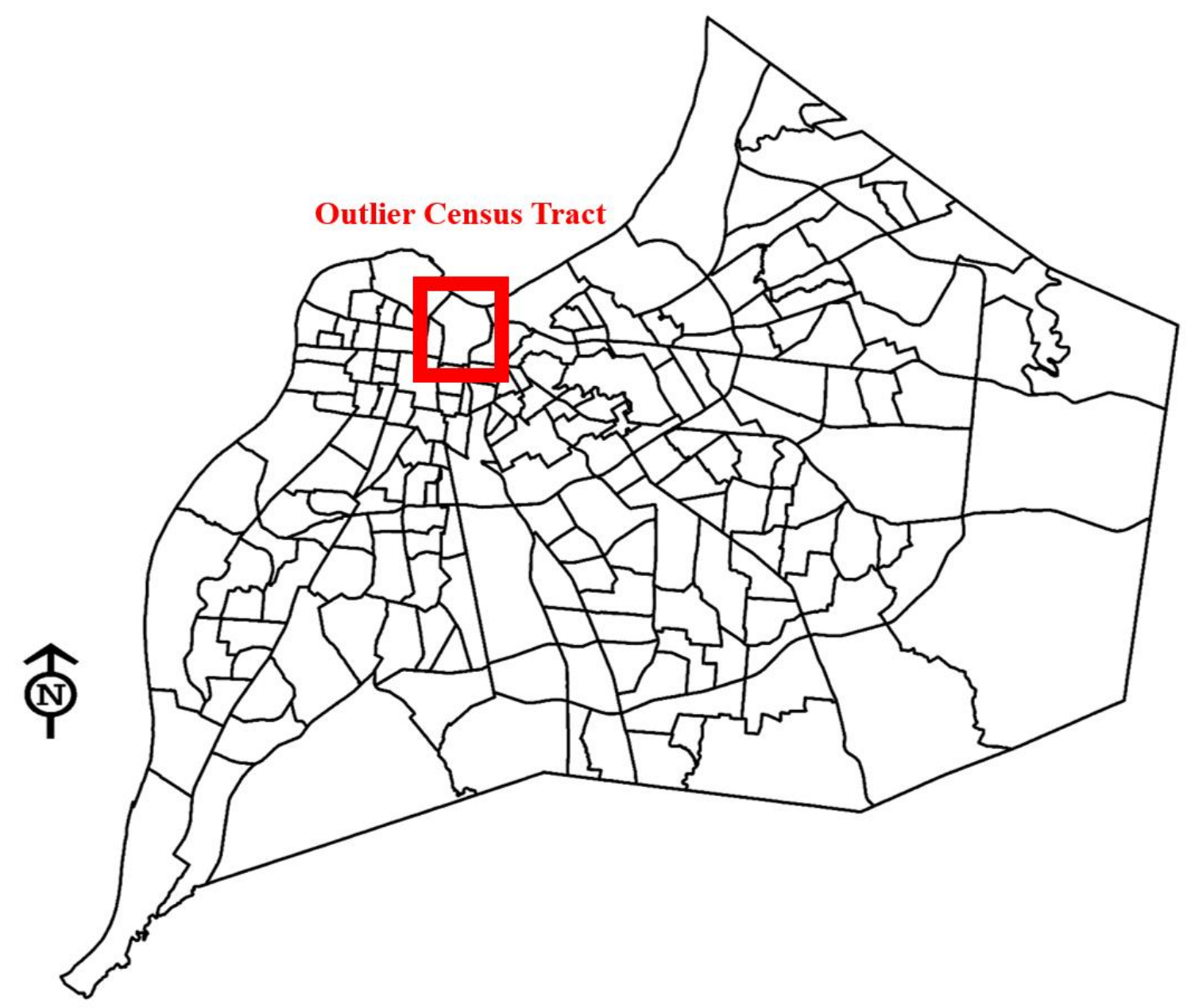

Figure 7. Outlier Census Tract 


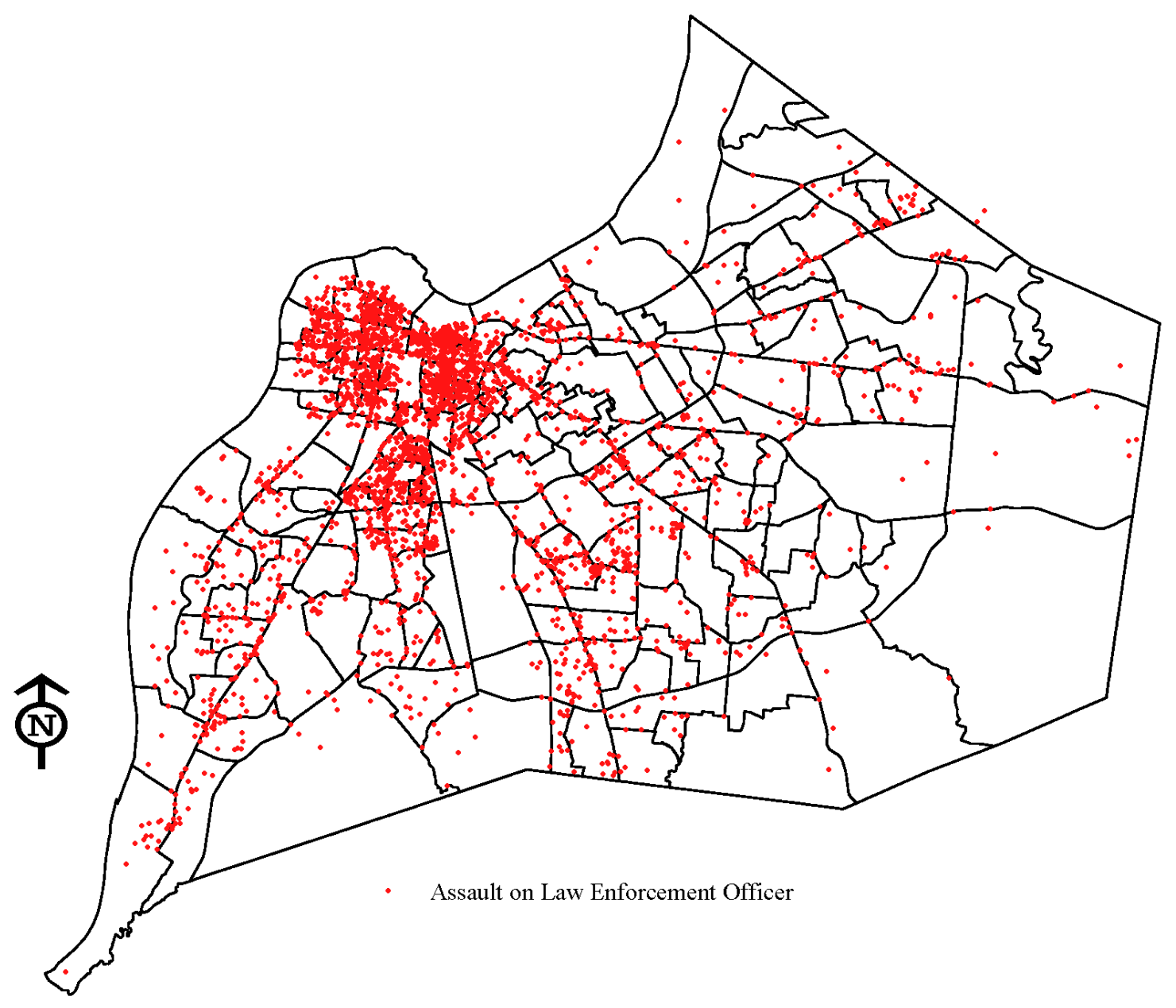

Figure 8. Total Assaults on Law Enforcement Officers Point Data (2010-2019) 


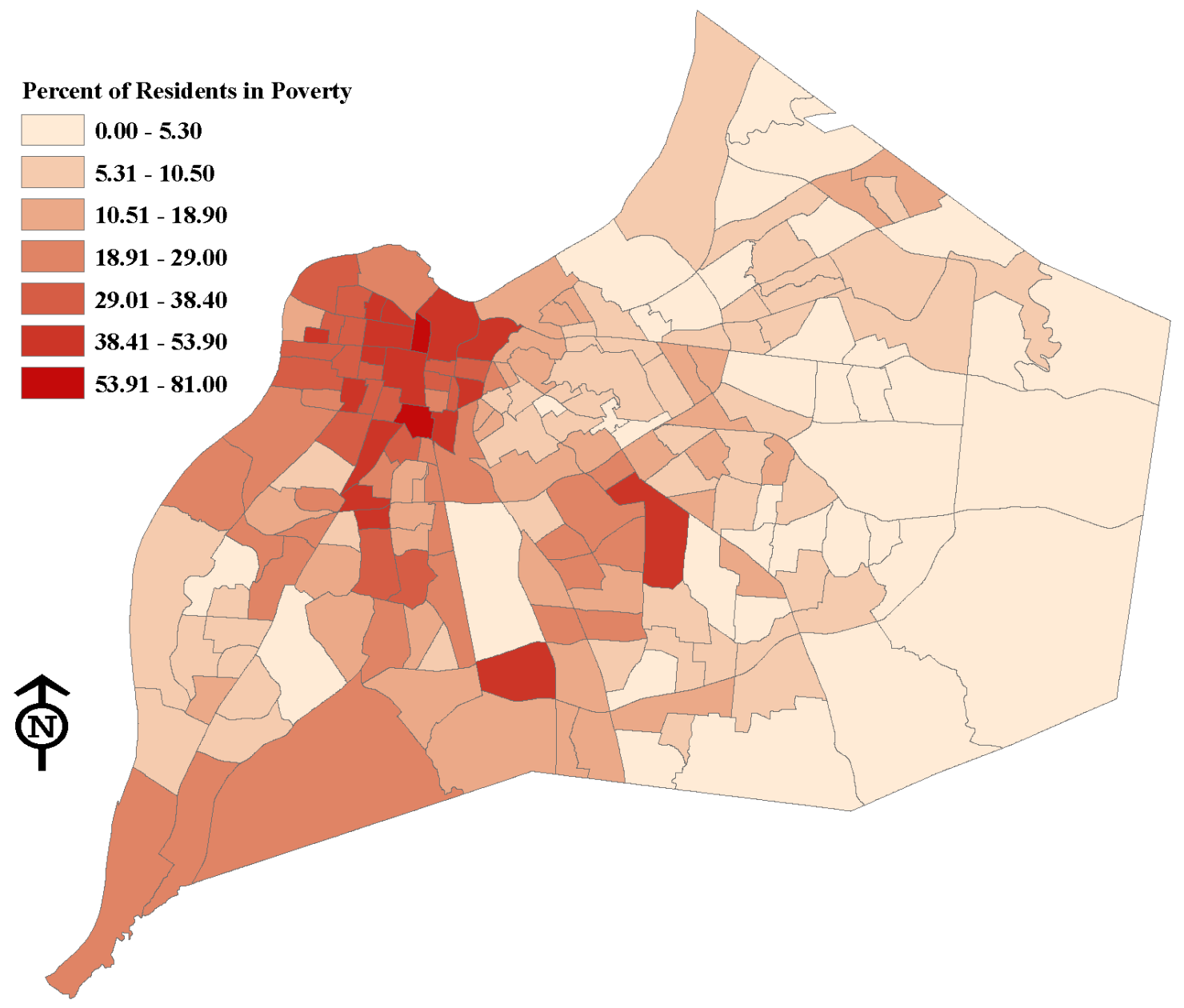

Figure 9. Percent of Residents in Poverty 


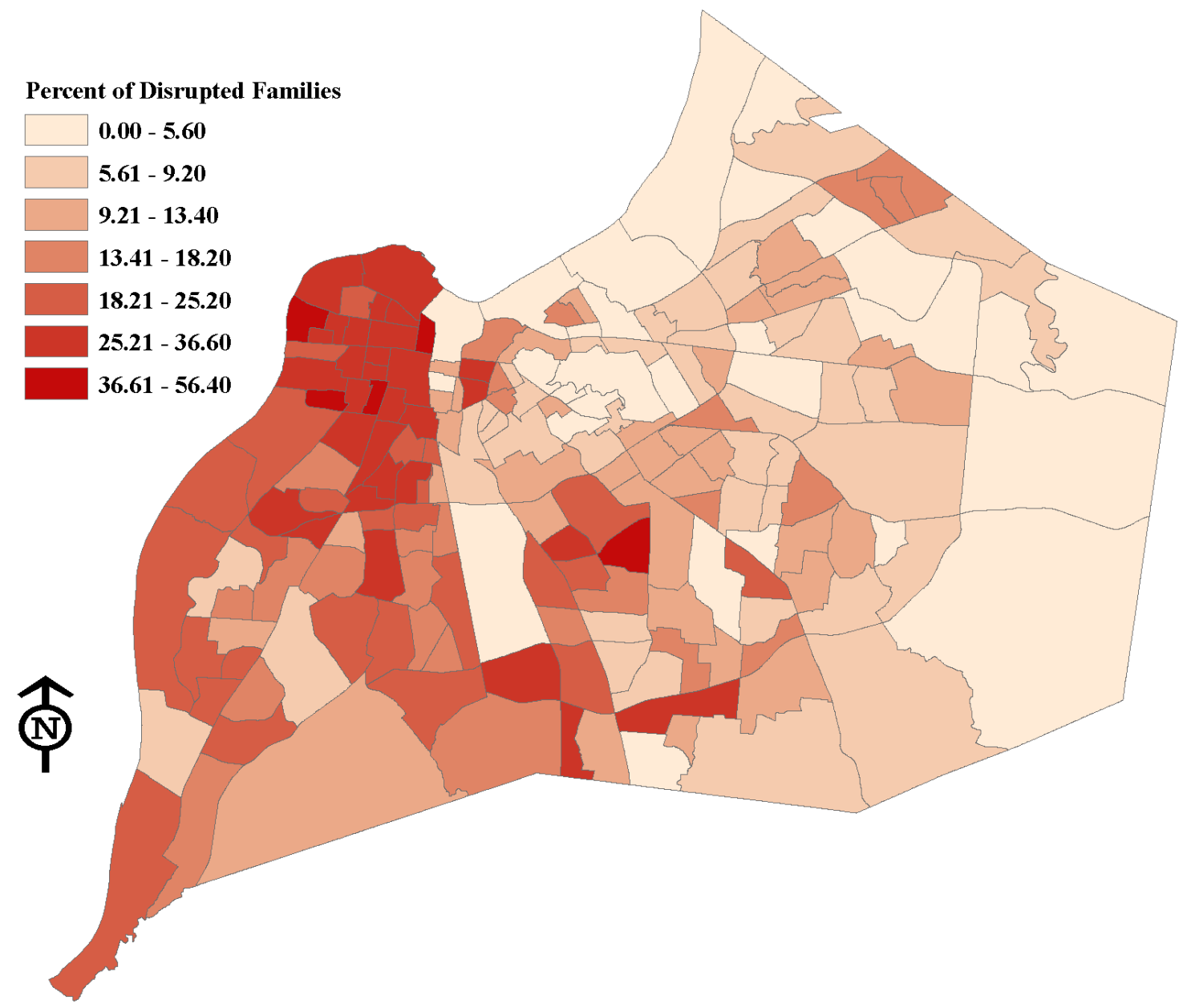

Figure 10. Percent of Disrupted Families 


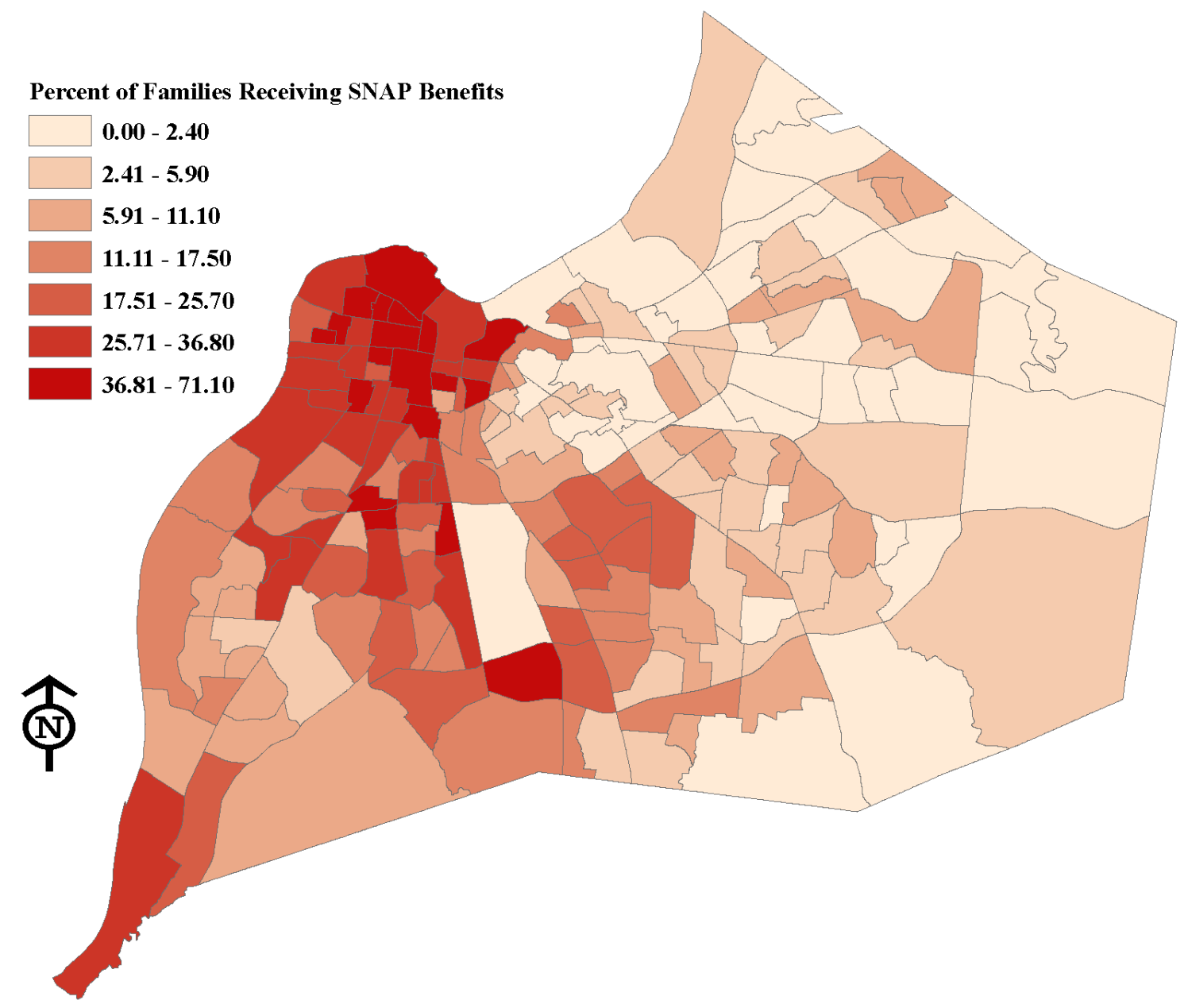

Figure 11. Percent of Families Receiving SNAP Benefits 


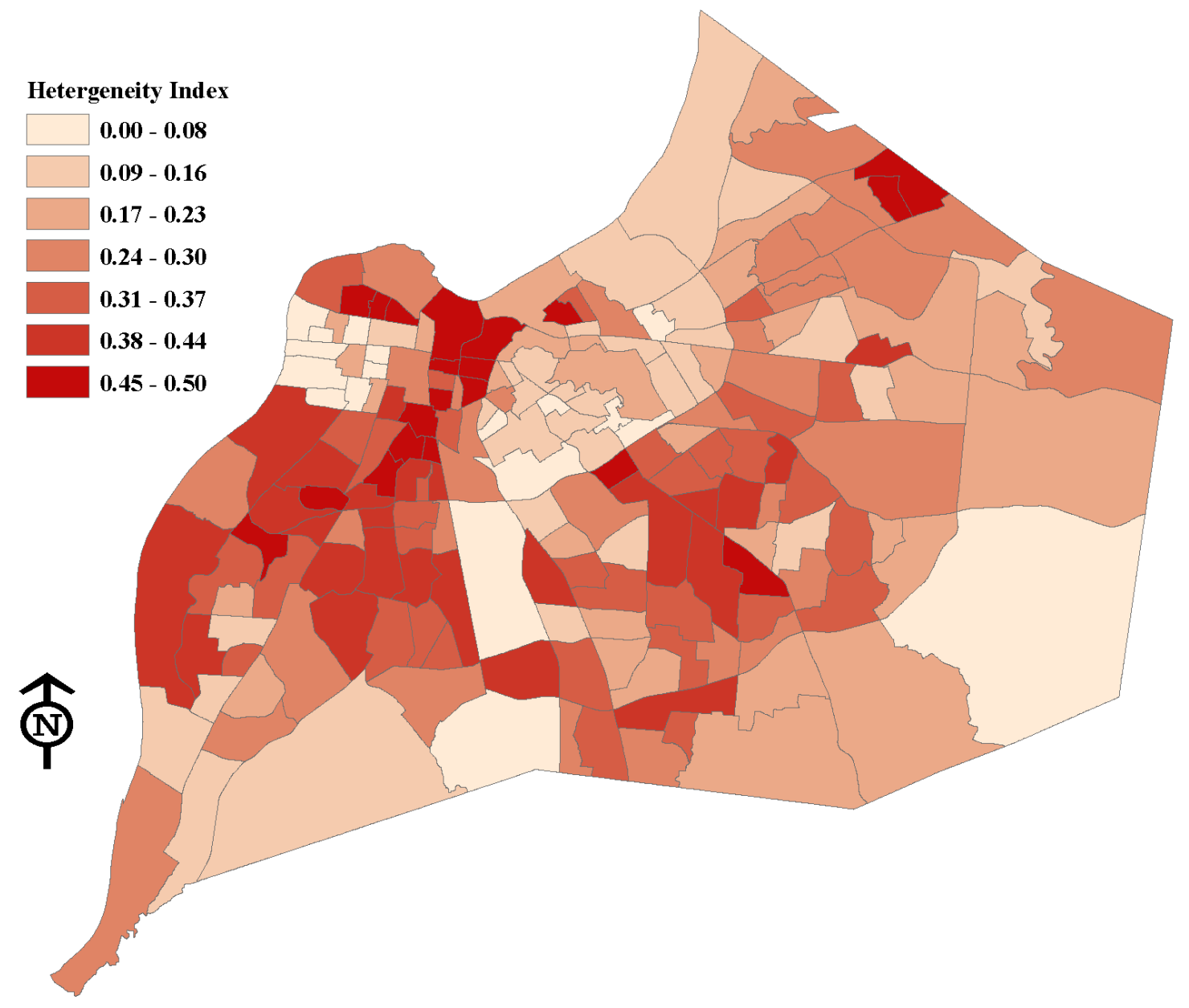

Figure 12. Racial Heterogeneity Index 


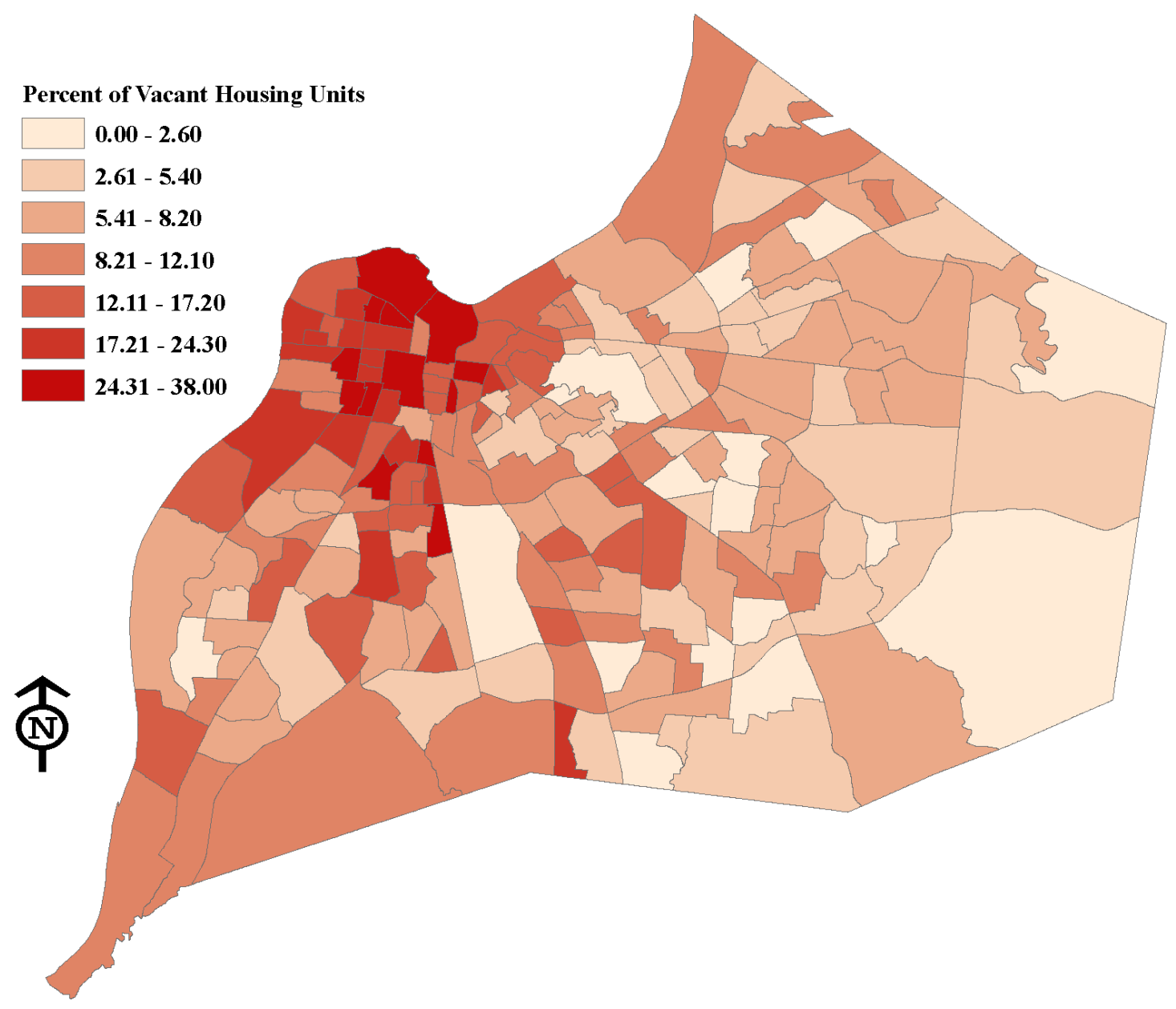

Figure 13. Percent of Vacant Housing Units 


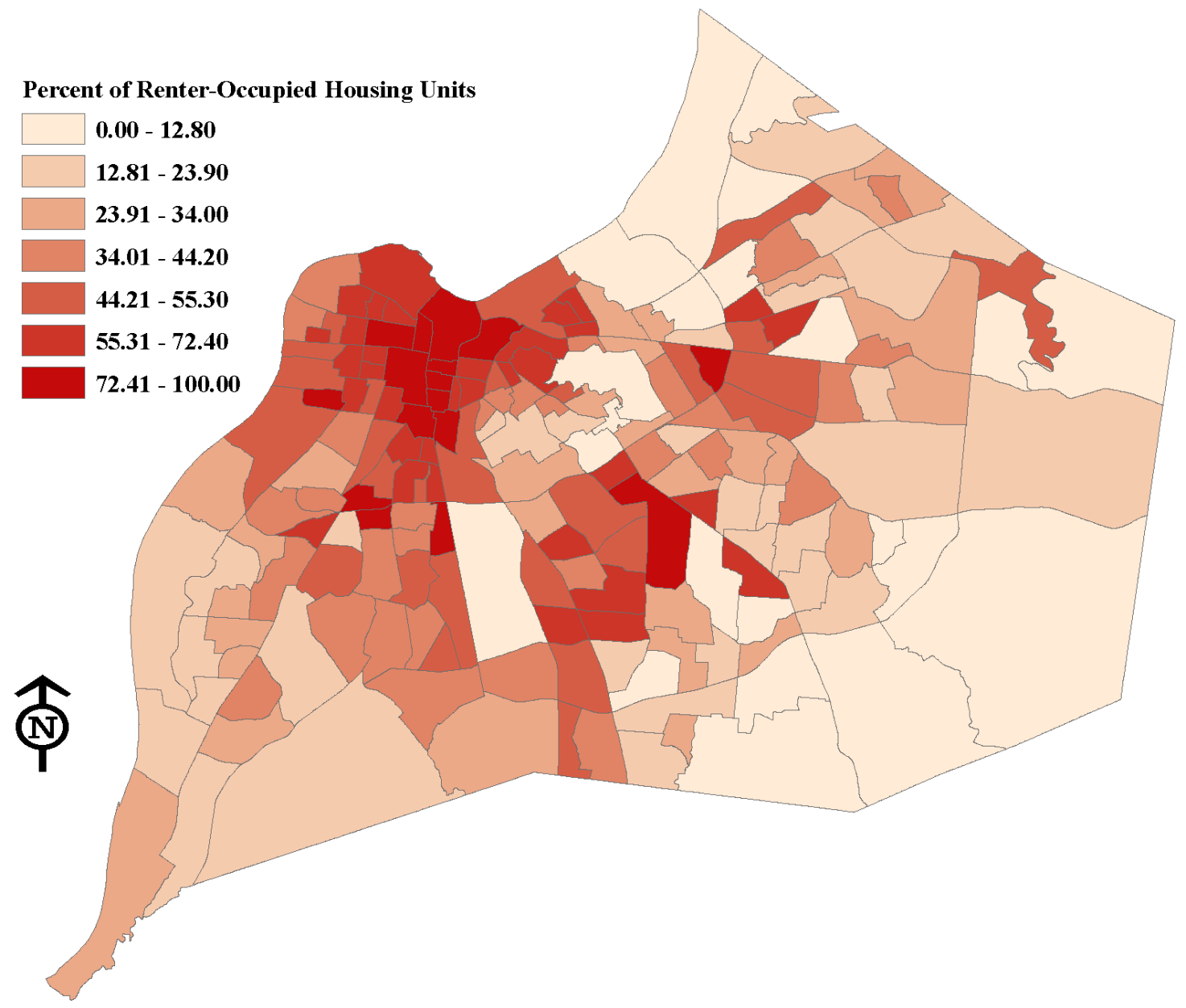

Figure 14. Percent of Renter-Occupied Housing Units 


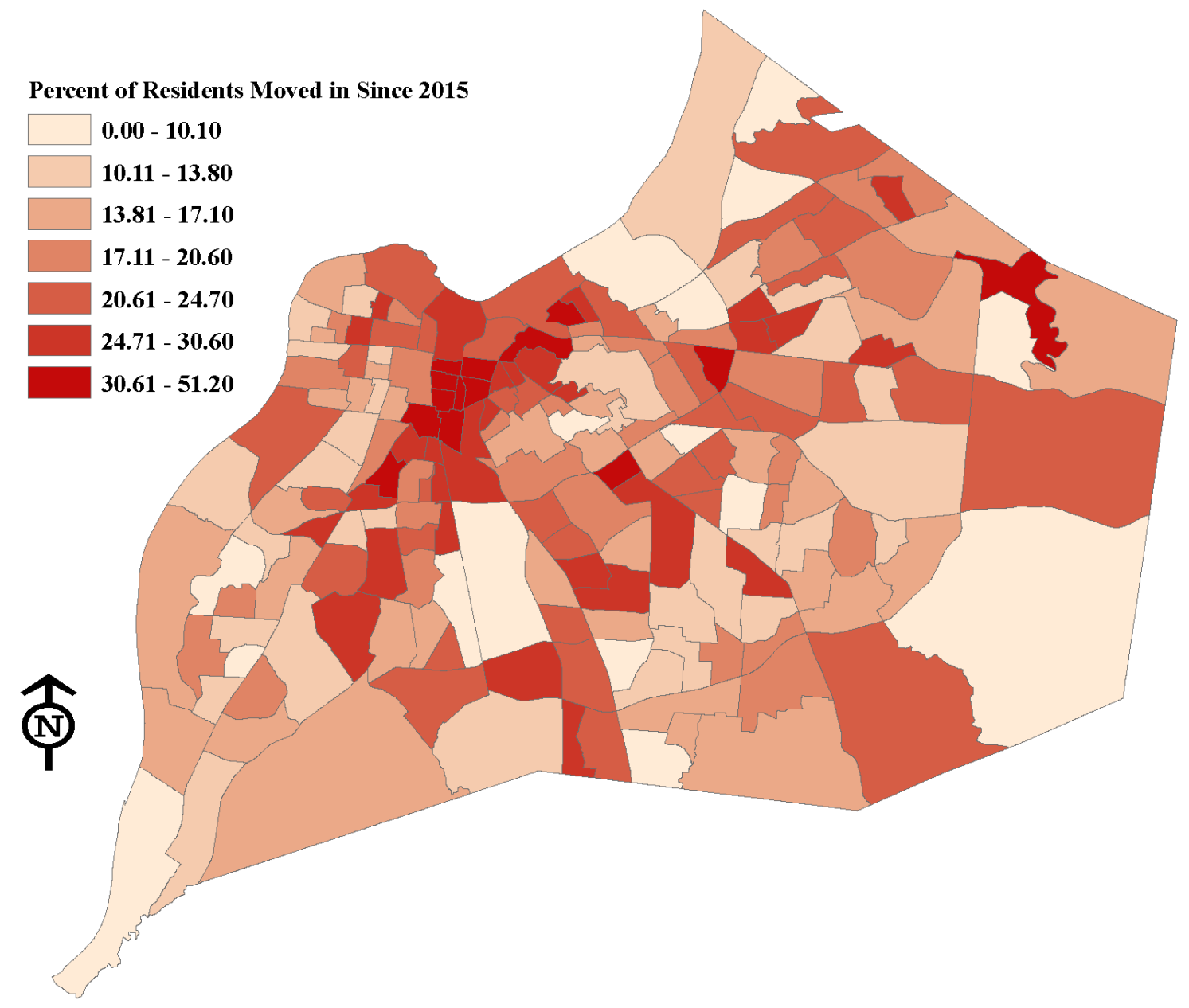

Figure 15. Percent of Residents Moved in Since 2015 


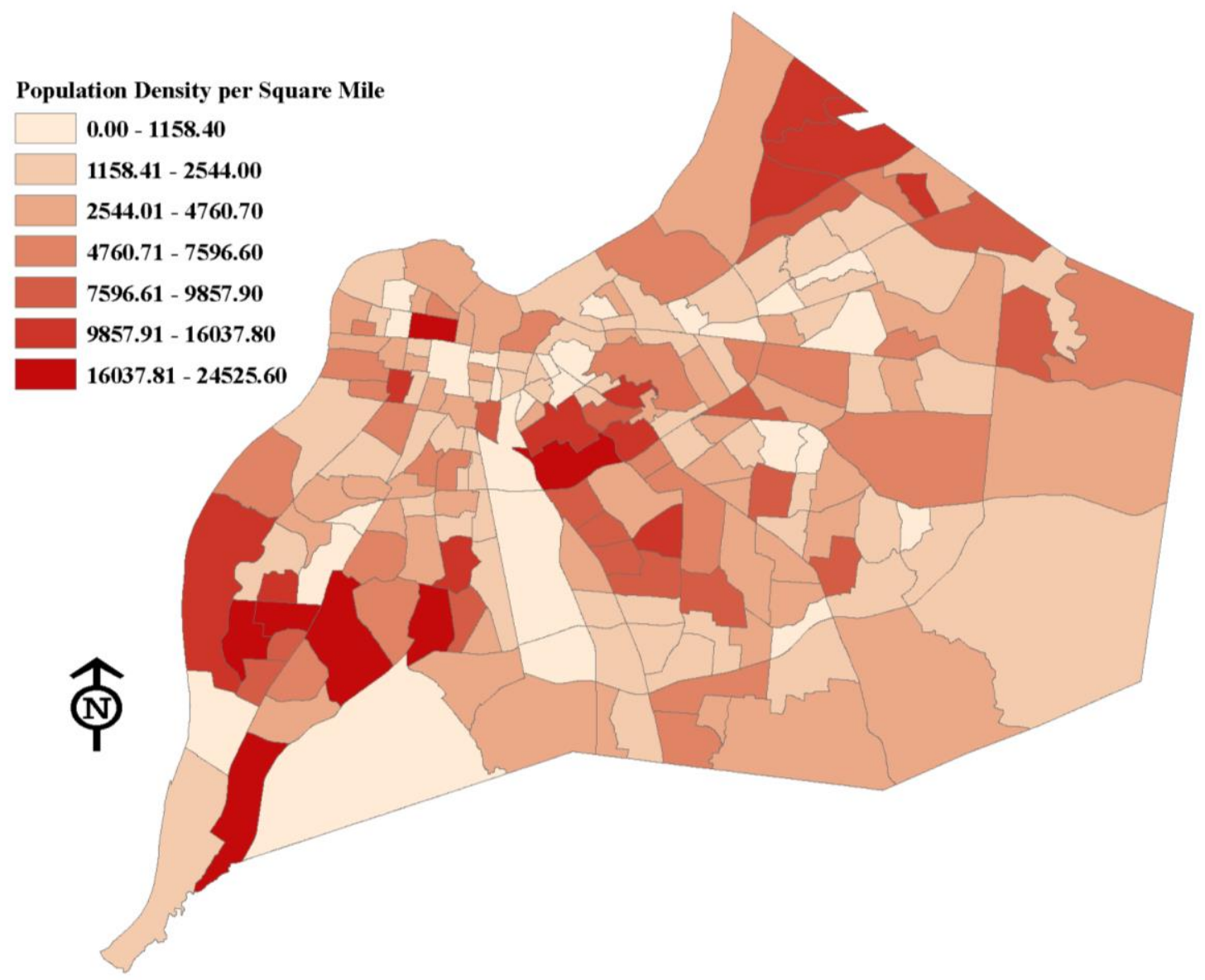

Figure 16. Population Density 


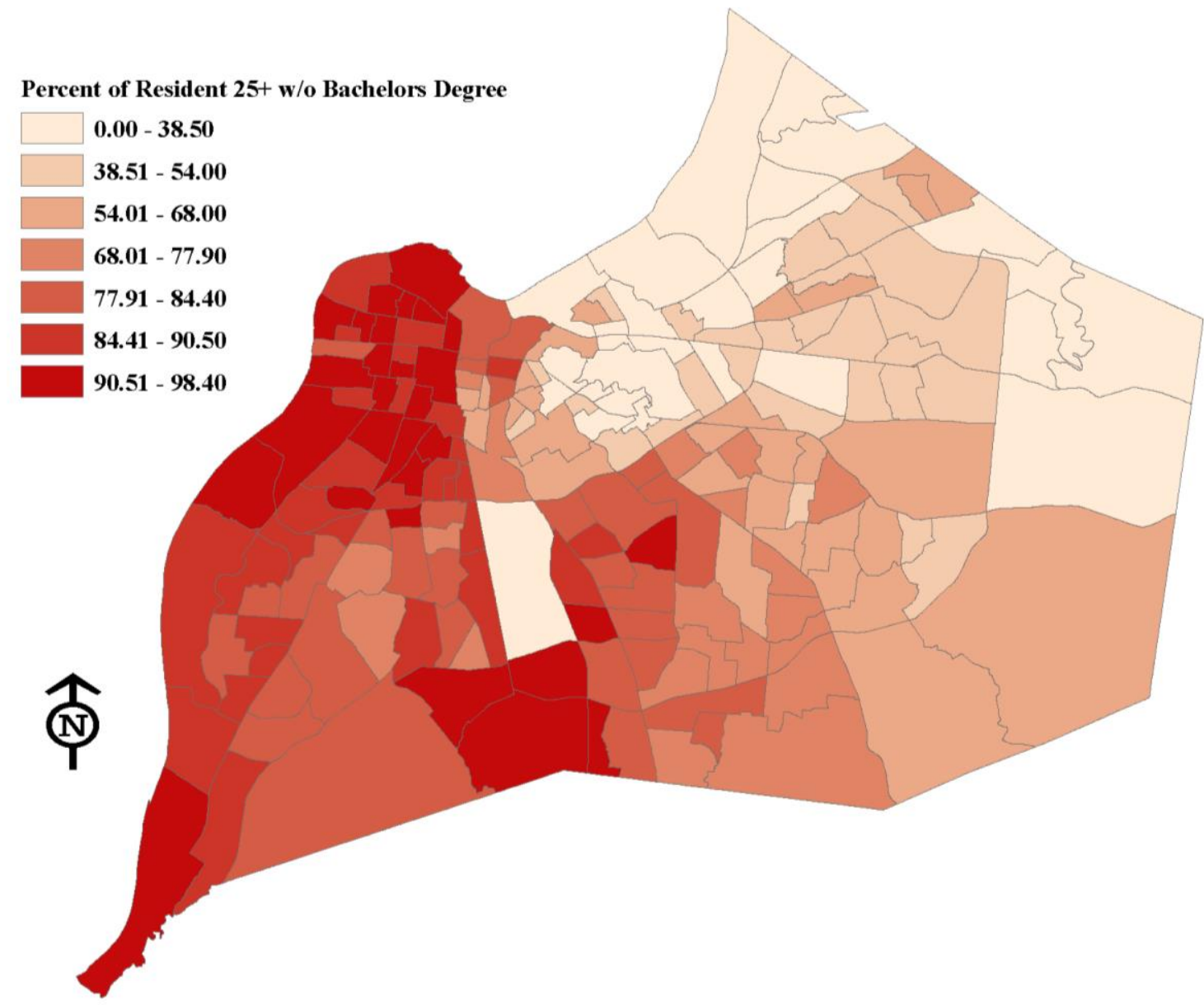

Figure 17. Percent of Residents 25+ without a Bachelor's Degree 


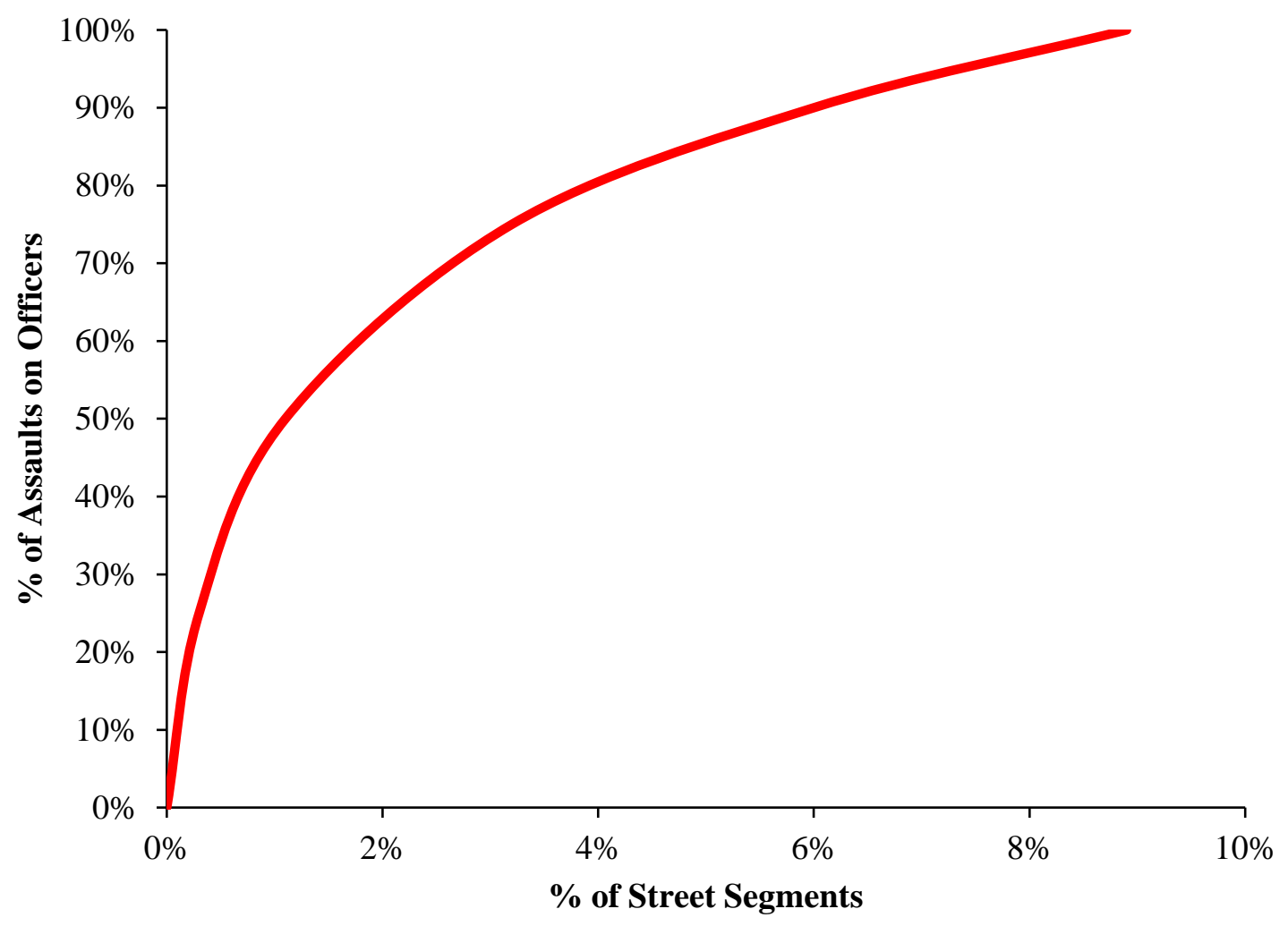

Figure 18. Percentage of Assaults on Law Enforcement Officers per Percentage of Street Segments 


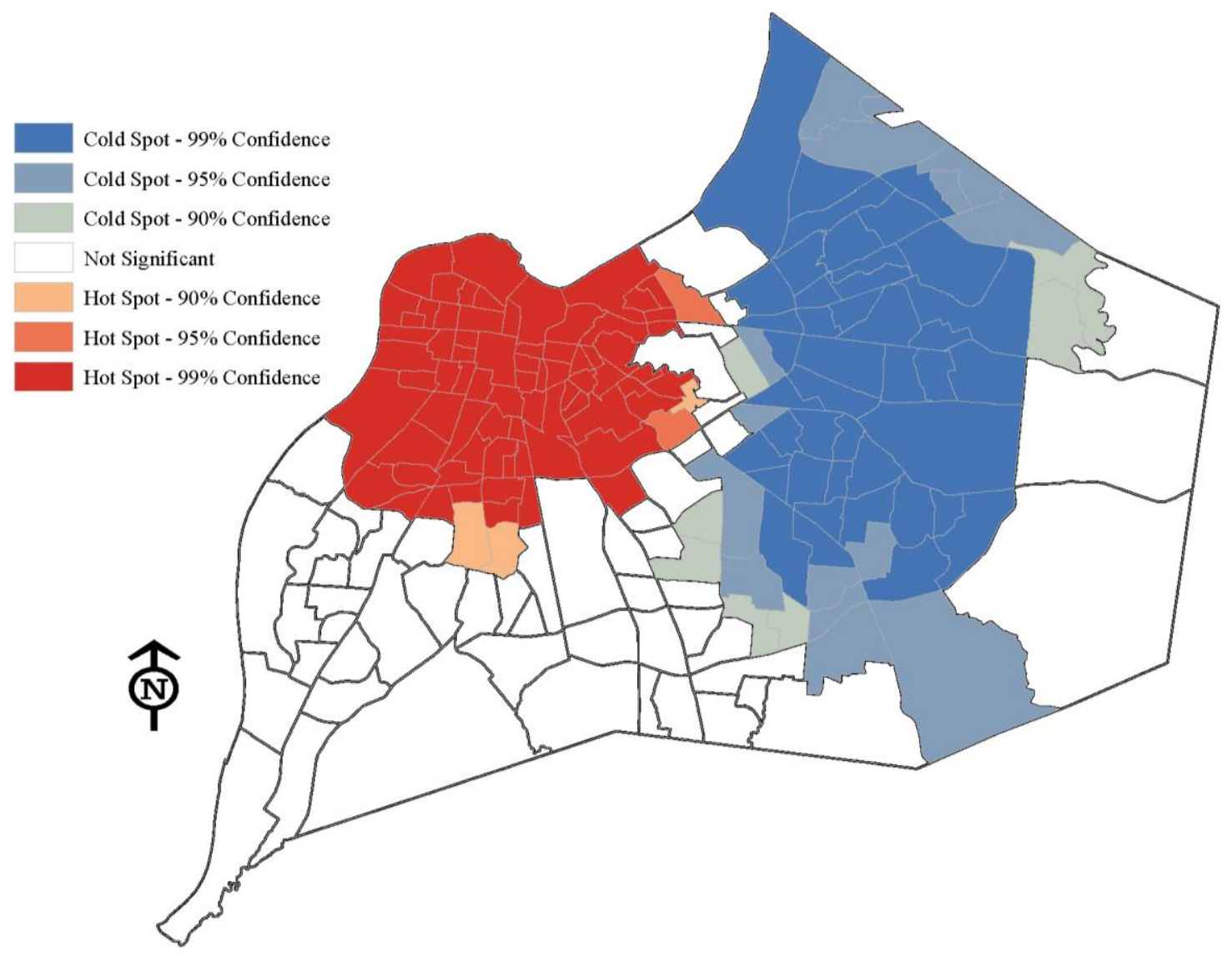

Figure 19. Optimized Hot Spot Analysis per Census Tract 


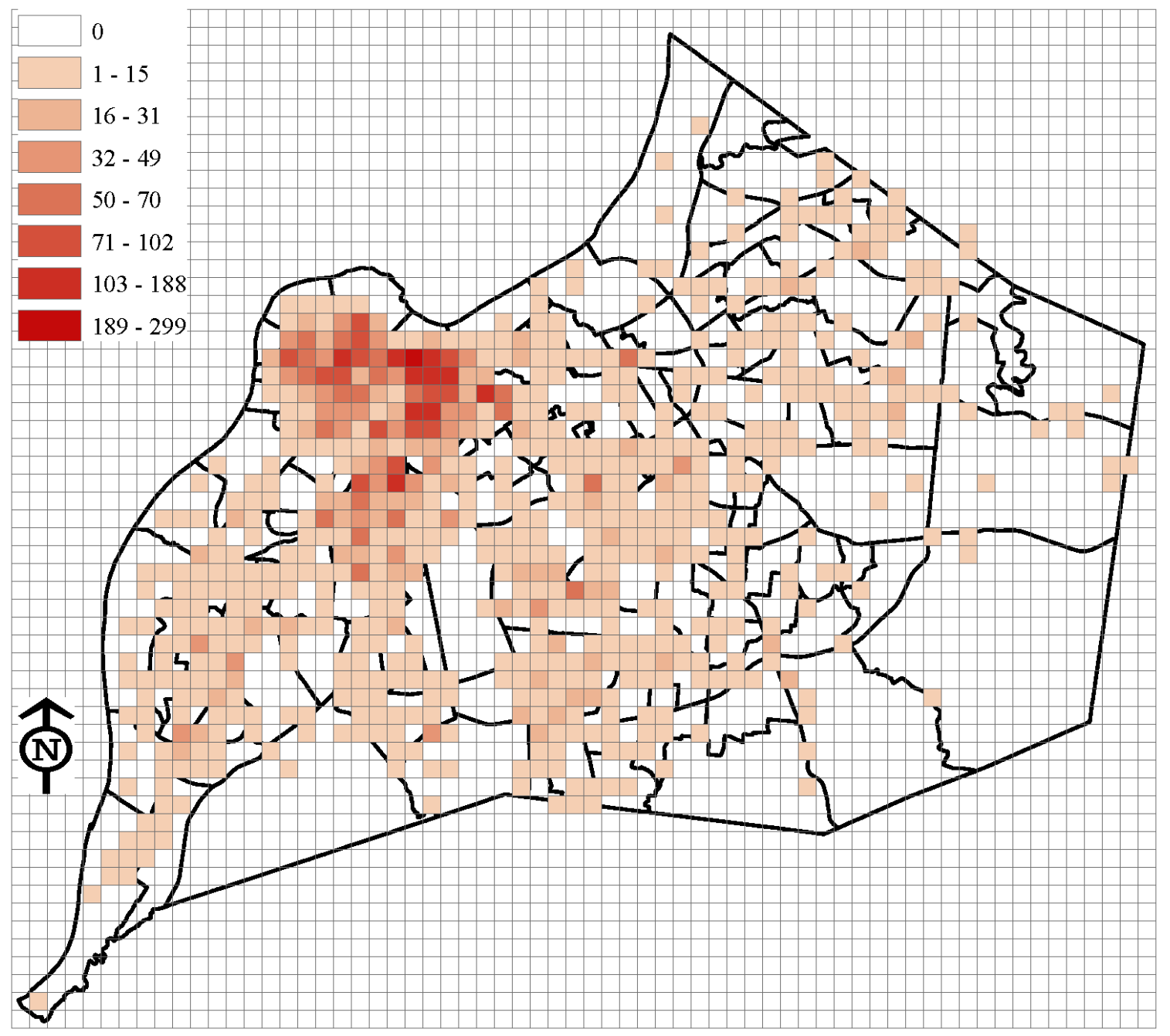

Figure 20. Fishnet Grid Hot Spot Analysis (2,500-Foot Grids) 


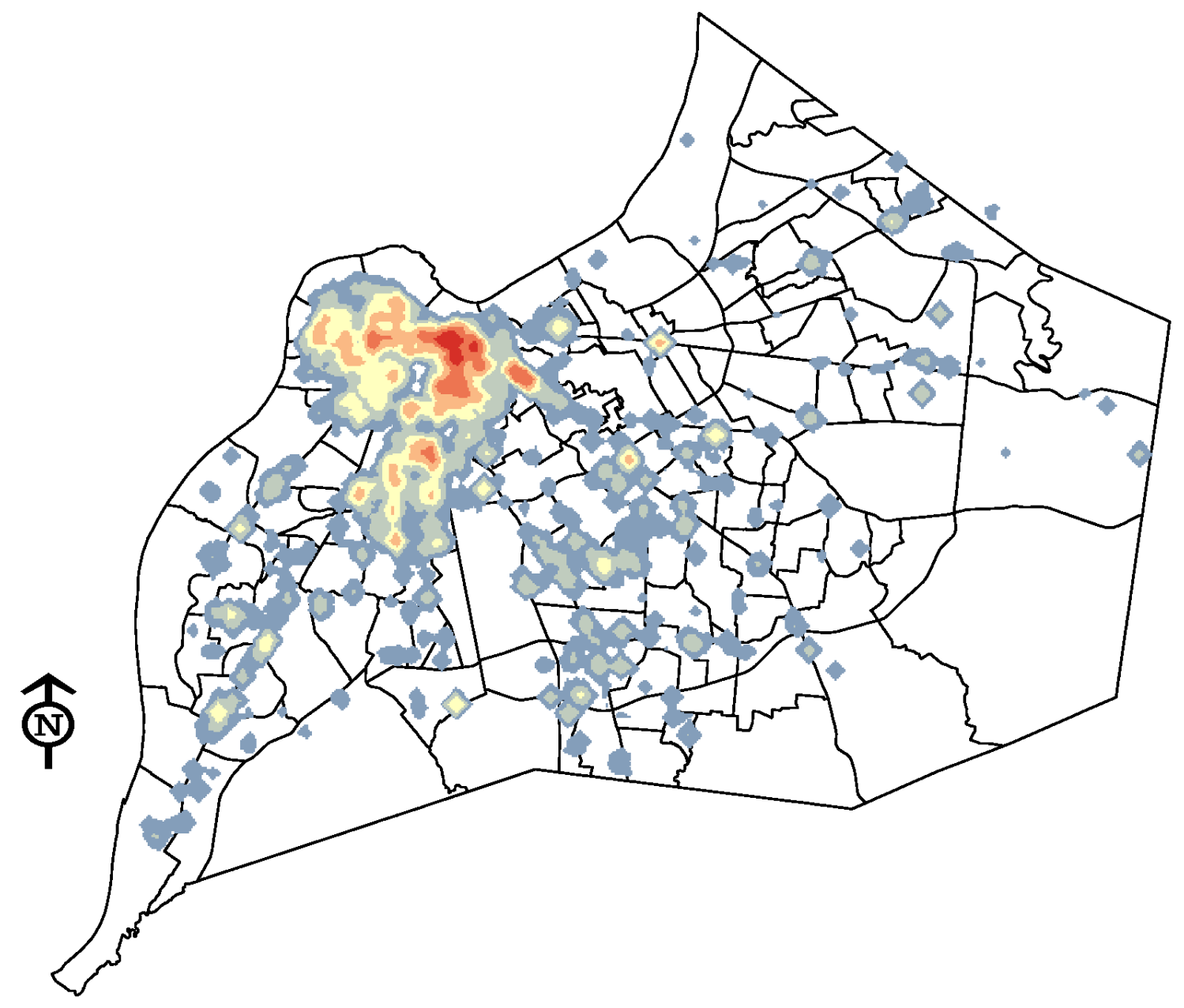

Figure 21. Kernel Density Hot Spot Analysis 
APPENDIX B

TABLES 


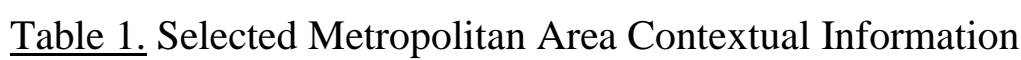

\begin{tabular}{lccc}
\hline Parameter & Selected Metropolitan Area & State County Average* & National Average** \\
\hline Land Area & 380.4 & 329.1 & $1,124.5$ \\
Population & 766,757 & 36,161 & $98,295.3$ \\
Population Density per Square Mile & $2,015.6$ & 109.9 & 87.4 \\
Percent of Residents in Poverty & 15.4 & 16.3 & 10.5 \\
Median Household Income (\$) & 54,357 & 48,392 & 60,293 \\
Diversity (percent White and African American) & $72.0 / 22.2$ & $87.5 / 8.5$ & $76.3 / 13.4$ \\
Percent Male/Female & $48.3 / 51.7$ & $49.3 / 50.7$ & $49.2 / 50.8$ \\
Total Households & 310,318 & $16,719.7$ & $38,118.47$ \\
Percent of Adults with High School Education or Higher & 90.0 & 85.7 & 87.7 \\
Percent of Adults 25+ with College Degree or Higher & 32.7 & 23.6 & 31.5 \\
Median Age & 37.9 & 39.1 & 37.2 \\
\hline
\end{tabular}

Source: U.S. Census Bureau, 2019

* Average based on 120 counties in the respective state.

** Average based on 3,141 counties and county equivalents in the United States. 
$\underline{\text { Table 2. Descriptive Statistics for All Variables (Census Tract Unit of Analysis) }}$

\begin{tabular}{|c|c|c|c|c|c|c|}
\hline Variable & Mean & SD & Skewness & Kurtosis & Minimum & Maximum \\
\hline Total Number of Assaults on Law Enforcement Officers & 47.97 & 71.95 & 5.82 & 50.27 & 0.0 & 755 \\
\hline Total Number of Assaults on Law Enforcement Officers* & 48.78 & 52.91 & 2.33 & 7.60 & 0.0 & 320 \\
\hline Assault Rate per 1,000 Residents & 1.46 & 2.09 & 3.80 & 23.65 & 0.0 & 18.47 \\
\hline Assault Rate per 1,000 Residents* & 1.53 & 1.76 & 1.72 & 2.74 & 0.0 & 8.24 \\
\hline Vacant Housing (\%) & 10.24 & 7.30 & 1.25 & 1.27 & 0.0 & 38.0 \\
\hline Poverty (\%) & 16.91 & 14.21 & 1.33 & 1.95 & 0.9 & 81.0 \\
\hline Rental Housing (\%) & 40.57 & 22.36 & 0.41 & -0.41 & 1.7 & 100.0 \\
\hline SNAP Benefits (\%) & 14.50 & 14.28 & 1.12 & 0.62 & 0.0 & 71.1 \\
\hline Education Attainment (\%) & 69.07 & 21.17 & -0.54 & -0.98 & 20.6 & 98.4 \\
\hline Family Disruption (\%) & 15.26 & 10.19 & 1.13 & 1.29 & 1.4 & 56.4 \\
\hline Resident Mobility (\%) & 19.61 & 7.40 & 0.82 & 1.01 & 6.3 & 51.2 \\
\hline Racial Heterogeneity (Index) & 0.27 & 0.13 & -0.01 & -0.87 & 0.0 & 0.50 \\
\hline Population Density (Per Square Mile) & 4623.27 & 4565.16 & 1.97 & 4.25 & 184.8 & 24525.6 \\
\hline
\end{tabular}

* Descriptive statistics based on removal of outlier census track. 
Table 3. Outlier Census Tract Contextual Information

\begin{tabular}{lcc}
\hline Parameter & Outlier Census Tract & Metropolitan Area Average* \\
\hline Vacant Housing (\%) & 27.8 & 10.2 \\
Poverty (\%) & 42.3 & 16.9 \\
Rental Housing (\%) & 89.8 & 40.6 \\
SNAP Benefits (\%) & 28.1 & 14.5 \\
Education Attainment (\%) & 80.5 & 69.1 \\
Family Disruption (\%) & 2.8 & 15.3 \\
Resident Mobility (\%) & 25.5 & 19.6 \\
Racial Heterogeneity (Index) & 0.53 & 0.27 \\
$\varpi_{\infty}$ & $3,623.3$ \\
\hline
\end{tabular}

Source: U.S. Census Bureau, 2019

* Average based on all 191 census tracts in selected metropolitan area. 
Table 4. Correlation Coefficients for Assaults on Law Enforcement Officers and Community Characteristics

\begin{tabular}{|c|c|c|c|c|c|c|c|c|c|c|}
\hline Variable & 1 & 2 & 3 & 4 & 5 & 6 & 7 & 8 & 9 & 10 \\
\hline 1. Assault Rate & 1 & & & & & & & & & \\
\hline 2. Vacant Housing & $.760^{* *}$ & 1 & & & & & & & & \\
\hline 4. Poverty & $.726^{* *}$ & $.652 * *$ & $.896^{* *}$ & 1 & & & & & & \\
\hline 5. Rental Housing & $.651^{* *}$ & $.596 * *$ & $.684 * *$ & $.741 * *$ & 1 & & & & & \\
\hline 8. Resident Mobility & $.311^{* *}$ & $.285^{* *}$ & $.177^{*}$ & $.326^{* *}$ & $.646 * *$ & .050 & -.024 & 1 & & \\
\hline 9. Racial Heterogeneity & $.180 *$ & .102 & $.234^{* *}$ & $.225^{* *}$ & $.309 * *$ & .109 & $.293^{* *}$ & $.332 * *$ & 1 & \\
\hline 10. Population Density & $-1.57^{*}$ & -.094 & -.047 & -.046 & $-1.60 *$ & .100 & .090 & $-.169^{*}$ & -.037 & 1 \\
\hline
\end{tabular}

** Correlation is significant at the 0.01 level.

* Correlation is significant at the 0.05 level. 
Table 5. Regression of Assaults on Law Enforcement Officers and Community Characteristics (Full Theoretical Model)

\begin{tabular}{|c|c|c|c|c|c|c|c|}
\hline & \multicolumn{2}{|c|}{$\begin{array}{c}\text { Unstandardized } \\
\text { Coefficients }\end{array}$} & \multirow{2}{*}{$\begin{array}{c}\begin{array}{c}\text { Standardized } \\
\text { Coefficients }\end{array} \\
\text { Beta }\end{array}$} & \multirow[b]{2}{*}{$\mathrm{t}$} & \multirow[b]{2}{*}{ Sig. } & \multicolumn{2}{|c|}{$\begin{array}{c}\text { Collinearity } \\
\text { Statistics }\end{array}$} \\
\hline & B & SE & & & & Tolerance & VIF \\
\hline (Constant) & -0.065 & 0.421 & & -0.154 & 0.878 & & \\
\hline Vacant Housing & 0.109 & 0.015 & 0.472 & 7.281 & 0.000 & 0.469 & 2.132 \\
\hline SNAP Benefits & 0.039 & 0.015 & 0.322 & 2.505 & 0.013 & 0.119 & 8.380 \\
\hline Family Disruption & -0.027 & 0.014 & -0.160 & -2.000 & 0.047 & 0.311 & 3.219 \\
\hline Poverty & 0.025 & 0.014 & 0.207 & 1.855 & 0.066 & 0.159 & 6.297 \\
\hline Rental Housing & 0.008 & 0.007 & 0.100 & 1.084 & 0.280 & 0.233 & 4.299 \\
\hline Education Attainment & -0.006 & 0.006 & -0.067 & -0.896 & 0.372 & 0.353 & 2.832 \\
\hline Residential Mobility & -0.003 & 0.016 & -0.014 & -0.198 & 0.843 & 0.397 & 2.517 \\
\hline $\mathrm{R}^{2}$ & 0.68 & & & & & & \\
\hline $\mathrm{F}$ & $39.48^{*}$ & & & & & & \\
\hline
\end{tabular}

* Significant at the 0.01 level. 
Table 6. Regression of Assaults on Law Enforcement Officers and Community Characteristics (Limited Theoretical Model)

\begin{tabular}{|c|c|c|c|c|c|c|c|}
\hline & \multicolumn{2}{|c|}{$\begin{array}{c}\text { Unstandardized } \\
\text { Coefficients }\end{array}$} & \multirow{2}{*}{$\begin{array}{c}\begin{array}{c}\text { Standardized } \\
\text { Coefficients }\end{array} \\
\text { Beta }\end{array}$} & \multirow[b]{2}{*}{$\mathrm{t}$} & \multirow[b]{2}{*}{ Sig. } & \multicolumn{2}{|c|}{$\begin{array}{c}\text { Collinearity } \\
\text { Statistics }\end{array}$} \\
\hline & $\mathrm{B}$ & $\mathrm{SE}$ & & & & Tolerance & VIF \\
\hline (Constant) & -0.151 & 0.159 & & -0.945 & 0.346 & & \\
\hline Vacant Housing & 0.120 & 0.014 & 0.517 & 8.320 & 0.000 & 0.529 & 1.892 \\
\hline SNAP Benefits & 0.065 & 0.009 & 0.540 & 6.880 & 0.000 & 0.331 & 3.017 \\
\hline Family Disruption & -0.036 & 0.012 & -0.212 & -2.994 & 0.003 & 0.407 & 2.456 \\
\hline $\mathrm{R}^{2}$ & 0.67 & & & & & & \\
\hline $\mathrm{F}$ & $111.130 *$ & & & & & & \\
\hline
\end{tabular}

N. $*$ Significant at the 0.01 level. 
Table 7. Principal Component Analysis for Economic Segregation and Residential Instability Composite Scales

\begin{tabular}{llll}
\hline \multicolumn{2}{c}{ Economic Segregation } & \multicolumn{2}{c}{ Residential Instability } \\
\hline Variable & Factor Loadings & Variable & Factor Loadings \\
\hline Poverty & 0.935 & Vacant Housing & 0.750 \\
Family Disruption & 0.880 & Rental Housing & 0.924 \\
SNAP Benefits & 0.961 & Resident Mobility & 0.785 \\
\hline Eigenvalue & 2.572 & & 2.033 \\
$\%$ of Total Variance & 85.848 & & 67.756 \\
\hline
\end{tabular}

$\bar{N}$ 
Table 8. Correlation Coefficients for Assaults on Law Enforcement Officers and Composite Scales

\begin{tabular}{lccc}
\hline Variable & Assault Rate & $\begin{array}{c}\text { Economic } \\
\text { Segregation }\end{array}$ & $\begin{array}{c}\text { Residential } \\
\text { Instability }\end{array}$ \\
\hline Assault Rate & 1 & & \\
Economic Segregation & $.718^{* *}$ & 1 & 1 \\
Residential Instability & $.694 * *$ & $.689 * *$ & 1 \\
\hline$* *$ Correlation is significant at the 0.01 level &
\end{tabular}

** Correlation is significant at the 0.01 level. 
Table 9. Regression of Assaults on Law Enforcement Officers and Composite Scales

\begin{tabular}{|c|c|c|c|c|c|c|c|}
\hline & \multicolumn{2}{|c|}{$\begin{array}{c}\text { Unstandardized } \\
\text { Coefficients }\end{array}$} & \multirow{2}{*}{$\begin{array}{c}\text { Standardized } \\
\text { Coefficients }\end{array}$} & \multirow[b]{2}{*}{$\mathrm{t}$} & \multirow[b]{2}{*}{ Sig. } & \multicolumn{2}{|c|}{ Collinearity Statistics } \\
\hline & B & SE & & & & Tolerance & VIF \\
\hline (Constant) & -1.048 & 0.222 & & -4.727 & 0.000 & & \\
\hline Economic Segregation & 0.022 & 0.003 & 0.457 & 6.505 & 0.000 & 0.525 & 1.905 \\
\hline Residential Instability & 0.021 & 0.004 & 0.379 & 5.390 & 0.000 & 0.525 & 1.905 \\
\hline $\mathrm{R}^{2}$ & 0.59 & & & & & & \\
\hline $\mathrm{F}$ & $113.986^{*}$ & & & & & & \\
\hline
\end{tabular}

* Significant at the 0.01 level.

$\stackrel{+}{\mathbb{N}}$ 
Table 10. Main Hypotheses Analytical Support Summary

\begin{tabular}{|c|c|c|c|}
\hline Hypothesis & Support Level & Analytical Test & Findings \\
\hline \multirow{2}{*}{$\begin{array}{l}\mathrm{H}_{1} \text { : Assaults on law enforcement officers } \\
\text { will be spatially concentrated in which } \\
\text { half ( } 50 \text { percent) of all incidents occur } \\
\text { within four percent of all street segments } \\
\text { within the metropolitan area. }\end{array}$} & \multirow[t]{2}{*}{ Full } & \multirow[t]{2}{*}{$\begin{array}{l}\text { Street Segment Spatial Analysis } \\
\text { Fishnet Grid Analysis }\end{array}$} & $\begin{array}{l}75 \text { percent of all assaults }(n=6,863) \text { occurred } \\
\text { in } 3.2 \text { percent of street segments }(n=1,113)\end{array}$ \\
\hline & & & $\begin{array}{l}50 \text { percent of all assaults }(n=4,565) \text { occurred } \\
\text { in } 2.8 \text { percent of grid cells }(n=56) \text {. }\end{array}$ \\
\hline \multirow{5}{*}{$\begin{array}{l}\mathrm{H}_{2} \text { : Assaults on law enforcement officers } \\
\text { will be spatially concentrated in and } \\
\text { around the downtown urban core with } \\
\text { decreasing incidents away from the } \\
\text { downtown urban core. }\end{array}$} & \multirow[t]{5}{*}{ Full } & Spatial Autocorrelation Analysis & \multirow{5}{*}{$\begin{array}{l}\text { Assaults on law enforcement officers were } \\
\text { spatially concentrated (Moran's } \mathrm{I}=.395, \mathrm{p}= \\
.00, \mathrm{z} \text {-score }=20.93 \text { ). } \\
\text { The spatial concentration of assaults on law } \\
\text { enforcement officers was located within and } \\
\text { around the downtown urban core per } \\
\text { multiple maps displaying point data, } \\
\text { thematic shading of variables, and hot spot } \\
\text { locations. }\end{array}$} \\
\hline & & & \\
\hline & & Optimized Hot Spot Analysis & \\
\hline & & Fishnet Grid Analysis & \\
\hline & & Kernel Density Hot Spot Analysis & \\
\hline \multirow{3}{*}{$\begin{array}{l}\mathrm{H}_{3} \text { : The presence of social disorganization } \\
\text { characteristics within census tracts will be } \\
\text { both positively and significantly } \\
\text { correlated with incidence of assaults on } \\
\text { law enforcement officers. }\end{array}$} & \multirow[t]{3}{*}{ Partial } & Pearson Coefficient & \multirow{2}{*}{$\begin{array}{l}\text { Combination of family disruption, SNAP } \\
\text { benefits, and vacant housing explains } 67 \\
\text { percent }\left(\mathrm{R}^{2}=0.67 \text { ) of variation in assaults on }\right. \\
\text { law enforcement officers per census tract ( } \mathrm{F} \\
=111.1, \mathrm{p}<0.01 \text { ). }\end{array}$} \\
\hline & & Multiple Linear Regression & \\
\hline & & & $\begin{array}{l}\text { Bivariate and multivariate testing revealed } \\
\text { remaining variables (education attainment, } \\
\text { population density, poverty, racial } \\
\text { heterogeneity, rental housing, and resident } \\
\text { mobility) were not significantly associated } \\
\text { with assaults on law enforcement officers. }\end{array}$ \\
\hline
\end{tabular}


Table 11. Sub-Hypotheses Analytical Support Summary

\begin{tabular}{|c|c|c|c|}
\hline Sub-Hypothesis & Support Level & Analytical Test & Findings \\
\hline $\begin{array}{l}\mathrm{H}_{3 \mathrm{~A}} \text { (Poverty): The percent of individuals } \\
\text { earning below the poverty line within a census } \\
\text { tract will be both positively and significantly } \\
\text { correlated with incidence of assault on law } \\
\text { enforcement officers. }\end{array}$ & Partial & $\begin{array}{l}\text { Pearson Coefficient } \\
\text { Multiple Linear Regression }\end{array}$ & $\begin{array}{l}\text { Bivariate testing revealed statistically } \\
\text { significant correlation }(\mathrm{r}=0.73, \mathrm{p}<0.01) \\
\text { Multivariate testing revealed insignificant } \\
\text { impact in full theoretical model }(\mathrm{t}=1.86, \mathrm{p}> \\
0.01) \text {. }\end{array}$ \\
\hline $\begin{array}{l}\mathrm{H}_{3 \mathrm{~B}} \text { (Family Disruption): The percent of } \\
\text { female-headed households within a census } \\
\text { tract will be both positively and significantly } \\
\text { correlated with incidence of assault on law } \\
\text { enforcement officers. }\end{array}$ & Full & $\begin{array}{l}\text { Pearson Coefficient } \\
\text { Multiple Linear Regression }\end{array}$ & $\begin{array}{l}\text { Bivariate testing revealed statistically } \\
\text { significant correlation }(\mathrm{r}=0.50, \mathrm{p}<0.01) \\
\text { Multivariate testing revealed significant } \\
\text { impact in testing of both full theoretical } \\
\text { model }(\mathrm{t}=-2.00, \mathrm{p}<0.01) \text { and limited } \\
\text { theoretical model }(\mathrm{t}=-2.99, \mathrm{p}<0.01)\end{array}$ \\
\hline $\begin{array}{l}\mathrm{H}_{3 \mathrm{C}} \text { (SNAP Benefits): The percent of } \\
\text { households within a census tract receiving } \\
\text { Supplemental Nutrition Assistance Program } \\
\text { (SNAP) benefits within a census tract will be } \\
\text { both positively and significantly correlated } \\
\text { with incidence of assault on law enforcement } \\
\text { officers. }\end{array}$ & Full & $\begin{array}{l}\text { Pearson Coefficient } \\
\text { Multiple Linear Regression }\end{array}$ & $\begin{array}{l}\text { Bivariate testing revealed statistically } \\
\text { significant correlation }(\mathrm{r}=0.73, \mathrm{p}<0.01) \text {. } \\
\text { Multivariate testing revealed significant } \\
\text { impact in testing of both full theoretical } \\
\text { model }(\mathrm{t}=2.51, \mathrm{p}<0.01) \text { and limited } \\
\text { theoretical model }(\mathrm{t}=6.88, \mathrm{p}<0.01)\end{array}$ \\
\hline $\begin{array}{l}\mathrm{H}_{3 \mathrm{D}} \text { (Racial Heterogeneity): The measure of } \\
\text { racial heterogeneity within a census tract will } \\
\text { be both positively and significantly correlated } \\
\text { with incidence of assault on law enforcement } \\
\text { officers. }\end{array}$ & None & Pearson Coefficient & $\begin{array}{l}\text { Bivariate testing revealed statistically } \\
\text { insignificant correlation }(r=0.18, p>0.01)\end{array}$ \\
\hline
\end{tabular}




\begin{tabular}{|c|c|c|c|}
\hline Sub-Hypothesis & Support Level & Analytical Test & Findings \\
\hline $\begin{array}{l}\mathrm{H}_{3 \mathrm{E}} \text { (Vacant Housing): The percentage of } \\
\text { vacant housing units within a census tract will } \\
\text { be both positively and significantly correlated } \\
\text { with incidence of assault on law enforcement } \\
\text { officers. }\end{array}$ & Full & $\begin{array}{l}\text { Pearson Coefficient } \\
\text { Multiple Linear Regression }\end{array}$ & $\begin{array}{l}\text { Bivariate testing revealed statistically } \\
\text { significant correlation }(\mathrm{r}=0.76, \mathrm{p}<0.01) \text {. } \\
\text { Multivariate testing revealed significant } \\
\text { impact in testing of both full theoretical } \\
\text { model }(\mathrm{t}=7.28, \mathrm{p}<0.01) \text { and limited } \\
\text { theoretical model }(\mathrm{t}=8.32, \mathrm{p}<0.01)\end{array}$ \\
\hline $\begin{array}{l}\mathrm{H}_{3 \mathrm{~F}} \text { (Rental Housing): The percentage of } \\
\text { renter-occupied housing units within a census } \\
\text { tract will be both positively and significantly } \\
\text { correlated with incidence of assault on law } \\
\text { enforcement officers. }\end{array}$ & Partial & $\begin{array}{l}\text { Pearson Coefficient } \\
\text { Multiple Linear Regression }\end{array}$ & $\begin{array}{l}\text { Bivariate testing revealed statistically } \\
\text { significant correlation }(\mathrm{r}=0.65, \mathrm{p}<0.01) . \\
\text { Multivariate testing revealed insignificant } \\
\text { impact in full theoretical model }(\mathrm{t}=1.08, \mathrm{p}> \\
0.01) \text {. }\end{array}$ \\
\hline $\begin{array}{l}\mathrm{H}_{3 \mathrm{G}} \text { (Resident Mobility): The percentage of } \\
\text { individuals who have moved into the census } \\
\text { track since } 2015 \text { will be both positively and } \\
\text { significantly correlated with incidence of } \\
\text { assault on law enforcement officers. }\end{array}$ & Partial & $\begin{array}{l}\text { Pearson Coefficient } \\
\text { Multiple Linear Regression }\end{array}$ & $\begin{array}{l}\text { Bivariate testing revealed statistically } \\
\text { significant correlation }(\mathrm{r}=0.31, \mathrm{p}<0.01) \text {. } \\
\text { Multivariate testing revealed insignificant } \\
\text { impact in full theoretical model }(\mathrm{t}=-0.20, \mathrm{p}> \\
0.01) .\end{array}$ \\
\hline $\begin{array}{l}\mathrm{H}_{3 \mathrm{H}} \text { (Population Density): The population } \\
\text { density within a census tract will be both } \\
\text { positively and significantly correlated with } \\
\text { incidence of assault on law enforcement } \\
\text { officers. }\end{array}$ & None & Pearson Coefficient & $\begin{array}{l}\text { Bivariate testing revealed statistically } \\
\text { insignificant correlation }(r=0.16, p>0.01)\end{array}$ \\
\hline $\begin{array}{l}\mathrm{H}_{3 \mathrm{I}} \text { (Education Attainment): The percent of } \\
\text { individuals without a Bachelor's degree or } \\
\text { higher within a census tract will be both } \\
\text { positively and significantly correlated with } \\
\text { incidence of assault on law enforcement } \\
\text { officers. }\end{array}$ & Partial & $\begin{array}{l}\text { Pearson Coefficient } \\
\text { Multiple Linear Regression }\end{array}$ & $\begin{array}{l}\text { Bivariate testing revealed statistically } \\
\text { significant correlation }(\mathrm{r}=0.44, \mathrm{p}<0.01) \text {. } \\
\text { Multivariate testing revealed insignificant } \\
\text { impact in full theoretical model }(\mathrm{t}=-0.90, \mathrm{p}> \\
0.01) \text {. }\end{array}$ \\
\hline
\end{tabular}




\section{CURRICULUM VITA}

NAME: $\quad$ Brian Keith Simpkins

ADDRESS: Department of Criminal Justice

Brigman Hall

University of Louisville

2301 South Third Street

Louisville, Kentucky 40208

EDUCATION: $\quad$ B.S., Criminal Justice

Marshall University

1997-2002

M.S., Criminal Justice

Eastern Kentucky University

2002-2004

Ed.D, Educational Leadership and Policy Studies

Eastern Kentucky University

2012-2015

Graduate Certificate, Intelligence and National Security

Eastern Kentucky University

2016-2017

Certificate in Leader Development, National Security and Strategy U.S. Army War College 2019

PROFESSIONAL

EMPLOYMENT: Lecturer - Homeland Security

Department of Safety and Security

School of Safety, Security, and Emergency Management

Stratton Building

Eastern Kentucky University

521 Lancaster Avenue

Richmond, Kentucky 40475

2017 - Present 
Program Director, Institute for Research, Innovation, and Scholarship

School of Security and Global Studies

American Public University System

111 West Congress Street

Charles Town, West Virginia 25414

$2016-2017$

Part-Time Faculty, Homeland Security

Department of Safety and Security

School of Safety, Security, and Emergency Management

Stratton Building

Eastern Kentucky University

521 Lancaster Avenue

Richmond, Kentucky 40475

$2009-2017$

Associate Director

Justice and Safety Center

Eastern Kentucky University

521 Lancaster Avenue

Richmond, Kentucky 40475

$2005-2017$

Infrastructure Analyst and Training Lead

Systems Planning and Analysis, Inc.

Protective Security Support Group

2001 North Beauregard Street

Alexandria, Virginia 22311

$2005-2006$

FACULTY

AWARDS: Mentor of the Year Award

College of Justice and Safety

Eastern Kentucky University

2020

Critical Thinking Teacher of the Year (Nominee)

Eastern Kentucky University

2019

Critical Reading Teacher of the Year Award

Eastern Kentucky University

2018 
PROFESSIONAL SOCIETIES:
American Board for Certification in Homeland Security

American Criminal Justice Association

American Criminal Justice Honor Society

American Society of Criminology

Federal Bureau of Investigation InfraGard, Kentucky Membership

Alliance

International Association for Intelligence Education

International Studies Association, Intelligence Studies Section

BOOKS: $\quad$ Baggett, Ryan, and Simpkins, Brian (2018). Homeland Security and Critical Infrastructure Protection ( $2^{\text {nd }}$ ed.). Santa Barbara, CA: Praeger Security International.

Baggett, Ryan, Foster, Chad, and Simpkins, Brian (2017). Homeland Security Technologies for the $21^{\text {st }}$ Century. Santa Barbara, CA: Praeger Security International.

\section{BOOK}

CHAPTERS: Simpkins, Brian (2019). Critical Infrastructure: Critical Manufacturing Sector. In Lauren Shapiro and Marie-Helen Maras (Eds.), Encyclopedia of Security and Emergency Management. New York, NY: Springer.

Simpkins, Brian (2019). Critical Infrastructure: Emergency Services Sector. In Lauren Shapiro and Marie-Helen Maras (Eds.), Encyclopedia of Security and Emergency Management. New York, NY: Springer.

Robbins, Kacy, and Simpkins, Brian (forthcoming publication). Government Facilities as a Terrorist Target. In William Lahneman and Joseph Rudolph (Eds.), Combatting Terrorism in the $21^{\text {st }}$ Century: American Laws, Strategies, and Agencies. Santa Barbara, CA: Praeger Security International.

Simpkins, Brian (forthcoming publication). Critical Infrastructure as a Terrorist Target. In William Lahneman and Joseph Rudolph (Eds.), Combatting Terrorism in the $21^{\text {st }}$ Century: American Laws, Strategies, and Agencies. Santa Barbara, CA: Praeger Security International.

Simpkins, Brian (forthcoming publication). Earth Liberation Front. In William Lahneman and Joseph Rudolph (Eds.), Combatting Terrorism in the $21^{\text {st }}$ Century: American Laws, Strategies, and Agencies. Santa Barbara, CA: Praeger Security International.

PRESENTATIONS: Simpkins, Brian (2019, June). Flipping the Intelligence Studies Classroom: Incorporating Team-Based Learning Strategies. $15^{\text {th }}$ Annual International Association for Intelligence Education Conference (New York City, NY). Session Presenter. 
Simpkins, Brian (2019, April). Individual Threat and Hazards Preparedness: A Theory Based Approach. EKU Scholars Week, University Presentation Showcase (Richmond, KY). Poster Presenter. Poster Link: https://encompass.eku.edu/swps_facultygallery/50/

Simpkins, Brian (2019, April). Preparing for Careers in the U.S. Intelligence Community. $12^{\text {th }}$ Annual Appalachian Institute of Digital Evidence Conference (Huntington, WV). Session Presenter.

Simpkins, Brian (2017, May). Teaching Intelligence Analysis. $13^{\text {th }}$ Annual International Association for Intelligence Education (IAFIE) Conference (Charles Town, WV). Panelist.

Simpkins, Brian (2017, February). BGS IC CAE Best Practices. Annual Meeting of the Intelligence Community Centers for Academic Excellence (IC CAE) (Tampa, FL). Panel Presenter: IC CAE Best Practices.

Simpkins, Brian (2015, November). Assessing Emergency Management Capabilities in Rural America: Where Were We Before, Where Are We Now, and Where Do We Need To Go? International Association of Emergency Managers (IAEM) 63 ${ }^{\text {rd }}$ Annual Conference (Las Vegas, NV). Breakout Session Speaker.

Simpkins, Brian (2015, September). Assessing Rural Law Enforcement Capabilities: A Longitudinal Analysis (2006 - 2015). Southern Criminal Justice Association (SCJA) Annual Conference (Charleston, SC). Panel Presenter: Policing in the South and Beyond.

Simpkins, Brian (2011, November). Needs Assessment Town Hall Meeting. 2011 State Administrative Agency Conference (Anniston, $\mathrm{AL}-$ Center for Domestic Preparedness). Panelist.

Simpkins, Brian (2010, April). 2009 National Training Needs Assessment. $3^{\text {rd }}$ Annual National Rural Emergency Preparedness Summit (Albuquerque, NM). Presenter.

Simpkins, Brian (2010, March). 2009 National Training Needs Assessment. Homeland Security: Global and Domestic Perspectives Conference (Warrensburg, MO). Presenter. 
Simpkins, Brian, and Paulsen, Derek (2003, November). The Moonshine of the New Millennium: Pharmaceutical/Prescription Drugs and Their Abuse. American Society of Criminology $59^{\text {th }}$ Annual Meeting (Denver, CO). Presenter.

Simpkins, Brian (2001, April). The Continuum of Adult Drug Abuse. Marshall University First Annual Undergraduate Research and Creativity Conference (Huntington, WV). Presenter. 